\title{
Endocrinology Handbook
}

\section{Imperial Centre for Endocrinology}

\section{Imperial College Healthcare NHS Trust}

\section{Charing Cross, Hammersmith and St. Mary's Hospitals}

\section{Updated: April 2016}

\section{First published: 1988}

Available as a .pdf file since 1999 on:

http://imperialendo.co.uk

http://meeran.info 


\section{INTRODUCTION}

Diagnosis and appropriate treatment in clinical endocrinology rely heavily on the accurate use and interpretation of diagnostic tests. This handbook was devised as a means of guiding new junior staff (and refreshing the memories of their seniors!) when confronted by clinical problems and their investigation. This bible is meant to be brief and didactic with the inevitable costs as well as benefits of such an approach. It is envisaged that it will be reprinted at 6 monthly intervals incorporating corrections and additions, any suggestions and comments from readers are welcome.

Grateful acknowledgements are due to: Professor Sir Stephen Bloom, Dr Simon Wallis, Professor Graham Joplin, Professor Kaye Ibbertson, Dr James Jackson, Dr Jacky Burrin, Mrs Veronica Ferguson, Mr Stuart Lavery, Mr Paul Bains, Dr Emma Walker, Dr Alexander Comninos and all our colleagues for their help and encouragement.

We are delighted to note that this handbook is forming the basis of many endocrine protocols on various website around the country. The first version of this was written by the registrars and consultants in the Endocrine Unit in 1988 and used as a handbook for the junior doctors ever since. It has been available on the web since 1999 and it has since been widely used as the central source of endocrine protocols ever since. Please feel free to use this information to educate your own staff, and please simply acknowledge the Imperial Centre for Endocrinology.

IMPORTANT NOTE: Any reference ranges provided apply specifically to Imperial College Healthcare NHS Trust (ICHNT). If using this resource at a difference centre, please check your local lab's reference ranges. 


\section{AUTHORS}

\begin{tabular}{|l|l|}
\hline Sarah Ali & Ben Jones \\
\hline Matthew Allum & Bernard Khoo \\
\hline Maha Barakat & Carl Le Roux \\
\hline Maria Barnard & Niamh Martin \\
\hline Sophie Barnes & Karim Meeran \\
\hline Duncan Bassett & Elaine Murphy \\
\hline Rachel Batterham & Nick Oliver \\
\hline Preeshila Behary & Fausto Palazzo \\
\hline Nicola Bridges & Arshia Panahloo \\
\hline Jaimini Cegla & Debbie Peters \\
\hline Harvinder Chahal & Michela Rossi \\
\hline Alexander Comninos & Amir Sam \\
\hline Gerry Conway & Leighton Seal \\
\hline Jaideep Dhariwal & Mano Sira \\
\hline Waljit Dhillo & Sarah Stanley \\
\hline Agnieska Falinszka & Tricia Tan \\
\hline John Frank & George Tharakan \\
\hline Stephen Gilbey & Jeannie Todd \\
\hline Tony Goldstone & Emma Walker \\
\hline Saira Hameed & Julian Waung \\
\hline Peter Hammond & Florian Wernig \\
\hline Emma Hatfield & John Wilding \\
\hline Andrew Hattersley & Matt Williams \\
\hline Chioma Izzi-Engbeaya & Zarni Win \\
\hline Sheba Jarvis & Sagen Zac-Varghese \\
\hline Channa Jayasena & \\
\hline
\end{tabular}




\section{CONTENTS}

INTRODUCTION

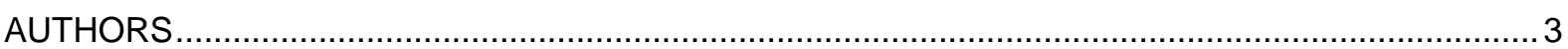

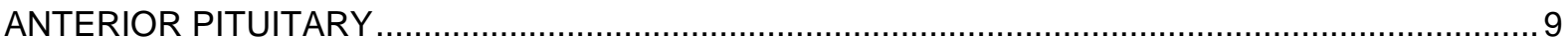

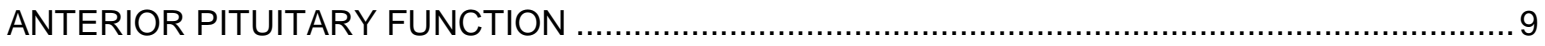

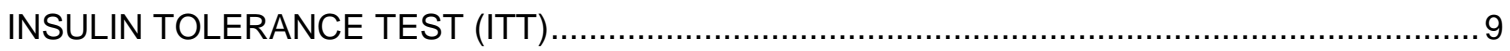

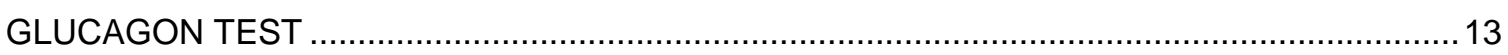

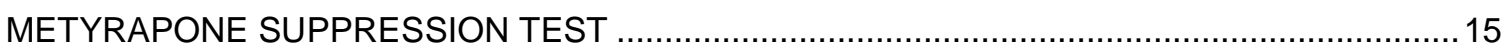

THYROTROPHIN RELEASING HORMONE (TRH) TEST ................................................. 17

GONADOTROPHIN RELEASING HORMONE GNRH/LHRH TEST .......................................18

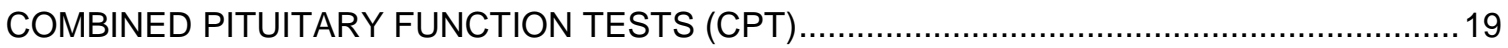

VISUAL FIELD TESTING (GOLDMANN AND HUMPHREYS PERIMETRY) ..............................22

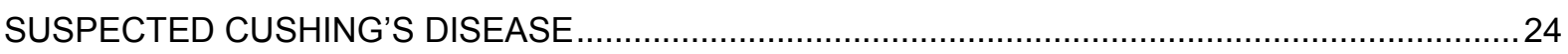

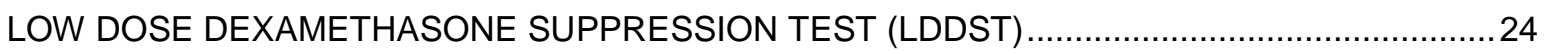

BILATERAL SIMULTANEOUS INFERIOR PETROSAL SINUS SAMPLING (IPSS) WITH CRH ....26

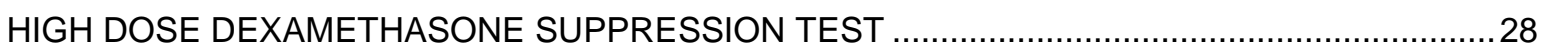

PRE-OPERATIVE PREPARATION OF PATIENTS WITH CONFIRMED CUSHING'S

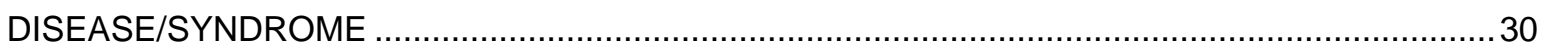

PERIPHERAL VENOUS SAMPLING FOR SOURCES OF ECTOPIC ACTH .............................. 30

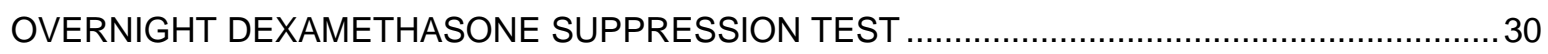

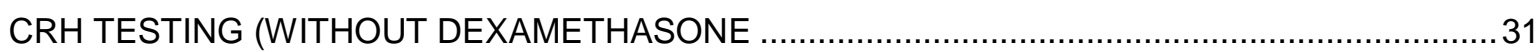

PROLACTINOMAS AND NON-FUNCTIONING PITUITARY ADENOMAS …....................................34

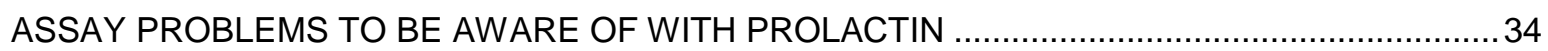

DISTINGUISHING PITUITARY MACROADENOMAS SECRETING PROLACTIN FROM NON-

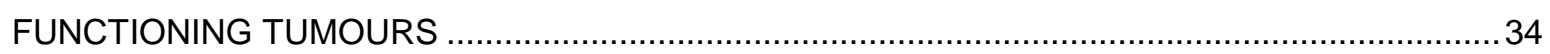

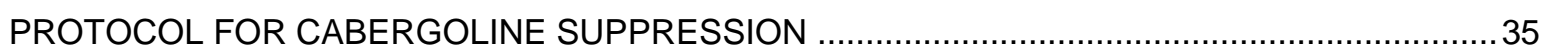

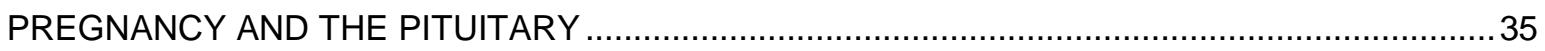

DOPAMINE AGONIST TREATMENT OF HYPERPROLACTINAEMIA ...................................... 36

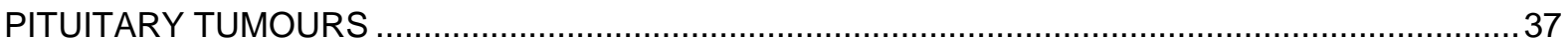

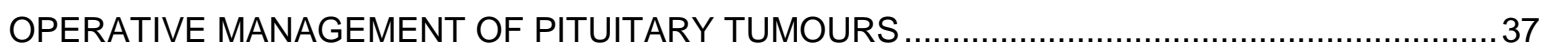

HYDROCORTISONE REPLACEMENT PRE- AND POST- PITUITARY SURGERY ........................ 38

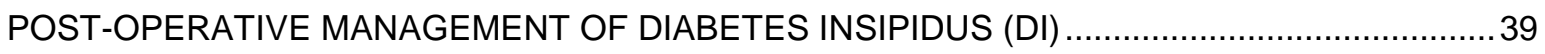

POST-OPERATIVE ASSESSMENT OF GH BURDEN IN ACROMEGALY ................................. 40 
IMMEDIATE POST-OPERATIVE ASSESSMENT OF EARLY REMISSION IN CUSHING'S

DISEASE

CUSHING'S DAY CURVE FOR ASSESSMENT OF EARLY REMISSION FOLLOWING TRANSSPHENOIDAL SURGERY FOR CUSHING'S DISEASE

FOLLOW UP OF PATIENTS WITH CUSHING'S DISEASE FOLLOWING BILATERAL

ADRENALECTOMY

HYDROCORTISONE DAY CURVE.

GROWTH HORMONE.

A WORD ON UNITS.

HUMAN GROWTH HORMONE (HGH) PRESCRIBING FOR ADULT ONSET GROWTH

HORMONE DEFICIENCY (AOGHD) .48

EXERCISE TEST .50

GHRH-ARGININE STIMULATION TEST. 51

ARGININE STIMULATION TEST. .53

ORAL GLUCOSE TOLERANCE TEST FOR ACROMEGALY..... .54

FOLLOW UP POST PITUITARY SURGERY AND RADIOTHERAPY .55

SCREENING COLONOSCOPY IN ACROMEGALY . .55

HISTORICAL METHODS OF ASSESSING EXCESS GROWTH HORMONE ...............................56

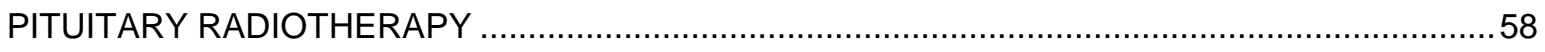

POLICY ON SPERM STORAGE PRIOR TO PITUITARY RADIOTHERAPY ..............................58

ASSESSMENT OF HYPOPITUITARISM FOLLOWING CRANIAL IRRADIATION .......................58

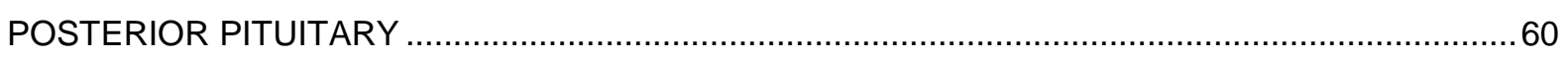

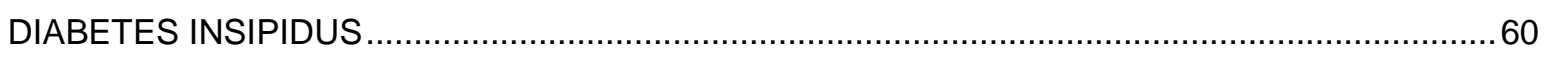

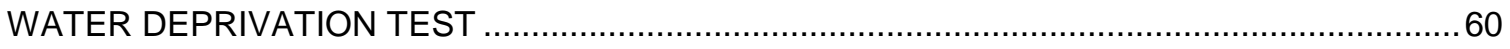

PROLONGED WATER DEPRIVATION TEST (MILLER AND MOSES) ....................................63

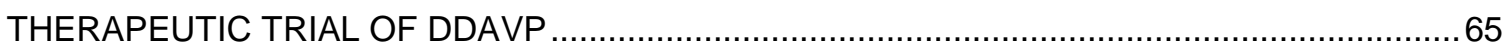

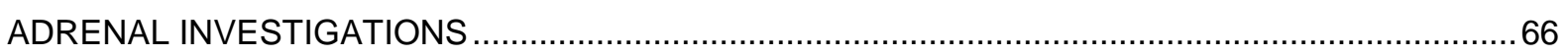

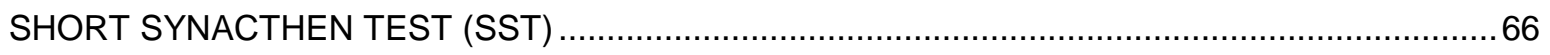

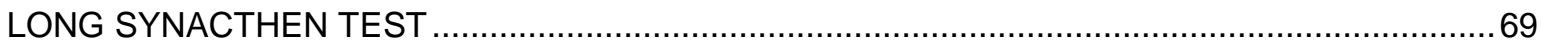

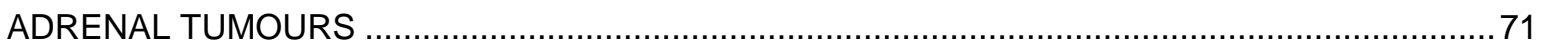

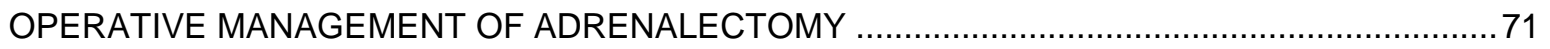

CUSHING'S SYNDROME (CS) IN BILATERAL ADRENAL DISEASE ........................................ 73

BILATERAL MACRONODULAR ADRENAL HYPERPLASIA (BMAH) ….................................. 74

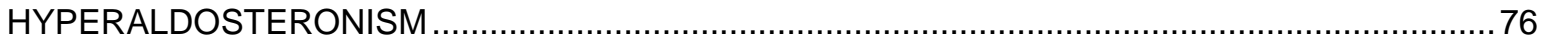




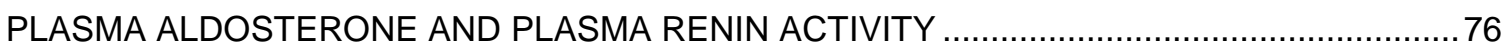

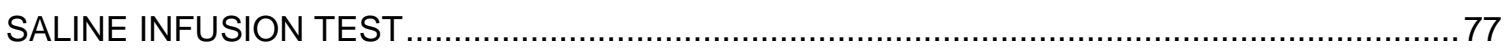

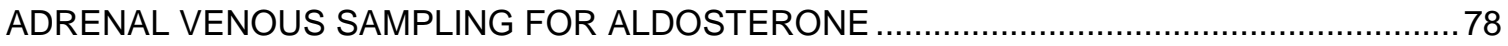

SELENIUM CHOLESTEROL SCANNING FOR CONN'S TUMOURS......................................... 83

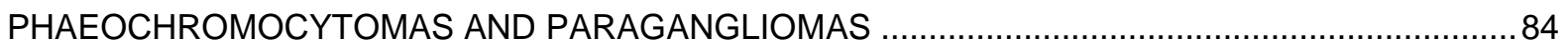

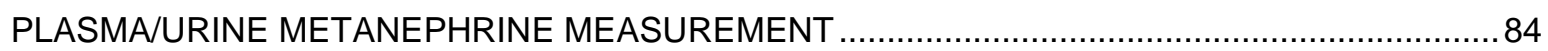

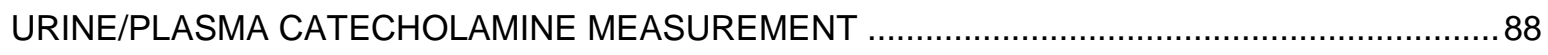

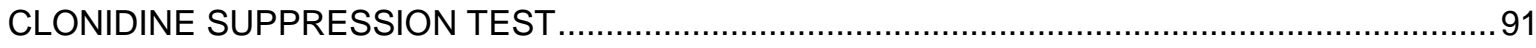

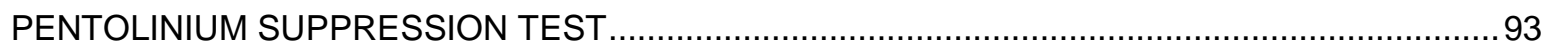

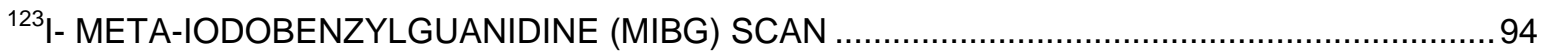

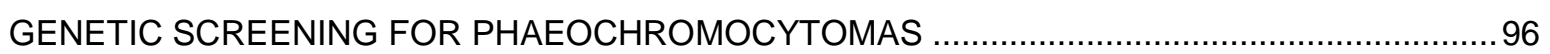

PERIOPERATIVE MANAGEMENT OF PHAEOCHROMOCYTOMAS ...........................................98

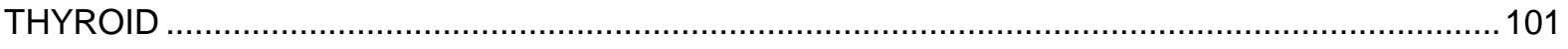

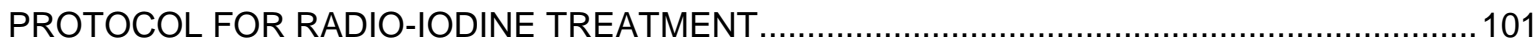

PROTOCOL FOR THE POST-RADIOIODINE TREATMENT TELEPHONE CLINIC....................... 102 INSTRUCTIONS FOR THOSE RUNNING THE TELEPHONE CLINIC....................................... 104

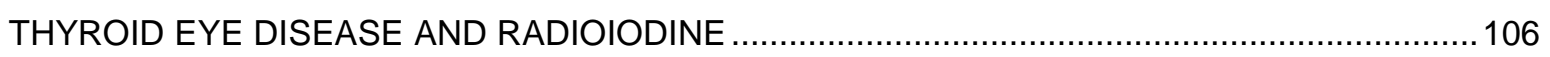

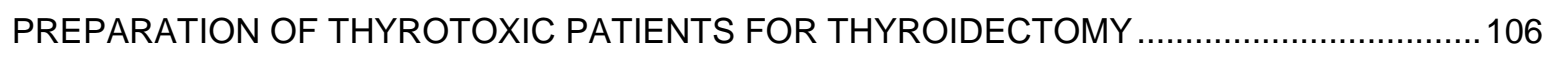

STARTING THYROXINE POST-TOTAL OR COMPLETION THYROIDECTOMY .......................107

PROTOCOL FOR THE MANAGEMENT OF THYROID EYE DISEASE (TED) .............................107

PENTAGASTRIN TEST FOR MEDULLARY THYROID CARCINOMA ….....................................111

CALCIUM INFUSION TEST FOR MEDULLARY THYROID CANCER ...........................................112

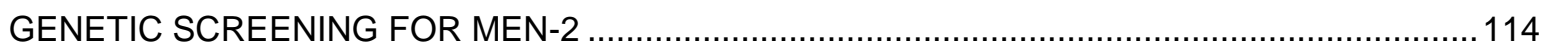

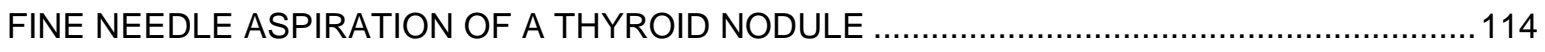

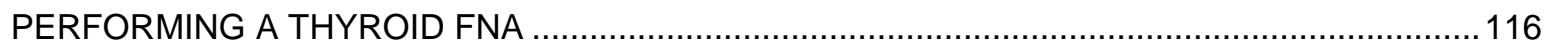

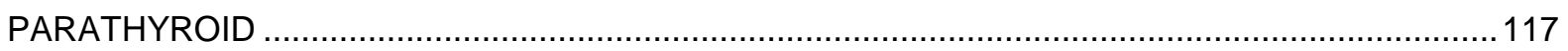

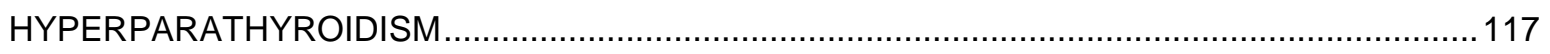

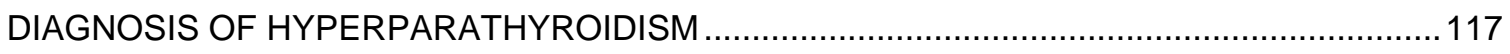

WHO TO CONSIDER FOR PARATHYROIDTHYROID SURGERY ......................................118

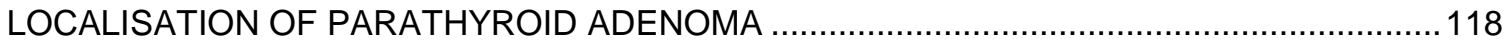

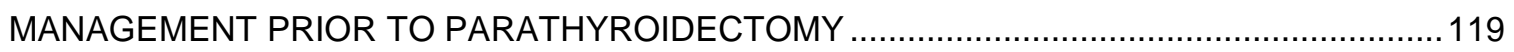

A NOTE ON VITAMIN D DEFICIENCY AND HUNGRY BONES ............................................ 119

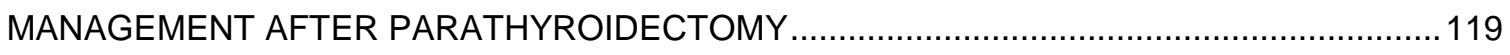




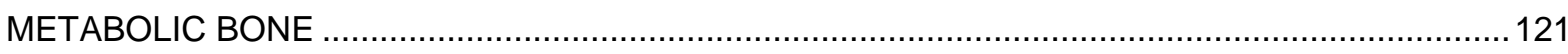

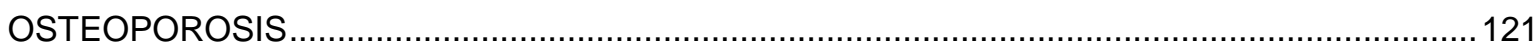

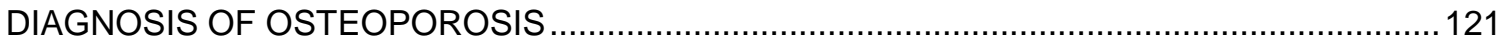

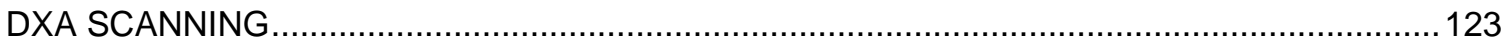

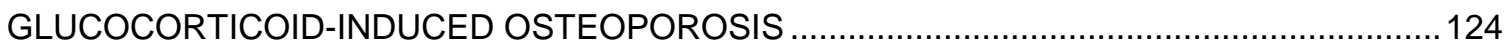

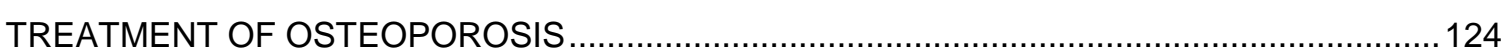

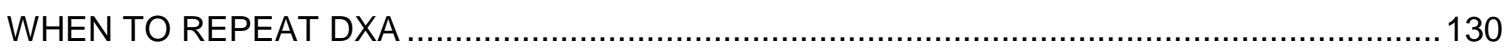

USE OF BISPHOSPHONATES IN ACUTE FRACTURE SITUATIONS .................................. 131

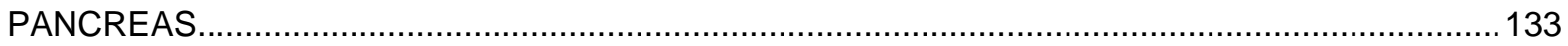

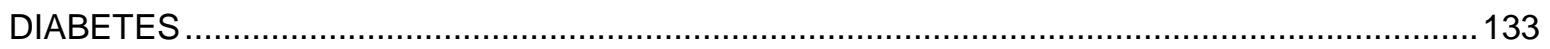

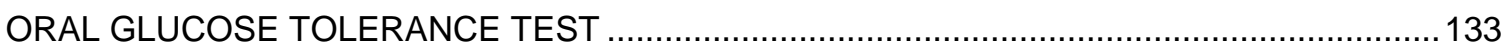

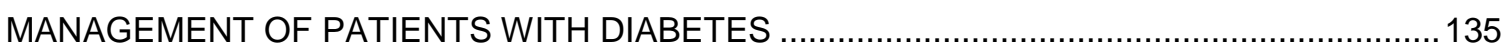

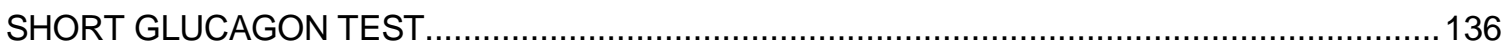

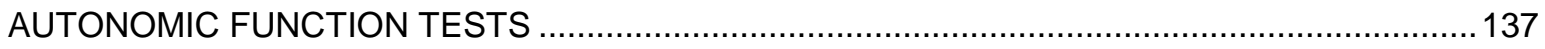

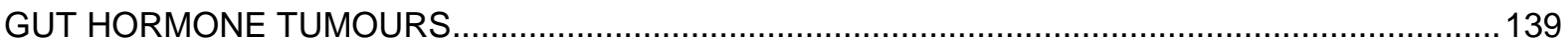

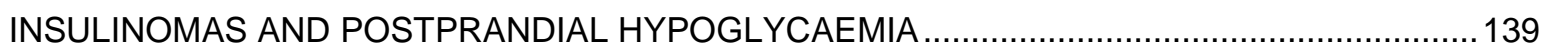

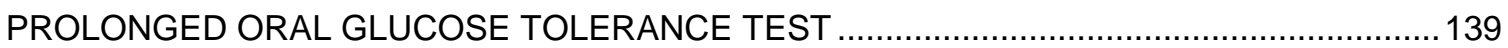

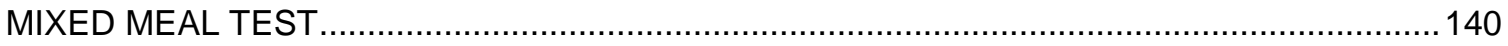

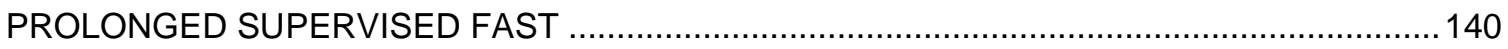

MANAGEMENT OF STABLE INSULINOMAS PRIOR TO SURGERY .......................................141

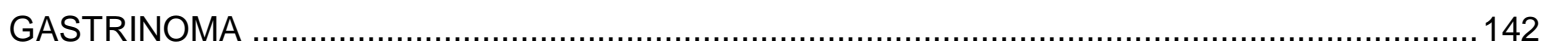

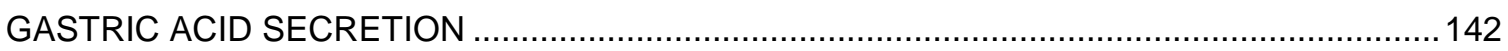

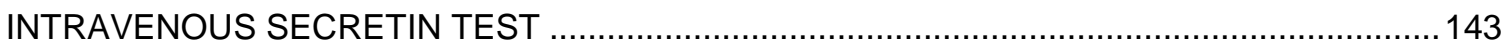

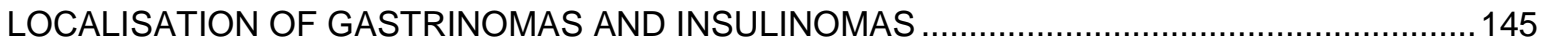

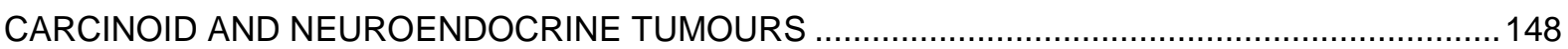

SCHEDULE FOR LUTETIUM-177 DOTA OCTREOTATE TREATMENT .......................................148

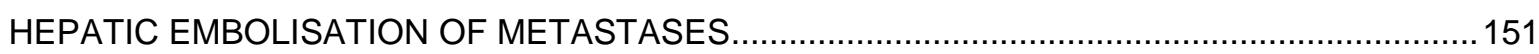

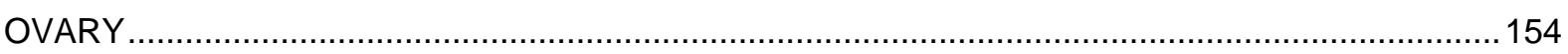

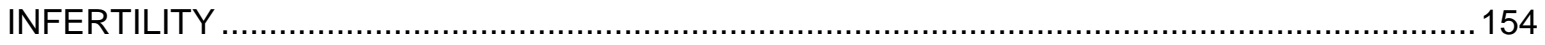

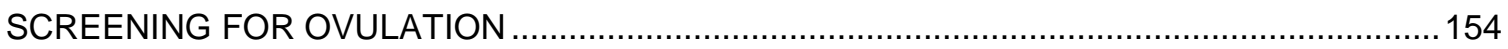

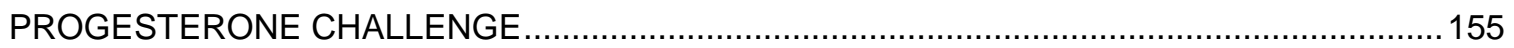

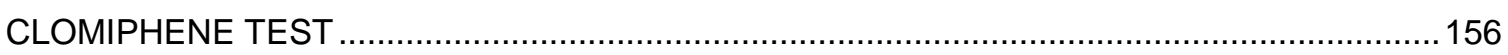

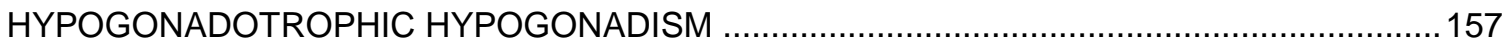




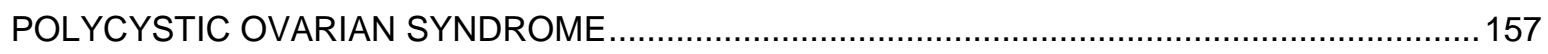

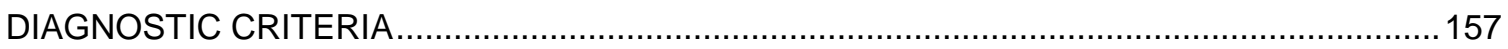

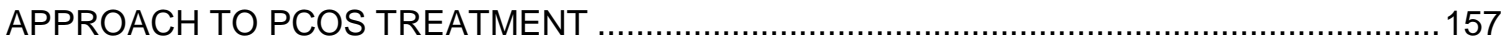

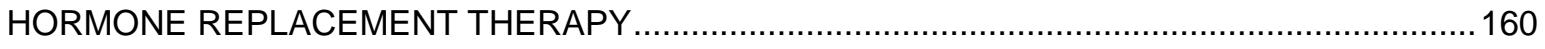

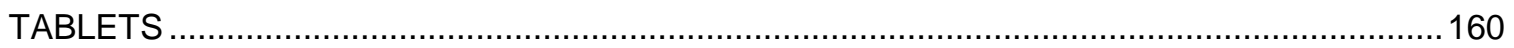

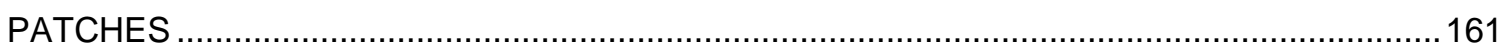

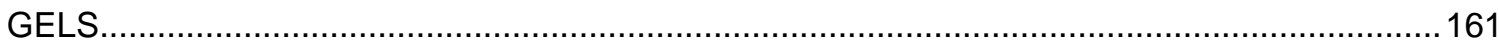

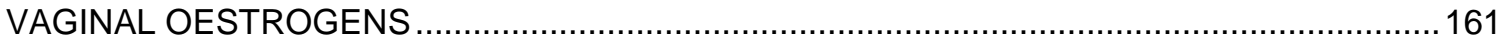

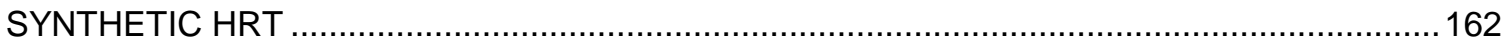

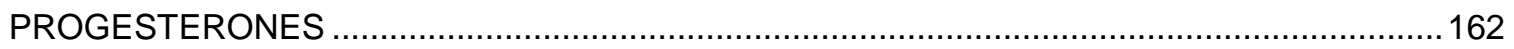

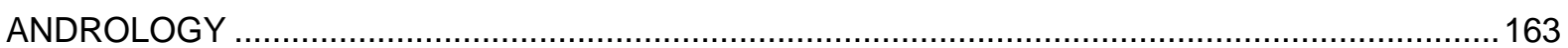

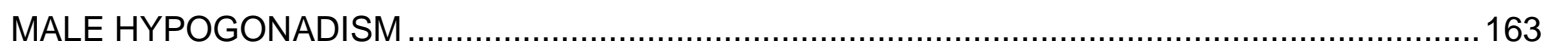

POLICY ON SPERM STORAGE PRIOR TO PITUITARY RADIOTHERAPY ...............................164

FERTILITY INDUCTION IN HYPOGONADOTROPHIC HYPOGONADISM ................................165

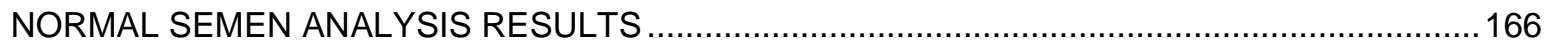

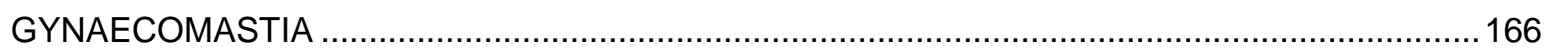

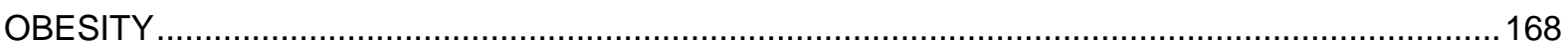

THE IMPERIAL WEIGHT CENTRE TIER 3 WEIGHT MANAGEMENT SERVICE, ST MARY'S

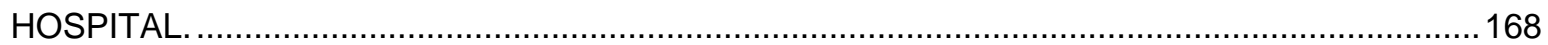

CRITERIA FOR REFERRAL TO THE TIER 3 WEIGHT MANAGEMENT SERVICE .....................168

BARIATRIC SURGERY AT THE IMPERIAL WEIGHT CENTRE, ST MARY'S HOSPITAL ........... 168

CRITERIA FOR REFERRAL FOR BARIATRIC SURGERY AT ST MARY'S HOSPITAL ..............169

CRITERIA FOR REFERRAL FOR BARIATRIC SURGERY AT ST MARY'S HOSPITAL FOR

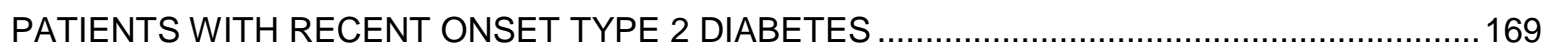

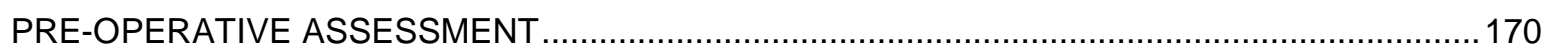

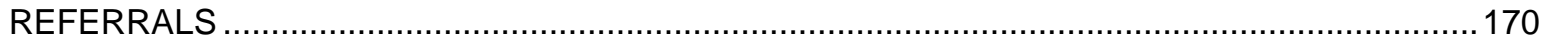

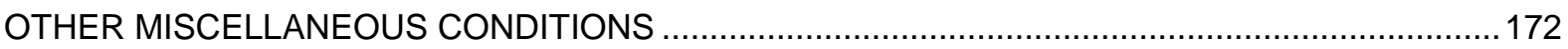

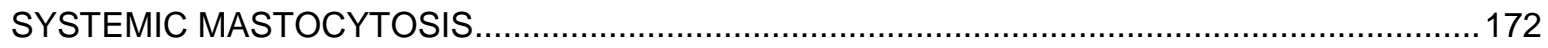

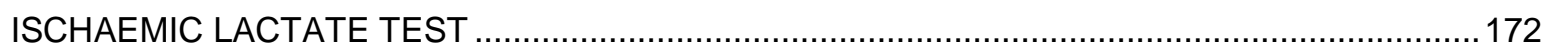

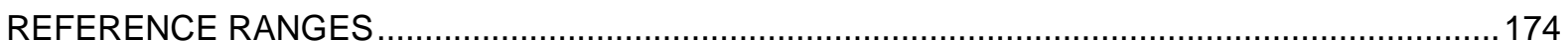

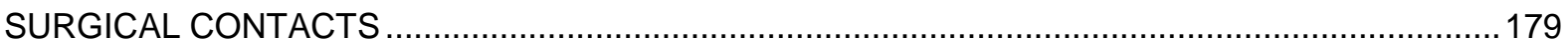

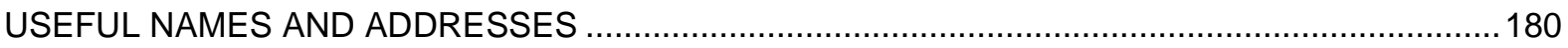




\section{ANTERIOR PITUITARY}

\section{ANTERIOR PITUITARY FUNCTION}

\section{INSULIN TOLERANCE TEST (ITT)}

\section{INDICATION}

1. Assessment of ACTH and cortisol reserve.

2. Assessment of growth hormone reserve in children with definite growth retardation and a subnormal growth hormone stimulation test (see exercise test).

3. Differentiation of Cushing's syndrome from depression.

4. GH response in adults.

\section{CONTRAINDICATIONS}

Ischaemic heart disease,

Epilepsy,

Untreated hypothyroidism (impairs the GH and cortisol response),

9am Serum cortisol $<100 \mathrm{nmol} / \mathrm{L}$.

\section{PREPARATION}

- The patient should fast overnight (water permitted) and be recumbent during the test. Medications can be given after completion of the test i.e. by lunchtime. If patient is taking hydrocortisone, then the last dose should be at midday the day before the test (i.e. omit evening dose and dose on morning of test).

- ECG must be normal and the patient's weight known.

- In peri-pubertal children (bone age $>10$ years) priming is needed

- M: $100 \mathrm{mg}$ testosterone enantate i.m. (single injection) 3 days before test. (This will come from a vial of $250 \mathrm{mg}$, which is the only available vial size).

- F: $100 \mathrm{mcg}$ ethinyloestradiol p.o. each for three days before the test.

- Calculate Actrapid Insulin dose:
- Normal pituitary function
$0.15 \mathrm{U} / \mathrm{kg}$
○ Hypopituitary
$0.10 \mathrm{U} / \mathrm{kg}$
- Acromegaly, diabetes, Cushing's
$0.2-0.3 \mathrm{U} / \mathrm{kg}$

- Oral oestrogens should be discontinued for 6 weeks before the test (transdermal oestrogens can be continued).

- If the patient is hypoadrenal for any reason (or on hydrocortisone or prednisolone), the case must be discussed with senior medical staff before administration of insulin. Patients with a cortisol $<100 \mathrm{nmol} / \mathrm{L}$ are very unlikely to have a normal response and may therefore not need 
the test.

- $20 \%$ dextrose must be available for immediate administration (but only use if persistent hypoglycaemia).

- Glucometer.

- 6 fluoride oxalate tubes (grey top Vacutainers)

- 6 red or yellow top Vacutainers

\section{SIDE EFFECTS}

Sweating, palpitations, loss of consciousness and rarely convulsions.

\section{METHOD}

1. Site intravenous (i.v.) cannula.

2. At 0 minutes, take baseline bloods and then inject insulin i.v.

3. Take samples for $\mathrm{GH}$, cortisol and glucose at $0,30,60,90$, and 120 minutes, flushing the cannula with saline between samples.

4. Check whole blood glucose on glucometer every time a specimen is taken. At 30 minutes check whole blood glucose with Glucometer and repeat the insulin dose if not hypoglycaemic (this will mean prolonging sampling by $30 \mathrm{~min}$ ).

5. Adequate hypoglycaemia is defined as glucose $\leq 2.2 \mathrm{mmol} / \mathrm{Lwith}$ symptoms. Record symptoms in the notes. Once this has been achieved, patients need not remain hypoglycaemic (see point 8). Obtain specimen for glucose before reversal of symptoms.

6. There must be at least 2 samples following adequate hypoglycaemia. This does not mean that the patients need spend that long hypoglycaemic.

7. At all times a doctor or nurse must be in attendance. A doctor should be present to administer the insulin but can leave once glucose levels start to rise following hypoglycaemia. The lowest glucose level following i.v. insulin is usually at 20-30 minutes, with spontaneous resolution.

8. Reverse hypoglycaemia with simple oral treatment (juice/lucozade). If symptoms very severe or patient unrousable (rare) consider giving i.v. $20 \%$ dextrose, or $1 \mathrm{mg}$ i.m. glucagon (kept in ward fridge), and continue sampling.

9. If a patient has a hypoadrenal crisis they should receive i.v. $0.9 \%$ saline and i.v. hydrocortisone $100 \mathrm{mg}$.

10. Once test completed, give supervised meal and ensure glucose normal before discharging.

11. Patient should not drive for 2 hours after the test.

\section{IMPORTANT NOTE ON ITT CORTISOL INTERPRETATION}

It is important to realise that the cortisol response to stress and the cortisol response to an ITT is highly variable. We use the ITT as a surrogate for stress, assuming that if patients cannot produce $500 \mathrm{nmol} / \mathrm{L}$ of cortisol during the ITT, that they might suffer an Addisonian crisis at times of stress. We also assume that patients who produce more than $500 \mathrm{nmol} / \mathrm{L}$ 
cortisol during an ITT are very unlikely to have an Addisonian crisis at times of stress, and thus do not need regular cortisol replacement. However, there is likely to be a grey area between a peak of $375 \mathrm{nmol} / \mathrm{L}$ and $500 \mathrm{nmol} / \mathrm{L}$. If a patient produces a peak cortisol of 400 $\mathrm{nmol} / \mathrm{L}$ for example, it is unlikely that they will have an Addisonian crisis, but one cannot be certain, and for this reason we tend to suggest glucocorticoid replacement. However, if such a patient is given full replacement with hydrocortisone three times daily (or prednisolone once daily), there is the possibility that we are causing subclinical Cushing's syndrome. Now that there is the suggestion that over-replacement with glucocorticoid can increase risk of death from stroke or other cardiovascular disease, we need to be cautious about indiscriminately prescribing glucocorticoids that in fact are not needed.

The cortisol cut-off (see below) has moved down for a number of reasons, including the fact that many assays have a negative bias at the higher concentrations compared to the new assays. The assay now used at Imperial is the Abbott Architect cortisol assay and these cutoffs are the best we have for this assay. Please can all endocrinologists using these guidelines recognise that you need to think about the prior probability of the patient needing glucocorticoids when you interpret data such as this, and realise that the peak cortisol "cutoff" that we have used for years has a poor evidence base.

\section{INTERPRETATION}

- The test cannot be interpreted unless hypoglycaemia $(\leq 2.2 \mathrm{mmol} / \mathrm{l})$ is achieved.

- Adequate cortisol response is defined as a rise of greater than $150 \mathrm{nmol} / \mathrm{L}$ to 500 $\mathrm{nmol} / \mathrm{L}$ or above.

Please note that these cortisol values are based on the cortisol assay at Imperial College Healthcare NHS Trust. Other centres must take into account the specific local assay as the values stated above may not apply to other assays.

- Patients with slightly impaired cortisol responses may only need steroid cover for major illnesses or stresses. They will need instructions about this and should carry a steroid card.

- In Cushing's syndrome there will be a rise of less than $140 \mathrm{nmol} / \mathrm{L}$ above the fluctuations of basal levels of cortisol.

- The European and Endo Society guidelines and NICE define severe GHD as GH $<3 \mathrm{mcg} / \mathrm{L}$ and partial $<5 \mathrm{mcg} / \mathrm{L}$

- In adults this may be a sensitive indicator of hypopituitarism but its principal role is in children who may require $\mathrm{GH}$ treatment. 
- In children a rise to $>10 \mathrm{mcg} / \mathrm{L}$ (>39 $\mathrm{mU} / \mathrm{L}$ ) is considered normal (ensure euthyroid). Appropriate priming is very important if they are peri-pubertal. By consensus children should have two different stimulatory tests before assigning a diagnosis of isolated GH deficiency (e.g. insulin, glucagon or GHRH-arginine tests) unless IGF-1 is decreased in which case one test may be considered adequate.

\section{SENSITIVITY AND SPECIFICITY}

If there is adequate hypoglycaemia and the patient is not hypothyroid then cortisol response is a good test of $\mathrm{ACTH} / \mathrm{adrenal}$ reserve. $5-15 \%$ of normal people will show a suboptimal response as defined by these two criteria.

$20 \%$ of patients with Cushing's syndrome will show a rise greater than $140 \mathrm{nmol} / \mathrm{L}$ but a rise of less than this is rare in depression or alcoholic pseudo-Cushing's.

$\mathrm{GH}$ responses are reduced in $20 \%$ of normal children and some small children whose peak $\mathrm{GH}$ is $3-6 \mathrm{mcg} / \mathrm{L}(10-20 \mathrm{mU} / \mathrm{l})$ may benefit from $\mathrm{GH}$ replacement.

\section{REFERENCES}

Greenwood et al., (1965) J. Clin. Invest. 45:429

Plumpton et al., (1969) Br. J. Surg. 56:21

Stanley (2002) Curr Opin Endocrinol Diabetes Obes 19 :47-52

Evaluation and treatment of adult growth hormone deficiency: an Endocrine Society clinical practice guideline._J Clin Endocrinol Metab (2011) 96:1587

Consensus guidelines for the diagnosis and treatment of adults with GH deficiency II: a statement of the GH Research Society in association with the European Society for Pediatric Endocrinology, Lawson Wilkins Society, European Society of Endocrinology, Japan Endocrine Society, and Endocrine Society of Australia.Eur J Endocrinol (2007) 157:695

Updated: Ben Jones and Chioma Izzi-Engbeaya 11/13, Alexander Comninos 9/15, Tony Goldstone $09 / 15$ 


\section{GLUCAGON TEST}

\section{INDICATION}

1. Assessment of growth hormone and ACTH/cortisol reserve, especially when insulininduced hypoglycaemia is contraindicated. This is a good assessment of GH reserve. Cortisol results should be interpreted with caution in light of the clinical picture.

2. Consider a combination of glucagon test and metyrapone test when ITT is contraindicated, and please note the caution about ALL cortisol cutoffs on pages $10 / 11$.

\section{CONTRAINDICATIONS}

Phaeochromocytoma or insulinoma (may provoke an attack).

Starvation $>48$ hours or glycogen storage diseases (inability to mobilise glycogen may result in hypoglycaemia).

Severe hypocortisolaemia (9am cortisol $<55 \mathrm{nmol} / \mathrm{l})$.

Thyroxine deficiency may reduce $\mathrm{GH}$ and cortisol responses.

\section{SIDE EFFECTS}

Nausea is common (30\%) and rarely patients may vomit.

\section{PREPARATION}

- Oral oestrogens should be discontinued for 6 weeks before the test (transdermal oestrogens can be continued).

- Fasting from midnight. The patient does not need to be continually observed as hypoglycaemia is not provoked.

- Calculate glucagon dose: adults: $1 \mathrm{mg},(1.5 \mathrm{mg}$ if $>90 \mathrm{~kg}) \quad$ children: $15 \mathrm{mcg} / \mathrm{kg}$

- 6 fluoride oxalate bottles (grey top Vacutainers) and 6 red or yellow top Vacutainers

\section{METHOD}

1. Insert an indwelling cannula.

2. Take basal samples for glucose, cortisol and $\mathrm{GH}$.

3. Give the glucagon i.m. (the deltoid may be a suitable site).

4. Take further samples at $90,120,150$ and 180 minutes.

\section{INTERPRETATION}

- Adequate cortisol response is defined as a rise of greater than $140 \mathrm{nmol} / \mathrm{L}$ to above $350 \mathrm{nmol} / \mathrm{L}$.

Please note that these cortisol values are based on the cortisol assay at Imperial College Healthcare NHS Trust. Other centres must take into account the specific 
local assay as the values stated above may not apply to other assays.

- Severe GHD defined as $\mathrm{GH}<3 \mathrm{mcg} / \mathrm{L}$ and partial $\mathrm{GHD} \mathrm{GH}<5 \mathrm{mcg} / \mathrm{L}$

\section{SENSITIVITY AND SPECIFICITY}

This test is probably a slightly less reliable test of somatotroph and corticotroph function than the ITT, with a sensitivity of $71 \%$ and a specificity of $57 \%$ for adequate cortisol reserve if a peak cortisol cut-off of $>350 \mathrm{nmol} / \mathrm{L}$ is used. It is a reasonable alternative in patients who cannot tolerate hypoglycaemia because of epilepsy, ischaemic heart disease or hypopituitarism (cortisol $<100 \mathrm{nmol} / \mathrm{L}$ ).

\section{REFERENCES}

Rao et al., (1987) Metabolism 36:658

Cegla et al., (2013) Clin Endo 78:738

Andrew Hattersley 12/89, revised Ben Jones and Chioma Izzi-Engbeaya 11/13, reviewed by Niamh Martin 08/14, Alexander Comninos 9/15 


\section{METYRAPONE SUPPRESSION TEST}

\section{INDICATION}

1. To establish the correct functioning of the ACTH axis in suspected secondary hypocortisolism, where Insulin tolerance or Glucagon stress tests are contraindicated.

2. As an alternative to the Short Synacthen Test for evaluation of primary hypocortisolism.

\section{CONTRAINDICATIONS}

Previous adverse reaction to metyrapone.

\section{SIDE EFFECTS}

Most commonly nausea and perhaps vomiting with the medication (reduced by taking metyrapone with a snack).

Headaches, dizziness and sedation, allergic skin reactions.

\section{PREPARATION}

- Stop all oestrogen therapy 6 weeks prior to test.

- No need to fast.

- 18-20g cannula.

- Yellow top Vacutainer (plain clotted) x 1, Purple top Vacutainer (EDTA) x 1 .

\section{METHOD}

1. Admit to hospital for overnight stay.

2. Calculate dose of metyrapone $(30 \mathrm{mg} / \mathrm{kg})$ :

3. Body weight dose of metyrapone

4. $<70 \mathrm{~kg} 2.0 \mathrm{~g}$

5. $\quad 70-90 \mathrm{~kg} \quad 2.5 \mathrm{~g}$

6. $>90 \mathrm{~kg} \quad 3.0 \mathrm{~g}$

7. Administer calculated dose of metyrapone at midnight with a snack (e.g. milk and biscuits).

8. At 0800h-0900h the following morning, sample for ACTH, 11-deoxycortisol, and cortisol.

9. After blood sample, administer hydrocortisone $10 \mathrm{mg} P O$ to cover for hypocortisolism.

10. Patient can be discharged home after hydrocortisone given. 
INTERPRETATION

\begin{tabular}{|c|c|c|}
\cline { 2 - 3 } \multicolumn{1}{c|}{} & $11-\mathrm{DOC}>200 \mathrm{nmol} / \mathrm{L}$ & $11-\mathrm{DOC} \leq 200 \mathrm{nmol} / \mathrm{L}$ \\
\hline Cortisol & Normal response & $\begin{array}{r}\text { Primary or secondary adrenal } \\
\text { insufficiency }\end{array}$ \\
\hline Cortisol & Uninterpretable & $\begin{array}{c}\text { Insufficient metyrapone inhibition } \\
\text { (i.e. non-diagnostic) }\end{array}$ \\
\hline $200 \mathrm{nmol} / \mathrm{L}$ & & .
\end{tabular}

\section{SENSITIVITY AND SPECIFICITY}

The performance of the Metyrapone test has been compared to the Insulin Tolerance Test (ITT) as a gold standard in various studies. Using the criteria as above the specificity is $77 \%$ and sensitivity $86 \%$.

\section{USE OF METYRAPONE SUPPRESSION TEST VERSUS GLUCAGON STIMULATION TEST}

If the ITT is contraindicated either a Glucagon stimulation test or an overnight Metyrapone test can be used to assess for ACTH deficiency. In our experience the overnight Metyrapone test should be used in preference to the Glucagon stimulation test due to its superior specificity $(77 \%)$ and sensitivity (86\%), compared with Glucagon stimulation test sensitivity (71\%) and specificity (57\%) using a cut-off of $\geq 350 \mathrm{nmol} / \mathrm{L}$.

\section{REFERENCES}

Steiner et al., (1994) Clin Endocrinol (Oxf). 102:33

Fiad et al., (1994) Clin Endocrinol (Oxf). 40:603

Courtney et al., (2000) Clin Endocrinol (Oxf). 53:309

Gibney et al., (2008) J Clin Endocrinol Metab. 93:3763

Tan et al., (2013) Clin Endocrinol (Oxf) 78: 738

\section{VERSION HISTORY}

Chioma Izzi-Engbeaya 11/13, Saira Hameed 03/15 


\section{THYROTROPHIN RELEASING HORMONE (TRH) TEST}

\section{INDICATION}

1. To assess $\mathrm{TSH}$ reserve

2. Differential diagnosis of pituitary and hypothalamic causes of TSH deficiency

\section{CONTRAINDICATIONS}

As patients should be off thyroxine for 3 weeks prior to this test, it is rarely used in patients on thyroxine.

\section{PREPARATION}

- Overnight fast not necessary.

- $200 \mathrm{mcg}$ TRH (Protirelin $200 \mathrm{mcg}$ in $0.2 \mathrm{ml}$ ).

- i.v. cannulae.

- $3 \times$ red top Vacutainers: $6 \mathrm{ml}$ per sample.

\section{SIDE EFFECTS}

Patients should be warned that they may have transient side effects after the injection such as a metallic taste in the mouth, flushing and mild nausea, and should be on a recliner or bed.

\section{METHOD}

1. Site intravenous cannula.

2. Take baseline bloods for TSH and thyroxine (T4).

3. Inject TRH slowly i.v. over 2 minutes.

4. Flush cannula with heparin/saline.

5. Take samples for $\mathrm{TSH}$ at $\mathrm{t}=30$ mins and 60 mins.

\section{INTERPRETATION}

- The normal result is a TSH rise to $>5 \mathrm{mU} / \mathrm{L}$ with the 30 mins value exceeding the 60 mins value.

- If the 60 mins sample exceeds the 30 mins value then this usually indicates primary hypothalamic disease.

- In hyperthyroidism, the TSH remains suppressed and in hypothyroidism there is an exaggerated response. With the current sensitive TSH assays basal levels are now adequate and dynamic testing is not usually needed to diagnose hyperthyroidism.

\section{SENSITIVITY AND SPECIFICITY}

An inadequate rise of TSH is not an indication for thyroxine replacement unless the serum free T4 or free T3 is reduced. The TSH is not only undetectable in pituitary disease and thyrotoxicosis but also in some cases of euthyroid ophthalmic Grave's disease and multinodular goitre.

A late rise in TSH may be seen rarely in thyroid and pituitary disease as well as hypothalamic disease. 


\section{REFERENCES}

Hall et al., Lancet 1972;1: 759-63.

Andrew Hattersley 11/89

\section{GONADOTROPHIN RELEASING HORMONE GNRH/LHRH TEST}

\section{INDICATION}

1. To investigate possible gonadotrophin deficiency.

2. To investigate precocious and delayedpuberty.

\section{PREPARATION}

- Overnight fast not necessary if done alone.

- In women with a normal menstrual cycle the test should be performed in the follicular phase (day 3-7 of the cycle). Greater LH responses are observed later on in the cycle.

- Larger dose or priming with LHRH may be necessary if hypogonadism is suspected.

- (N.B. Do not prime with sex steroids if indication 2 above)

- $100 \mathrm{mcg} \mathrm{GnRH}$ - Gonadorelin.

- 3 clotted tubes (red or yellow top Vacutainers $-7 \mathrm{ml}$ )

\section{METHOD}

1. Site intravenous cannula.

2. Take baseline bloods: LH, FSH and testosterone (M) or oestradiol (F).

3. Inject $\mathrm{GnRH}$ intravenously.

4. Flush cannula with saline.

5. Take samples for $\mathrm{LH}$ and $\mathrm{FSH}$ at $\mathrm{t}=30$ and 60 mins.

\section{INTERPRETATION}

- The normal peaks can occur at either 30 or 60 minutes. LH should exceed $10 \mathrm{IU} / \mathrm{Land}$ FSH should exceed $2 \mathrm{IU} / \mathrm{l}$. An inadequate response may be an early indication of hypopituitarism.

- Gonadotrophin deficiency is diagnosed on the basal levels rather than the dynamic response. In males this is based on low testosterone in the absence of raised basal gonadotrophins and in females low oestradiol without elevated basal gonadotrophins and no response to clomiphene.

- Pre-pubertal children should have no response of LH or FSH to GnRH. If sex steroids are present (i.e. the patient is undergoing precocious puberty), the pituitary will be "primed" and will therefore respond to GnRH. Therefore, priming with steroids MUST NOT occur before this test. Please also remember to consider if there are other features of precocious puberty such as advanced Tanner Stage, increased testicular volume, increased bone age, and circulating sex steroid levels which are higher than expected for the patient's age. 


\section{SENSITIVITY AND SPECIFICITY}

This test has a very low sensitivity and specificity for hypogonadotrophic hypogonadism. The response may be normal or even exaggerated (especially in patients with hypothalamic disease). Basal gonadotrophin and sex steroid levels are better discriminants in hypogonadotrophic hypogonadism. Serial investigations in patients with pituitary disease especially irradiation may give early indication of the development of hypopituitarism.

\section{REFERENCE}

Mortimer C. H. et al., (1973) BMJ 4:73

Job et al., (1977) Horm Res 8:171

VERSION HISTORY: Andrew Hattersley 11/89, Arshia Panahloo 1/98 Ben Jones and Sagen ZacVarghese 11/13, reviewed by Channa Jayasena 08/14, Alexander Comnios 09/15

\section{COMBINED PITUITARY FUNCTION TESTS (CPT)}

\section{INDICATION}

Assessment of all components of anterior pituitary function used particularly in pituitary tumours or following tumour treatment.

\section{CONTRAINDICATIONS}

Ischaemic heart disease.

Epilepsy.

Untreated hypothyroidism (impairs the GH and cortisol response).

Serum cortisol $<100 \mathrm{nmol} / \mathrm{L}$.

\section{SIDE EFFECTS}

Sweating, palpitations, loss of consciousness and rarely convulsions with hypoglycaemia.

Patients should be warned that with the TRH injection they may experience transient symptoms of a metallic taste in the mouth, flushing or nausea. 


\section{PREPARATION}

- The patient should fast overnight and be recumbent during test.

- ECG must be normal and the patient's weight known.

- In peri-pubertal children (bone age $>10$ years) priming is needed

- M: $100 \mathrm{mg}$ testosterone enantate i.m. (single injection from a vial of $250 \mathrm{mg}$ ) three days before test

F: $\quad 100 \mathrm{mcg}$ ethinyloestradiol p.o. each for three days before the test.

- Calculate Actrapid Insulin dose:

- Normal pituitary function $\quad 0.15 \mathrm{U} / \mathrm{kg}$

○ Hypopituitary $0.10 \mathrm{U} / \mathrm{kg}$

- Acromegaly, diabetes, Cushing's $\quad 0.2-0.3 \mathrm{U} / \mathrm{kg}$

- $\mathrm{TRH}$ (Roche) $200 \mathrm{mcg}$ as slow i.v. injection.

- $\mathrm{GnRH}-100 \mathrm{mcg}$ as i.v. bolus.

- $100 \mathrm{mls} 20 \%$ dextrose available for immediate administration.

- Cannula, 18-20g.

- Glucometer.

- 6 fluoride oxalate tubes (grey top Vacutainers).

- 7 clotted tubes (red or yellow top Vacutainers) for samples.

- $500 \mathrm{ml}$ of $0.9 \%$ saline to flush cannula.

- 3 way tap to assist the taking of samples.

\section{STANDARD METHOD}

1. Site intravenous cannula.

2. Take baseline blood samples for testosterone/oestradiol, prolactin, thyroxine, LH, FSH, TSH, $\mathrm{GH}$, cortisol (14 $\mathrm{ml}$ clotted) and glucose (2 $\mathrm{ml}$ fluoride).

3. Then at $T=0$ inject insulin and $G n R H$ i.v. as boluses followed by the TRH i.v. over 2 minutes.

4. Take samples for $\mathrm{LH}, \mathrm{FSH}, \mathrm{TSH}$, prolactin, $\mathrm{GH}$, cortisol $(7 \mathrm{ml}$ clotted $)$ and glucose $(2 \mathrm{ml}$ fluoride) at 30,60 minutes and $\mathrm{GH}$, cortisol, glucose at 90 and 120 minutes (ensuring to discard dead-space first).

5. Flush the cannula with saline between samples.

6. At 30 minutes check blood glucose with Glucometer and repeat the insulin dose if not hypoglycaemic. Adequate hypoglycaemia is defined as glucose $\leq 2.2 \mathrm{mmol} / \mathrm{L}$ with symptoms. Record symptoms in the notes. Once this has been achieved, patients need not remain hypoglycaemic.

7. Hypoglycaemia should be reversed by giving i.v. $20 \%$ dextrose, or i.m. glucagon and continue sampling. Take further samples for $\mathrm{GH}$, cortisol and glucose at 90 and 120 minutes. There must be at least 2 specimens following adequate hypoglycaemia.

8. At all times a doctor or nurse must be in attendance.

9. If the patient has a hypoadrenal crisis with hypotension then they should be given i.v. $0.9 \%$ saline and i.v. 100mg hydrocortisone. 
10. Once test completed, give supervised meal and ensure glucose normal pre-discharge

11. Patient should not drive for 2 hours after the test.

\section{"SPLIT" COMBINED PITUITARY FUNCTION TEST}

This test is no longer used, but the details are kept for historical reasons.

In patients with prolactinomas, and in some acromegalics with near-normal GH levels, it is useful to monitor the responses to $\mathrm{TRH}$ and $\mathrm{GnRH}$ alone. This test is only useful after treatment if it is known there was an abnormal test result prior to treatment. In these patients, the test is "split" as follows:

\begin{tabular}{|c|c|c|c|c|c|c|c|c|c|}
\hline Time & Glucose & TSH & T4 & PRL & GH & LH & FSH & Testo/E2 & Cortisol \\
\hline 0 & & Take & Take & Take & Take $^{*}$ & Take & Take & Take & \\
\hline \multicolumn{7}{|c|}{ Give GnRH 100 mcg IV bolus and TRH 200 mcg IV over 2 mins } \\
\hline 30 & & Take & & Take & Take $^{*}$ & Take & Take & & \\
\hline 60 & Take & Take & & Take & Take & Take & Take & & Take \\
\hline \multicolumn{7}{|c|}{ Give insulin IV bolus as calculated above. } \\
\hline 90 & Take & & & Take $^{\dagger}$ & & & & Take \\
\hline 120 & Take & & & & Take $^{\dagger}$ & & & & Take \\
\hline 150 & Take & & & & Take $^{\dagger}$ & & & & Take \\
\hline 180 & Take & & & & Take $^{\dagger}$ & & & & \\
\hline
\end{tabular}

*only if an acromegalic with low GH

${ }^{\dagger}$ not needed if acromegalic with low GH

\section{INTERPRETATION}

- The interpretation of the different components of the standard CPT is listed under the Insulin tolerance test, the TRH test and the $\mathrm{GnRH}$ test.

- In the "split" protocol it is possible to observe the isolated response of $\mathrm{GH}$ and Prolactin to $\mathrm{TRH}$. In healthy subjects the prolactin will rise by $100 \%$ of its basal value while in patients with prolactinomas there is frequently a subnormal response. In healthy subjects there is a reduction in GH with TRH but there is a rise in $80 \%$ of acromegalics. It is only worth using the "split" protocol on a patient following treatment if they were tested by this protocol pretreatment. The loss of the paradoxical rise to TRH in acromegaly is a good indicator of successful treatment.

\section{VERSION HISTORY}

Andrew Hattersley 12/89 


\section{VISUAL FIELD TESTING (GOLDMANN AND HUMPHREYS PERIMETRY)}

\section{INDICATION}

1. Before and after pituitary surgery

2. Before and during pregnancy in patients with macroprolactinomas/non-functioning adenomas It is important to assess the entire visual pathway and patients will require assessment of:

- Near and far visual acuity (using Snellen Charts)

- Visual field testing (using Humphrey or Goldmann Perimetry)

\section{METHOD}

1. All referrals need to be made using the referral form accessible via 'The Source' - Orthoptics and Visual Fields.

2. All patients will initially have Humphrey perimetry which assesses the central 24 degrees of vision.

3. If this is normal they will then proceed to Goldmann perimetry assessing the whole visual field.

Visual field testing is ONLY performed by qualified orthoptists or ophthalmologists. However, we have included the method below for interest.

If you are doing it yourself, follow the instructions below.

1. There is an automated Visual field (Allergan Humphrey) testing machine in the eye room of clinic A (room A11). It is computer controlled and fairly user friendly.

2. Switch machine on. It will perform a self-test taking about 5 minutes. Once this is complete the computer will ask you several patient details, such as which eye you are testing. These can be easily entered using the screen touch-sensitive pen.

3. Cover one eye with the eye patch present on top of the machine. Place the patient's chin on the rest at the centre of the hemisphere and the head against the upper band. You will need to manually adjust the position of the chin rest (using the rotating control) until the patient, when looking straight ahead, can see the yellow dot.

4. The patient must be given the hand-held pushbutton and told to fix on the yellow dot. He must press the button whenever he sees a flash of light anywhere in the sphere. The patient may need his glasses to allow him to see the object.

5. When the patient is ready, simply select "AUTOMATIC DIAGNOSTIC TEST" from the menu. The machine will automatically find the blind spot and proceed to check the entire visual field by flashing lights at random. It will also check that the patient continues to fixate on the yellow dot by occasionally checking his blind spot.

6. When complete, a printout of the field can be obtained. Repeat the procedure for the other eye. 


\section{INTERPRETATION}

- Formal perimetry is highly accurate and reproducible. Field loss is always significant; it can occur as the result of the pituitary tumour or from the treatment of the tumour. If an increasing field loss is noted it is vital that the patient has neuroimaging (MRI or CT if MRI contraindicated) on that admission.

\section{VERSION HISTORY}

Jaideep Dhariwal and Veronica Ferguson 07/08. 


\section{SUSPECTED CUSHING'S DISEASE}

- Initial testing for Cushings should involve either 24 hour urine free cortisol (x2), late-night salivary cortisol (x2), $1 \mathrm{mg}$ overnight dexamethasone suppression test, or low dose dexamethasone suppression test (LDDST) (Nieman et al., (2008) J Clin Endocrinol Metab 93:1526-1540). This should be followed by a second confirmatory test.

- Order 1 vial of CRH for any patient with suspected Cushing's for their IPSS.

- Book two admissions at the start (one for midnight cortisol, LDDST, and the second for IPSS), and book the IPSS with Dr James Jackson at Hammersmith Hospital.

- We have found that the combined LDDST-CRH test is less specific than the LDDST, so we do not advocate using this test in the diagnosis of Cushing's syndrome (Martin et al., (2006) J Clin Endocrinol Metab 91:2582).

\section{LOW DOSE DEXAMETHASONE SUPPRESSION TEST (LDDST)}

\section{INDICATION}

1. Screening test for Cushing's syndrome, especially if the result of the overnight dexamethasone suppression test contradicts other investigations.

2. In women with a high testosterone this test may be used to differentiate PCOS and partial hydroxylase deficiencies $(\mathrm{CAH})$ from autonomous androgen secreting tumours.

\section{CONTRAINDICATIONS}

Patients on enzyme inducing drugs (e.g. anti-convulsants) that may rapidly metabolise dexamethasone or malabsorption syndromes that may lead to insufficient dexamethasone absorption. Oestrogens (e.g. pregnancy, HRT or COCP) may induce cortisol binding globulin (CBG) and therefore artificially increase total cortisol levels.

Care in diabetes mellitus and patients who are psychologically unstable.

\section{PREPARATION}

- This is usually an inpatient test with no particular patient preparation. Occasionally the test can be done as an outpatient if you believe the patient is likely to take their tablets on time.

- They need a $0900 \mathrm{~h}$ cortisol at the start $(T=0)$ and end $(T=48 \mathrm{~h})$ of the test. The final $\left(8^{\text {th }}\right)$ dexamethasone dose is given 6 hours (i.e. $T=42 h$ ) before the final cortisol sample at $T=48 \mathrm{~h}$.

- An ACTH should be measured at the start of the test (ie 0900h just prior to the first dose of dexamethasone), but not throughout the rest of the test.

Stop all oral oestrogen therapy 6 weeks prior to test. Patients on sex steroid implants might generate 
results that are difficult to interpret. Measuring SHBG and CBG might be helpful in this circumstance.

\section{METHOD}

1. The patient takes $0.5 \mathrm{mg}$ dexamethasone p.o. at strict 6 hour intervals (i.e. $0900 \mathrm{~h}, 1500 \mathrm{~h}, 2100 \mathrm{~h}$ and $0300 \mathrm{~h}$ ) for 48 hours.

2. The cortisol (red or yellow top), ACTH (purple top) are measured at 0900h (before the first dose of dexamethasone) on the first day ( $\mathrm{T}=0 \mathrm{~h}$ ) of the test and at 48 hours later (6 hours after the last dose). Samples are taken in red or yellow top Vacutainers for cortisol and purple top tubes on ice for ACTH. The red or yellow topped sample can be used to measure SHBG and CBG if needed.

3. A total of eight doses of dexamethasone should be written up $(0900 \mathrm{~h}, 1500 \mathrm{~h}, 2100 \mathrm{~h}, 0300 \mathrm{~h}$ 0900h, 1500h, 2100h and 0300h ).

\section{INTERPRETATION}

- If the $0900 \mathrm{~h}$ cortisol $(T=48 \mathrm{~h})$ value is less than $50 \mathrm{nmol} / \mathrm{l}$, the patient has shown appropriate suppression.

- Failure to suppress is seen in the autonomous secretion of cortisol found in Cushing's syndrome. However, since there are several common conditions associated with impaired cortisol suppression following a LDDST (e.g. morbid obesity, depression), the result should always be interpreted in conjunction with the degree of clinical suspicion.

- In virilisation from PCOS or partial hydroxylation deficiencies there will be complete/partial suppression of testosterone. This is not seen in ovarian or adrenal tumours.

\section{SENSITIVITY AND SPECIFICITY}

Suppression in patients with Cushing's syndrome is rare (2-5\%). Sensitivity for Cushings Syndrome is above $95 \%$ with a reported specificity of $70 \%$. Some reported cases metabolise dexamethasone slowly and so achieve higher circulating levels than expected. This test is more specific than the overnight suppression test with a lower false positive rate. Failure of suppression in patients may be seen in patients with systemic illness, endogenous depression, or on enzyme inducing drugs e.g. phenytoin or rifampicin. The predictive value of all tests is falling as morbid obesity becomes more common.

\section{REFERENCES}

Crappo et al., (1979) Metabolism 28:955

Kennedy et al., (1984) BMJ 289:1188-1191

Yanovski et al., (1993) JAMA 269:2232

Newell Price et al., (1998) Endocrine Reviews 19: 647

Nieman (2007) JCEM 92:2876-2878

\section{VERSION HISTORY}

Andrew Hattersley 11/89, Karim Meeran 07/02, Karim Meeran 01/03, Niamh Martin 07/08, Ben Jones 


\section{BILATERAL SIMULTANEOUS INFERIOR PETROSAL SINUS SAMPLING (IPSS) WITH CRH}

\section{INDICATION}

1. Patients with Cushing's syndrome and high ACTH levels in whom there is not a clinically definite pituitary source. The aim of this test is to differentiate pituitary from a non-pituitary source of ACTH and to attempt to lateralise a corticotroph adenoma prior to surgery.

\section{CONTRAINDICATIONS}

(Discuss with interventional radiology x34943)

Allergy to contrast dye.

Ischaemic Heart Disease.

Orthopnoea.

Bleeding tendencies.

\section{PREPARATION}

- If patient on aspirin/clopidogrel, discuss with Dr James Jackson, (Hammersmith Hospital, Interventional Radiology).

- Metyrapone and ketoconazole need to be stopped 1 week before IPSS, as the test should be carried out when cortisol levels are elevated.

- Order synthetic human CRH (corticorelin) in advance from Pharmacy (allow 5 days). DDAVP (desmopressin) (10 micrograms i.v.) is a poor but possible alternative if $\mathrm{CRH}$ is not available. Document (in the notes) what type of $\mathrm{CRH}$ is being used.

- Warn Duty Biochemist on x30348 24-48 hours in advance and on the day of the procedure.

- Consent patient (risks of bleeding from cannula sites, CVA, dye allergy, pulmonary embolus). This should be performed by the radiologists.

- The day before the procedure, check FBC, $U+E, I N R, G+S$.

- Fast for at least 4 hours.

- 2 people to attend to assist sample processing.

- 18 red or yellow Vacutainers, labelled before the study.

- 18 EDTA Vacutainers, labelled before the study.

- Syringes for sampling and flushing cannulae.

- Ice for ACTH samples

- Arrangements to transfer ACTH samples on ice for centrifugation within 15 minutes of taking.

\section{SIDE EFFECTS}

$\mathrm{CRH}$ can cause flushing and hypotension but this is rare with $100 \mathrm{mcg}$.

No complications of IPS sampling have been reported in over 50 patients reported in the literature, 
but we have had one patient who had a pulmonary embolus following the procedure and one who became asystolic during the procedure, but subsequently recovered.

\section{METHOD}

1. One catheter is placed in each inferior petrosal sinus (IPS) and their position confirmed on screening. A third catheter is placed peripherally $(P)$ in the arm.

2. Two baseline samples are taken at approximately -5 and 0 minutes. Ask the radiologist for $10 \mathrm{ml}$ from each site: one purple for ACTH and one red or yellow Vacutainer at each site. At T $=0$ the $\mathrm{CRH}$ is injected intravenously as a bolus over 1 minute peripherally. For adults the dose is 100 mcg or $60 \mathrm{mcg}$ per square meter body surface in children.

3. Simultaneous samples from the 3 sampling sites are taken at $T=2,5$, and 10 minutes. At the same time as one of the sets of basal samples an arterial sample may be taken from the femoral artery if a pulmonary source of ACTH is possible, and peripheral samples may be taken at $T=60$ and 90 minutes (see below). Only samples taken for ACTH should be stored in ice and spun within 15 minutes.

4. ACTH is measured in all samples. Cortisol is measured in the basal samples from all sites and in all the peripheral samples. Prolactin is measured in both IPS series.

\section{INTERPRETATION}

- A basal IPS:P (i.e. central:peripheral) ratio > 2.0 indicates a pituitary source with $95 \%$ sensitivity and $100 \%$ specificity. A CRH stimulated IPS:P ratio $>3.0$ increases the sensitivity to $100 \%$, the 2 and 5 minute samples usually being sufficient.

- If in addition the basal or stimulated ACTH level for one IPS sample is 1.5 times as high as the simultaneous contralateral side, this localises the pituitary tumour to the ipsilateral side with a sensitivity of $99 \%$ and a specificity of $82 \%$. It has also been reported that prolactin and $\mathrm{GH}$ are often raised on the side of the tumour and that this is augmented by $\mathrm{CRH}$.

- In IPS sampling the principal difficulty arises from the positioning of the sampling catheter. Jugular venous samples do not consistently show lateralisation. The measurement of prolactin can be used as a marker of proximity to the pituitary.

- Using the peripheral samples it is possible to look at the response to $\mathrm{CRH}$ of venous levels of Cortisol. The interpretation of this response is difficult but in general patients with Cushing's disease tend to have an exaggerated response $(>850 \mathrm{nmol} / \mathrm{L})$ and ectopic ACTH sources have a reduced response. The interpretation of the $\mathrm{CRH}$ test at present is uncertain as the reported series use different end points, varying doses of $\mathrm{CRH}$ and small numbers of patients. Until there is more local experience (see above) of this test it should not be used to differentiate sources of ACTH.

- It appears that in ectopic ACTH production a cortisol response greater than normal has not been described. It is not a sensitive test as approximately $25 \%$ of Cushing's disease do not respond to $\mathrm{CRH}$ with cortisol responses greater than normals. 


\section{REFERENCES}

Landolt et al., (1986) Clin Endocrinol (Oxf) 25:687

Grossman et al., (1988) Clinical Endocrinol (Oxf) 29:167

Oldfield et al., (1991) NEW ENGL J MED 325:897

\section{VERSION HISTORY}

Andrew Hattersley; Peter Hammond 08/92.; Karim Meeran 07/02; Ben Jones 11/13

\section{HISTORICAL INTEREST}

\section{HIGH DOSE DEXAMETHASONE SUPPRESSION TEST}

\section{INDICATION}

Patients with definite Cushing's syndrome of unknown aetiology.

The pre-test probability of ACTH-dependent Cushing's syndrome being secondary to Cushing's disease is $85-90 \%$. The HDDST correctly identifies $69 \%$ of patients as having Cushing's disease. Since the diagnostic accuracy of this test in identifying Cushing's disease is less than the pretest probability of making this diagnosis; we rarely use this test now. If ACTH-dependent Cushing's syndrome has been diagnosed following a LDDST, patients can move straight to IPSS to exclude an ectopic source of ACTH.

\section{CONTRAINDICATIONS}

Patients on enzyme inducing drugs e.g. anti-convulsants may rapidly metabolise dexamethasone.

Oestrogens (e.g. pregnancy, HRT or COC) may induce cortisol binding protein and artefactually increase total cortisol levels. Take care in patients with severe depression or hypomania.

\section{PREPARATION}

- Stop all oral oestrogen therapy 6 weeks prior to test. Again implants can cause problems.

- $\quad$ This is an inpatient test and should only be performed after at least 2 baseline values for 24 hour urinary free cortisol and 0900h cortisol and ACTH levels (see below).

\section{METHOD}

1. This test used to often follows the LDDST. The final sample from the LDDST $(2+48)$ can often be used as the basal sample for this test. Basal 0900h cortisol (red or yellow top Vacutainer) and ACTH (purple tops Vacutainers on ice) are measured ("8+0").

2. During the test the patient takes $2 \mathrm{mg}$ dexamethasone p.o. at strict 6 hour intervals (i.e. $0900 \mathrm{~h}$, $1500 \mathrm{~h}, 2100 \mathrm{~h}$ and $0300 \mathrm{~h}$ ) for 48 hours.

3. The cortisol and ACTH are measured at $0900 \mathrm{~h}$ on the first day of the test and 48 hours later (" $8+48$ "). In some patients the dexamethasone may be continued for 72 hours in which case an 
additional 0900h serum cortisol and ACTH are taken ("8+72").

\section{INTERPRETATION}

- If the $0900 \mathrm{~h}$ cortisol is less than $50 \%$ (some say $90 \%$ ) of the basal value after 48 hours of dexamethasone this is classified as showing suppression.

- Suppression with high dose dexamethasone is usually seen in Cushing's disease but not in ectopic ACTH production or adrenal tumours.

\section{SENSITIVITY AND SPECIFICITY}

The high dose dexamethasone test is useful but not totally reliable in the differential diagnosis of Cushing's syndrome as it is neither very sensitive nor specific. Suppression occurs in $75 \%$ of patients with Cushing's disease, $10-25 \%$ of patients with ectopic ACTH and $0-6 \%$ of patients with adrenal tumours. Patients with ectopic ACTH who show suppression tend to have occult and relatively benign tumours with lower levels of ACTH and cortisol. These patients are very hard to differentiate from Cushing's disease.

The $0900 \mathrm{~h}$ cortisol after 48 hours is considered to be the best parameter to use to discriminate between Cushing's disease and ectopic ACTH. The criterion of $50 \%$ suppression at 48 hours should not be applied too rigidly as many cases of Cushing's disease will suppress by 40 or $45 \%$ or suppress after 72 hours. In difficult cases it is advisable to repeat the test as no patients with an adrenal tumour have been shown to have reproducible suppression and cases of Cushing's syndrome may show cyclical variation.

\section{REFERENCES}

Crappo et al., (1979) Metabolism 28:955

Aron, Raff and Findling (1997) (JCEM 82: 1780-1785). The limited value of the HDDST. 


\section{PRE-OPERATIVE PREPARATION OF PATIENTS WITH CONFIRMED CUSHING'S DISEASE/SYNDROME}

If the IPSS confirms pituitary Cushing's, the patient should be booked for pituitary surgery at Charing Cross in about 6 weeks. The merits of starting each patient on cortisol-lowering medication should be discussed first, preferably via the pituitary MDT, since these agents may make early post-operative assessment of cortisol difficult. Decision will be based on the size of the tumour, how clinically Cushingoid the patient is and how quickly the pituitary surgeon can operate. For adrenal tumours or patients undergoing bilateral adrenalectomy as primary treatment, some patients may need at least 6 weeks of cortisol lowering medication pre-operatively aiming for a serum cortisol of $150-300 \mathrm{nmol} / \mathrm{L}$.

First-line medical treatment to lower cortisol is ketoconazole (200mg bd) however due to issues accessing ketoconazole following concerns about hepatotoxicity, we are now using metyrapone first line. If you are using ketoconazole, note that ketonconazole requires an acid $\mathrm{pH}$ environment for adequate absorption, therefore patients need to avoid PPIs if possible.

Monitor cortisol and LFTs weekly. If cortisol $>300 \mathrm{nmol} / \mathrm{L}$, increase metyrapone. Metyrapone can be increased up to a maximum of $6 \mathrm{~g} / \mathrm{day}$. The side effects of metyrapone are nausea (take with food), hypertension and ankle swelling (due to mineralocorticoid effects of 11-deoxycortisol), and hirsutism (if long-term).

If required, etomidate at subhypnotic doses (2.5-5 mg/hr IV) can be used to control cortisol levels, but this requires supervision under ITU. Aim for cortisol of 150-300 nmol/Lin the weeks before surgery.

\section{PERIPHERAL VENOUS SAMPLING FOR SOURCES OF ECTOPIC ACTH}

This is rarely performed at Hammersmith in view of its low sensitivity.

\section{OVERNIGHT DEXAMETHASONE SUPPRESSION TEST}

\section{INDICATION}

Initial screening test for Cushing's syndrome in a patient with a low clinical suspicion of Cushing's if it is difficult to admit patient for a standard (48h) low-dose dexamethasone suppression test (LDDST).

\section{CONTRAINDICATIONS}

Patients on enzyme inducing drugs e.g. anti-convulsants may rapidly metabolise dexamethasone.

Oestrogens (e.g. pregnancy, HRT or COCP) may induce cortisol binding globulin and artefactually 
increase total cortisol levels.

Urine collection for $24 \mathrm{hr}$ urinary free cortisol must not occur during this test.

\section{PREPARATION}

- Outpatient test with no particular patient preparation.

\section{METHOD}

1. The patient takes $1 \mathrm{mg}$ dexamethasone p.o. at $2300 \mathrm{~h}$ and the $0900 \mathrm{~h}$ cortisol is measured the next morning ( $7 \mathrm{ml}$ clotted blood, in red top Vacutainer). Higher doses of dexamethasone do not improve the accuracy of this test significantly (Crapo (1979) Metabolism 28:955-977).

2. If the patient is collecting a $24 \mathrm{hr}$ urine sample for urinary free cortisol, this should be completed before taking the dexamethasone.

\section{INTERPRETATION}

If the $0900 \mathrm{~h}$ cortisol value is less than $50 \mathrm{nmol} / \mathrm{L}$ the patient has shown adequate suppression. Failure to suppress is seen in the autonomous secretion of cortisol found in Cushing's syndrome. With this cut off, there will be a high false positive rate.

\section{SENSITIVITY AND SPECIFICITY}

Using a cortisol of $50 \mathrm{nmol} /$ Las the test cut-off, provides sensitivity of $95 \%$ with $80 \%$ specificity (Wood et al. (1997) Ann Clin Biochem 34:222-229). Specificity is increased to 95\% if the cut-off is raised to 140nmol/L(Pecori et al/ (2007) Clin Endocrinol 66:251-257). If there is strong clinical or biochemical evidence for Cushing's syndrome, a formal 48h low dose dexamethasone test should be performed as this is more specific. Repeat the test if in any doubt about the result in either direction.

Normal subjects rarely fail to suppress with overnight dexamethasone unless they are depressed (10$50 \%)$, obese $(10 \%)$ or systemically unwell $(10-20 \%)$.

\section{CRH TESTING (WITHOUT DEXAMETHASONE)}

Samples for ACTH should be collected in purple topped EDTA tubes and stored on ice in transit and taken rapidly to the lab to be centrifuged (within 15 minutes). This test will thus need regular transport to the lab. Samples for cortisol are red or yellow topped and can be left to clot.

\section{PREPARATION}

Fast from midnight.

Label eight (8) tubes for ACTH (purple top) and eight (8) tubes for cortisol (red or yellow top).

Admit Monday $8.30 \mathrm{am}$. Cannulate and take basal Cortisol and ACTH at 8.30am.

Patient to remain recumbent (and fasted) until 9am. 


\section{METHOD.}

(Two further baseline samples at -15 mins $(8.45 \mathrm{am})$ and 0 mins (9am) for ACTH and Cortisol). Administer 100 micrograms human $\mathrm{CRH}$ at $9 \mathrm{am}(\mathrm{T}=0)$.

Then sample at 15, 30, 45, 60, 90 and 120 mins (final sample 11am) for ACTH and cortisol at all timepoints.

\section{INTERPRETATION.}

- A rise in cortisol from basal to peak of $>20 \%$ suggests a pituitary source.

- A rise in $\mathrm{ACTH}$ from basal to peak of $>50 \%$ suggests a pituitary source.

- A rise by $35 \%$ in ACTH at +15 and +30 minutes (mean) in comparison to the basal ( -1 and -5 minutes) values suggests a pituitary source.

Please note that ovine (oCRH) was used in most studies. Human ( $\mathrm{hCRH}$ ) appears less potent, so smaller rises may be acceptable, suggesting Cushing's disease.

\section{REFERENCES}

Kaye and Crappo (1990) Ann Intern Med 112:434

Nieman et al., (1993). J Clin Endocrinol Metab 77:1308

\section{CUSHING'S DAY CURVE}

\section{INDICATION}

1. Assessment of control of Cushing's syndrome while on therapy pre-operatively.

2. Assessment of possibility of early recurrence of hypercortisolism.

\section{CONTRAINDICATIONS}

None

\section{SIDE EFFECTS}

None

\section{PREPARATION}

Stop all oestrogen therapy 6 weeks prior to test.

No hydrocortisone from midday the day before the test (ie omit evening dose day before test and no hydorocortisone on the day of the test).

Non-fasting: breakfast and normal dose of tablets (except hydrocortisone as above) are taken at the usual time.

18-20g cannula.

6 red or yellow top Vacutainers. 


\section{METHOD}

0900h \}

1200h T Take blood

$1500 \mathrm{~h} \quad$ f for cortisol

$1800 \mathrm{~h}\} \quad$ measurement

(2400h) \}

\section{INTERPRETATION}

- The target range is a mean serum cortisol between 150 and $300 \mathrm{nmol} / \mathrm{L}$ and should be maintained while patients are awaiting surgery.

- Higher levels indicate a need for increased therapy.

- Random concentrations of cortisol can also be used on a day-to-day basis to determine effectiveness of cortisol suppression on medical treatment (with ketoconazole (up to $400 \mathrm{mg}$ bd), metyrapone (up to $6 \mathrm{~g} /$ day) or etomidate ( $3 \mathrm{mg}$ per hour by i.v. infusion).

\section{REFERENCE}

Trainer et al., (1993) Clin. Endocrinol (Oxf) 39:441

\section{VERSION HISTORY}

Karim Meeran 07/01, Niamh Martin 09/08, Ben Jones 11/13, reviewed by Alexander Comninos and Niamh Martin 09/15 


\section{PROLACTINOMAS AND NON-FUNCTIONING PITUITARY ADENOMAS}

\section{ASSAY PROBLEMS TO BE AWARE OF WITH PROLACTIN}

The hook effect: very high levels are subject occasionally to the hook effect, whereby the assay reports a falsely lower prolactin in the presence of extremely high concentrations of prolactin unless the laboratory dilutes the sample. This effect is due to impairment of immunoassay antigen-antibody binding as a result of saturation by the very high antigen levels.

Macroprolactin: this is defined as circulating prolactin in a complex (most often with $\lg G$ ) which has a molecular mass of $>100 \mathrm{kDa}$ on gel filtration chromatography. This form of prolactin reacts with immunoassays for prolactin (to differing extents depending on the exact assay) and causes elevated prolactin levels. Although macroprolactin is biologically active in vitro, it is thought that it is inactive in vivo as the high molecular weight prevents it from crossing the vascular endothelium. The definitive method of assaying for macroprolactin is gel filtration chromatography. Polyethylene glycol (PEG) precipitation is used routinely as a screening test, although a false-positive for macroprolactin can occasionally occur due to hypergammaglobulinaemia. Within Imperial College Healthcare NHS Trust, the lab will not routinely check for macroprolactin in endocrine patients and you will have to request this separately if suspected. In the absence of symptoms of hyperprolactinaemia, the patient with proven hyperprolactinaemia due to macroprolactin does not usually require any treatment.

\section{REFERENCES}

Fahie-Wilson et al., (2005) Ann Clin Biochem 42:175

Ram et al., (2008) Ann Clin Biochem 45:256

\section{DISTINGUISHING PITUITARY MACROADENOMAS SECRETING PROLACTIN FROM NON-FUNCTIONING TUMOURS}

Non-functioning adenomas (NFAs) also might have a high prolactin, as they have the capacity to cause "disconnection hyperprolactinaemia", where the mass blocks dopamine inhibition of lactotrophs. Such patients (with NFAs) may present with amenorrhea and even galactorrhoea. A retrospective analysis of NFAs in Oxford has shown that the majority of NFAs (98.7\%) generate levels $<2000 \mathrm{mU} / \mathrm{L}$.

Although macroadenomas secreting prolactin are generally easy to diagnose and to differentiate from NFAs on the basis that they secrete very high levels of prolactin (>2000 mU/L), occasionally it may be difficult to distinguish between the two conditions. In this situation, the cabergoline suppression test 
may be useful to distinguish between the two.

\section{REFERENCE}

Karavitaki et al., (2006) Clin Endocrinol (Oxf) 65:524

\section{PROTOCOL FOR CABERGOLINE SUPPRESSION}

\section{METHOD}

1. The patient will be admitted to the Planned Investigation Unit at $8.30 \mathrm{am}$. Fasting is not necessary. A urine beta-HCG test is mandatory to exclude pregnancy.

2. At 9 am take blood for prolactin.

3. Patient to take $0.5 \mathrm{mg}$ of cabergoline $\mathrm{PO}$.

4. Further blood samples for prolactin to be taken at $0.5,1,3,6,24,72$ hours, and 7 days.

5. The patient can go home after the blood test at 6 hours, but should return to have blood samples for prolactin taken at 24,72 hours, and 7 days.

\section{INTERPRETATION}

A marked fall in prolactin following a single dose of cabergoline (or bromocriptine) suggests a NFA, whereas prolactinomas have a more gradual fall.

\section{PREGNANCY AND THE PITUITARY}

The normal pituitary lactotrophs expand during pregnancy and can push up a NFA towards the optic chiasm, so regular field testing is essential in macroadenomas. Prolactinomas (micro and macro) often grow during pregnancy.

Dopamine agonists can be continued, and in difficult cases up to $1.5 \mathrm{mg}$ cabergoline daily has been used with good effect(however this is NOT currently licensed). Bromocriptine has been around since 1974 , and is thus often favoured in pregnancy although cabergoline seems to have fewer side effects. Pituitary expansion continues during breastfeeding, and thus risks and benefits of breastfeeding need to be discussed fully with the patient.

Currently, patients at 34 weeks gestation can have a trial off cabergoline if they would like to breastfeed. These women need to be told that on stopping their cabergoline, there is a risk of lactotroph enlargement and hence visual field compromise. Therefore they need regular visual fields on stopping cabergoline and also shortly after delivery (when lactotroph hyperplasia continues if breastfeeding ensues).

If pre-pregnancy imaging suggests there is little space between the tumour and the optic chiasm, an MRI pituitary at around 32 weeks gestation may be helpful to guide whether cabergoline could be 
stopped.

If the decision is taken to stop cabergoline at 34 weeks, perimetry should be performed and reviewed weekly in clinic until delivery and at 2 weeks post-partum.

\section{DOPAMINE AGONIST TREATMENT OF HYPERPROLACTINAEMIA}

The three currently licensed dopamine agonists in the UK for hyperprolactinaemia are bromocriptine, cabergoline and quinagolide. All are subject to the side effects of nausea and mood effects (in rare cases, these drugs have caused psychosis and mania).

Bromocriptine: $1.25 \mathrm{mg}$ od, up to $30 \mathrm{mg}$ daily. Most often subject to nausea, this side effect can be minimized by advising the patient to take the medication with a meal.

Cabergoline: $250 \mathrm{mcg}$ weekly up to $4.5 \mathrm{mg}$ weekly (can be given as 1 or 2 doses in the week). Usually the first-line choice. Studies in patients taking higher doses of cabergoline for Parkinson's disease show an association with valvular heart disease. Several studies have reported no increased risk of valvular dysfunction with the doses of cabergoline used to treat prolactinomas.

Quinagolide: $25 \mathrm{mcg}$ nocte for three days, then titrated up by $25 \mathrm{mcg}$ every three days to maintenance dose of 75-150 mcg nocte. Less often used than bromocriptine or cabergoline. As it is a non-ergot derived dopamine agonist, this drug has the theoretical benefit that it should not cause valvular heart disease.

\section{REFERENCES}

Tan et al., (2010) Clin Endocrinol (Oxf) 73:369

Steffensen et al., (2012) J Clin Endocrinol Metab 97:1629

Auriemma et al., (2013) Eur J Endocrinol 169:359

\section{VERSION HISTORY}

Karim Meeran, Niamh Martin and Tricia Tan 08/08, Ben Jones and Chioma Izzi-Engbeaya 11/13, reviewed by Niamh Martin 08/14 


\section{PITUITARY TUMOURS}

\section{OPERATIVE MANAGEMENT OF PITUITARY TUMOURS}

PRE-ADMISSION Patient should have had:

- Full endocrine assessment.

- Neurosurgical assessment.

- Neuro-ophthalmological assessment including Humphrey fields in previous 6 months.

- Baseline investigations:

CT/MRI pituitary

Free T4, TSH, prolactin, oestradiol (females), testosterone (males), FSH, LH, cortisol profile. IGF-1, GH, with oral GTT if clinically indicated

$E C G$ and $C X R$ if age $>60$ years.

- In patients with acromegaly the following co-morbidities should be evaluated:

- Hypertension, diabetes mellitus, cardiovascular disease, osteoarthritis, sleep apnoea

- Perform a thyroid USS if there is thyroid nodularity

- If prolactinoma confirmed, treat with dopamine agonist drug (e.g. Cabergoline), then repeat CT/MRI scan (1-3 months after prolactin normalised or at minimum plateau). Surgery indicated if tumour non-responsive.

- Check TFTs. If patient is hypothyroid need short synacthen test to exclude associated steroid dependency. Replace with T3 $20 \mathrm{mcg}$ tds for 4 days pre-op if surgery urgent, or thyroxine if surgery not imminent.

- Cushing's disease: start patient on cortisol-lowering medication (see section TREATMENT OF PATIENTS WITH CONFIRMED CUSHING'S SYNDROME for medication and how to decide who warrants pre-operative cortisol lowering), titrating to random cortisol 150-300 nmol/).

\section{PRE-OPERATIVE MANAGEMENT}

- Confirm neurosurgical operating date (day 0) with consultant neurosurgeon, Mr. Nigel Mendoza (Day 0 , Usually a Thursday). If surgery is on Wednesday, call this day -1 , so that the protocol below is not affected. (Thursday remains day "0"). If surgery is on Friday, treat this as "day 1 " and proceed directly to dexamethasone over the weekend.

- Admit 1-2 days pre-op (Surgical decision).

- For trans-sphenoidal surgery:

Hydrocortisone $50 \mathrm{mg}$ i.m. qds starting with pre-medication. (An i.v. infusion of $4.2 \mathrm{mg}$ per hour (100 $\mathrm{mg}$ over 24 hours) is an alternative). 


\section{HYDROCORTISONE REPLACEMENT PRE- AND POST- PITUITARY SURGERY}

- Peri- and post-operatively, use pre-filled drugs chart available on neurosurgical ward and via http://www.meeran.info. Online prescribing using "pituitary", will bring up the whole of the protocol below directly into the patients electronic drug chart.

- Only proceed to oral hydrocortisone if tolerating oral intake. If not, patient will need to stay on i.m./i.v. infusion hydrocortisone until eating and drinking properly.

\section{Surgical protocol}

Thursday (operative day)

Friday (post-op day 1)

Saturday (post-op day 2)

Sunday (post-op day 3)

Monday (post-op day 4)

i.m. hydrocortisone $50 \mathrm{mg}$ qds (9am, 12pm, 3pm, 9pm)

i.m. hydrocortisone 50mg tds (9am, 3pm, 9pm)

Oral prednisolone $10 \mathrm{mg}$ 9am

Oral prednisolone $5 \mathrm{mg} 9 \mathrm{am}$.

Switch via coding to endocrine team rather than neurosurgical team (Mendoza to Meeran, neurosurgical team to trigger)

6am-9am (morning) serum cortisol sample (red or yellow topped tube) before prednisolone $4 \mathrm{mg}$ (range $3 \mathrm{mg}$ to $5 \mathrm{mg}$ ) administered on Monday and Tuesday (days 4 and 5).

Call CXH duty Clinical Biochemist on bleep 8256 (telephone x30348) to warn of sample coming. Mark as URGENT and deliver to lab on First Floor. Hand over sample to staff (do not leave in basket outside) and tell them 'urgent for cortisol as discussed with Duty Clinical Biochemist'. Cortisol is now run with electrolytes, so results are rapidly available.

For all post-op pituitary patients EXCEPT those with Cushing's disease, once 9AM cortisol sample taken, if delay in accessing cortisol result, patient can be re-started on prednisolone whilst awaiting confirmation of 9am cortisol with plans to formally assess at 6 weeks postoperatively (see below).

\section{INTERPRETATION OF RESULTS:}

- Interpretation of cortisol result from days 4 or 5 (post-operative days 4 or 5 ): If cortisol $>350$ $\mathrm{nmol} / \mathrm{L}$, then can be sent home without prednisolone.

If 300-350 nmol/L, then use clinical grounds and pre-op assessment.

If $<300 \mathrm{nmol} / \mathrm{L}$, then continue prednisolone $4 \mathrm{mg}$ OM (an alternative replacement regimen is hydrocortisone $10 / 5 / 5 \mathrm{mg}$ ). 


\section{POST-OPERATIVE ARRANGEMENTS}

- Sick day rules and steroid card (available on meeran.info) for all patients discharged on hydrocortisone.

- All patients should return to Charing Cross at 10 days post-op to check U\&E. This should be requested on Cerner before discharge and a date given to the patient. Make a record of the patient's phone number so that they can be contacted if an abnormality of the plasma sodium is found. The strongly preferred option is for this blood test to be done at Charing Cross. If the patient lives some distance from Charing Cross, arrangements can be made via the referring endocrinologist for U\&E to be checked locally:.

- An arrangement should be made by the $\mathrm{CXH}$ endocrinology registrar with endocrinology registrar at the patient's local hospital.

- The local registrar should have contact details for the $\mathrm{CXH}$ registrar and the results must be discussed on the afternoon of the blood test.

- 6 week post-operative insulin tolerance test/ glucagon stress test to be arranged for all postoperative pituitary patients unless $9 \mathrm{AM}$ cortisol $<100 \mathrm{nmol} / \mathrm{L}$ (then to stay on hydrocortisone lifelong).

- TFTs and oestradiol/testosterone levels may not be interpretable for at least 6 weeks postoperatively. Therefore, ALL patients attending for a post-operative ITT/glucagon stress test should have baseline anterior pituitary function tests, including testosterone/oestradiol, FSH, LH, TFTs (fT3, fT4, TSH - this may be difficult to interpret).

\section{VERSION HISTORY}

Niamh Martin 07/08 and reviewed 04/14, Alexander Comninos and Saira Hameed 04/15

\section{POST-OPERATIVE MANAGEMENT OF DIABETES INSIPIDUS (DI)}

- Fluid balance charts should be kept. A spot urine osmolality is checked every 4 hours.

- If urine output $>1 \mathrm{~L}$ per 4 hours, consider desmopressin (adult dose 0.5-1.0 mcg s.c. q6h). Prior to administration check paired plasma and urine osmolality.

- DI is confirmed by the presence of a high plasma osmolality (>295 mosmol $/ \mathrm{kg}$ ) in the presence of an inappropriately low urine osmolality $(U: P$ ratio $<2: 1)$ (urine $S G<1.005)$.

- If the plasma osmolality is low the patient may be over-drinking due to a dry mouth (oftern due to mouth-breathing due to nasal packing). A low urine osmolality is appropriate. 


\section{POST-OPERATIVE ASSESSMENT OF GH BURDEN IN ACROMEGALY}

The Endocrine Society Guidelines (2014) state that surgery results in an initial remission rate $>85 \%$ for microadenomas and $40-50 \%$ for macroadenomas. Cavernous sinus invasion indicates tumour that is likely surgically un-resectable. Five year disease recurrence rates range from 2 to $8 \%$. All case series and clinical guidelines emphasise the superior outcome rates when a highly experienced surgeon operates in a centre with a high pituitary surgery case load.

\section{A NOTE ON PRE-OPERATIVE SOMATOSTATIN ANALOGUE USE}

Although the routine, pre-operative use of somatostatin analogues is not recommended, in a subset of patients following an MDT discussion, a somatostatin analogue (Lanreotide Autogel, 120mg s.c.) might be used pre-operatively because such a strategy has been shown to reduce tumour volume, reduce GH and IGF-1 and improve acromegalic symptoms.

It is important to be aware of pre-operative somatostatin analogue use as caution should be exercised in planning and interpreting post-operative biochemistry in this group of patients. Based on the half life of Lanreotide Autogel (25.5 days), it would be reasonable to defer post-operative GH assessment (e.g.OGTT) for 3 months to allow for drug elimination.

\section{POST-OPERATIVE ASSESSMENT OF ACROMEGALY}

Although GH testing may be performed in the early post-operative period, these $\mathrm{GH}$ values may reflect surgical stress. The decline in IGF-1 is delayed because of IGF-binding proteins and an IGF-1 level measured at 12 weeks post-op is a valid reflection of surgical remission.

Therefore, following surgery, an IGF-1 and a random GH should be measured at 12 weeks or later. An age normalised IGF-1 value within the reference range and a GH of $<1 \mathrm{mcg} / \mathrm{L}$ are sufficient to indicate surgical remission

In patients with a random $\mathrm{GH}>1 \mu \mathrm{g} / \mathrm{L}$, an OGTT should be performed and a nadir $\mathrm{GH}$ should be measured

If $\mathrm{GH}<1 \mathrm{mcg} / \mathrm{L}$ and IGF- 1 within the age normalised reference range, measuring random GH and IGF1 is sufficient for further follow up rather than performing annual OGTTs. Patients who have not achieved biochemical remission post-operatively should be discussed in a pituitary MDT to review pre- and post-operative imaging and to plan what further treatment is necessary. It is important to document features which may reduce the likelihood of complete biochemical remission e.g. evidence of pre-operative cavernous sinus invasion. 


\section{POST-OPERATIVE IMAGING}

Post-operative imaging should be performed no sooner than 12 weeks after surgery to allow for involution of gel foam and fat packing. This will then serve as the new baseline image for follow-up assessment.

\section{POST-OPERATIVE VISUAL FIELD TESTING}

Post-operative visual field testing should be performed in patients with a pre-operative visual field defect. In some patients, the visual field deficits continue to improve up to 1 year after surgery.

\section{REFERENCES}

Astruc, et al., (2005) J Clin Pharmacol, 45:836

Giustina A et al., (2010) J Clin Endocrinol Metab 95:3141

Caron PJ et al., (2014) J Clin Endocrinol Metab 99:1282

Katznelson et al., (2014) J Clin Endocrinol Metab 99:3933

\section{VERSION HISTORY}

Niamh Martin 07/08. Updated Niamh Martin and Saira Hameed 03/15 


\section{IMMEDIATE POST-OPERATIVE ASSESSMENT OF EARLY REMISSION IN CUSHING'S DISEASE}

Peri- and post-operatively, use pre-filled drugs chart available on neurosurgical ward and via http://www.meeran.info.

\section{Reduction of cortisol pre-operatively:}

- This will depend on size of tumour and clinical assessment of patient (i.e. extent of Cushing's clinically). Not all patients will automatically start metyrapone/ketonconazole (can make early post-op assessment of cortisol difficult).

- Patients to be discussed on case-by-case basis at pituitary MDT (will also need early neurosurgical date if not for medical treatment pre-operatively).

\section{Surgical protocol}

Thursday (operative day)

Friday (post-op day 1)

Saturday (post-op day 2)

Sunday (post-op day 3)

Monday (post-op day 4) i.m. hydrocortisone $50 \mathrm{mg}$ qds (9am, 12pm, 3pm, 9pm)

i.m. hydrocortisone $50 \mathrm{mg}$ tds (9am, 3pm, 9pm)

Oral prednisolone $10 \mathrm{mg}$ 9am

Oral prednisolone $5 \mathrm{mg} 9 \mathrm{am}$.

Switch via coding to endocrine team rather than neurosurgical team

(Mendoza to Meeran, neurosurgical team to trigger)

6am-9am (morning) serum cortisol sample (red or yellow topped tube) before prednisolone $4 \mathrm{mg}$ (range $3 \mathrm{mg}$ to $5 \mathrm{mg}$ ) administered on Monday and Tuesday (days 4 and 5).

Call CXH duty Clinical Biochemist on bleep 8256 (telephone x30348) to warn of sample coming. Mark as URGENT and deliver to lab on First Floor. Hand over sample to staff (do not leave in basket outside) and tell them 'urgent for cortisol as discussed with Duty Clinical Biochemist'. Cortisol is now run with electrolytes, so results are rapidly available.

NO further prednisolone or hydrocortisone to be given until result of 9am cortisol from today available.

Cortisol results will be ready by $5 \mathrm{pm}$ that day

Give prednisolone $4 \mathrm{mg}$ or hydrocortisone (i.e. $10 / 5 / 5 \mathrm{mg}$ ) if cortisol $<50 \mathrm{nmol} / \mathrm{L}$, otherwise withold.

Will need brief clinical assessment at $5 \mathrm{pm}$ that day.

Tuesday (post-op day 5) 9am serum cortisol sample (red or yellow topped tube)

Call CXH duty Clinical Biochemist on bleep 8256 (telephone x30348) 
to warn of sample coming. Mark as URGENT and deliver to lab on First Floor. Hand over sample to staff (do not leave in basket outside) and tell them 'urgent for cortisol as discussed with Duty Clinical Biochemist'.

Give hydrocortisone (i.e. 10/5/5mg PO) if cortisol $<200 \mathrm{nmol} / \mathrm{L}$ (or alternatively $4 \mathrm{mg}$ prednisolone PO OM), otherwise withold. Check 9am cortisol daily whilst planning further management.

\section{ALL PATIENTS TO BE SENT HOME WITH STEROID ALERT CARD AND SICK DAY RULES (available on meeran.info)}

Day 5 cortisol < $50 \mathrm{nmol} / \mathrm{L}$ :

Best prognosis for long term remission (10\% relapse at $10 \mathrm{y})$, but still will need regular assessment. Discharge on $4 \mathrm{mg}$ prednisolone OM (or alternatively hydrocortisone $10 \mathrm{mg} / 5 \mathrm{mg} / 5 \mathrm{mg}$ ) (plus steroid alert card) and plan for return for 9AM day 11 cortisol (plus $U$ \& Es check due to risk of hyponatraemia/SiADH).

Day 5 cortisol 50-200 nmol/L:

Risk of relapse no greater than for those with day 5 cortisol of $<50 \mathrm{nmol} / \mathrm{L}$, so no immediate intervention, but will need regular assessment for recurrence. Discharge on hydrocortisone.

Discharge on $4 \mathrm{mg}$ prednisolone OM (or alternatively hydrocortisone $10 \mathrm{mg} / 5 \mathrm{mg} / 5 \mathrm{mg}$ ) (plus steroid alert card) and plan for return for 9AM day 11 cortisol (plus $U$ \& Es check due to risk of hyponatraemia/SiADH).

Day 5 cortisol > $200 \mathrm{nmol} / \mathrm{L}$ :

Review histology (i.e. evidence of a corticotroph adenoma), review pre-operative imaging (e.g. size of adenoma, invasion etc.) with regards to whether re-do is likely to achieve cure and discuss with Endocrine Consultant and Pituitary Surgeon. It is often worth waiting to see what the day 11 cortisol value is to guide further surgery.

MAKE ARRANGEMENTS AT DISCHARGE FOR ALL PATIENTS TO COME BACK ON POST-OP DAY 11 (WILL USUALLY BE A MONDAY) FOR A FURTHER 9AM CORTISOL MEASUREMENT (PLUS U \& ES).

PATIENTS NEED TO OMIT 4PM HYDROCORTISONE DOSE THE DAY BEFORE AND MORNING HYDROCORTISONE DOSE ON THE MORNING OF TEST. THE MORNING DOSE CAN THEN BE TAKEN AFTER BLOOD SAMPLE HAS BEEN TAKEN. 


\section{HOW TO INTERPRET DAY 11 CORTISOL LEVELS \\ Day 11 cortisol $<100 \mathrm{nmol} / \mathrm{L}$}

Start $4 \mathrm{mg}$ prednisolone OM (or alternatively hydrocortisone $10 \mathrm{mg} / 5 \mathrm{mg} / 5 \mathrm{mg}$ ) (plus steroid alert card) NOT for post-operative ITT/glucagon stress test (ie.. must remain on hydrocortisone indefinitely).

\section{Day 11 cortisol 100-300 nmol/L}

Start $4 \mathrm{mg}$ prednisolone OM (or alternatively hydrocortisone $10 \mathrm{mg} / 5 \mathrm{mg} / 5 \mathrm{mg}$ ) (plus steroid alert card) and book formal ITT/glucagon stress test for 6 weeks post-op via PIU.

\section{Day 11 cortisol > 300nmol/L}

Can stop prednisolone or hydrocortisone. Book PIU admission for cortisol day curve at 4 weeks postoperatively (to assess whether early remission has actually been achieved) and ITT/glucagon stress test at 6 weeks post-operatively.

\section{ON DISCHARGE}

- If needing prednisolone, discharge on $4 \mathrm{mg}$ prednisolone $\mathrm{OM}$ (or alternatively hydrocortisone $10 \mathrm{mg} / 5 \mathrm{mg} / 5 \mathrm{mg}$ ). Give steroid alert card and discuss 'sick day rules' (http://www.imperialendo.com/for-doctors/toolkit-for-doctors). Patient should be discussed (with histology) at the next available pituitary MDT.

- Acromegaly: Assessment of HPA axis (ITT/glucagon stress test), assessment of GH burden via GH day curve and OGTT (see 'Post-operative assessment of acromegaly') performed 6 weeks post-op (later if on pre-op lanreotide). Remind patients to omit their pm dose of hydrocortisone the day before their ITT/ glucagon stress test). Hydrocortisone to be resumed after test until results known.

- Cushing's disease: ALL patients with Cushing's disease must have a post-operative assessment at 4 weeks, 3-6 months and annually. At 4 weeks and 3-6 months post-operatively, this should include clinical assessment and a cortisol day curve $(9 \mathrm{am}, 12 \mathrm{pm}, 3 \mathrm{pm}, 6 \mathrm{pm}$, mean cortisol should be $150-300 \mathrm{nmol} / \mathrm{L}$ ) (NB this is NOT a hydrocortisone day curve, this is to assess endogenous cortisol production). Planning for a 6 week post-operative ITT/glucagon stress test will depend on the results of 9am cortisols and days 5, 11 and at 4 weeks post-op.

- ALL post-operative patients MUST have an endocrine OPD arranged on discharge to ensure post-operative assessment occurs.

\section{REFERENCES:}

Biller et al., (2008) J Clin Endocrinol Metab 93:2454

\section{VERSION HISTORY}

Arshia Panahloo 01/98, Karim Meeran 07/01, Niamh Martin 07/08 


\section{CUSHING'S DAY CURVE FOR ASSESSMENT OF EARLY REMISSION FOLLOWING TRANS-SPHENOIDAL SURGERY FOR CUSHING'S DISEASE}

\section{PREPARATION}

- Last dose of hydrocortisone is taken at midday the day prior to the test

- Patients advised to omit hydrocortisone on day of test

NB This is NOT a hydrocortisone day curve. This is to assess endogenous cortisol production

18-20g cannula.

6 red or yellow top Vacutainers.

Syringes.

METHOD

0900h \}

1200h $\quad\} \quad$ Take blood

1500h \} for cortisol

1800h $\quad\} \quad$ measurement (OFF hydrocortisone treatment)

\section{INTERPRETATION}

Mean cortisol should be $150-300 \mathrm{nmol} / \mathrm{L}$.

\section{REFERENCES}

Trainer et al., (1993) Clin. Endocrinol (Oxf) 39:441

Biller et al., (2008) J Clin Endocrinol Metab 93:2454

\section{VERSION HISTORY}

Karim Meeran 07/01, Niamh Martin 09/08, reviewed by Niamh Martin 04/14 


\section{FOLLOW UP OF PATIENTS WITH CUSHING'S DISEASE FOLLOWING BILATERAL ADRENALECTOMY}

\section{PREPARATION}

Prior to bilateral adrenalectomy:

- Pituitary MRI (baseline) - if one not done within last 6 months.

- Baseline ACTH (ideally at 9am pre-hydrocortisone) but otherwise random (must document when ACTH measured in relation to hydrocortisone administration).

\section{REMEMBER - ACTH MUST GO IN A PURPLE TOPPED EDTA TUBE AND BE TAKEN IMMEDIATELY TO THE LAB ON ICE}

\section{POST-BILATERAL ADRENALECTOMY}

- Measurement of ACTH within 3 months of surgery: sample taken at 9am (pre-hydrocortisone) and 2 hours after morning hydrocortisone.

- Greatest risk of corticotroph tumour progression if ACTH $>1000 \mathrm{ng} / \mathrm{L}$ (pre-hydrocortisone) in first year post-adrenalectomy. If ACTH below $300 \mathrm{ng} / \mathrm{Lin}$ first year, best prognosis.

- Frequency of surveillance pituitary MRI should be guided by ACTH levels.

\section{REFERENCE}

Assie G et al., (2007) J Clin Endocrinol Metab 92:172

\section{VERSION HISTORY}

Naimh Martin 07/08 


\section{HYDROCORTISONE DAY CURVE}

\section{INDICATION}

1. Establish correct dose and distribution of hydrocortisone replacement throughout the day.

\section{CONTRAINDICATIONS}

None

\section{SIDE EFFECTS}

None

\section{PREPARATION}

- Stop all oestrogen therapy 6 weeks prior to test.

- No need to fast.

- Take normal morning hydrocortisone and patient should note down actual time taken.

- $18-20 \mathrm{~g}$ cannula.

- Red or yellow top Vacutainers.

- Syringes.

\section{METHOD}

Take blood at the following times:

1. Blood sample on arrival, noting time of sample and time and dose of hydrocortisone.

2. Pre lunchtime $\left(2^{\text {nd }}\right)$ dose

3. 1 hour post lunchtime $\left(2^{\text {nd }}\right)$ dose

4. pre evening $\left(3^{\text {rd }}\right)$ dose

5. post evening $\left(3^{\text {rd }}\right)$ dose or at $6 \mathrm{pm}$.

\section{INTERPRETATION -}

- Aim for adequate cortisol levels throughout the day (peak $<900 \mathrm{nmol} / \mathrm{L}$, trough $>100 \mathrm{nmol} / \mathrm{L}$ ).

- As a very rough guide, the values below are what we commonly find. Minor departures do not necessarily need dose adjustment, especially if the patient is well:

- Morning peak cortisol $500-800 \mathrm{nmol} / \mathrm{L}$

- Lunchtime peak cortisol $400-500 \mathrm{nmol} / \mathrm{L}$

- Post evening dose $300-400 \mathrm{nmol} / \mathrm{L}$

- Once adequate levels are achieved, this rarely needs to be repeated, unless there is a significant change in other medication (eg. Starting HRT/enzyme inducers).

\section{VERSION HISTORY}

Karim Meeran 07/00. 


\section{GROWTH HORMONE}

\section{A WORD ON UNITS}

Note that from June 2008, we have changed the GH assay at Imperial College Healthcare NHS Trust to be reported in $\mathrm{mcg} / \mathrm{Lrather}$ than $\mathrm{mU} / \mathrm{L}$. An approximation for conversion of $\mathrm{mU} / \mathrm{Lto} \mathrm{mcg} / \mathrm{L}$ is to divide by 2-3 (2 at lower end of normal, 3 at upper end of normal).

\section{HUMAN GROWTH HORMONE (HGH) PRESCRIBING FOR ADULT ONSET GROWTH HORMONE DEFICIENCY (AOGHD)}

The prescription of HGH follows NICE guidelines, (issued August 2003).

$\mathrm{HGH}$ is recommended if the patient fulfils the following 3 criteria.

1. Confirmed severe $\mathrm{GH}$ deficiency, peak $\mathrm{GH}$ of less than $9 \mathrm{mU} / \mathrm{L}$, which approximates to 3 $\mathrm{mcg} / \mathrm{L}$, on ITT, or a cross-validated GH threshold in an equivalent test (e.g. Glucagon Stress Test).

2. Perceived Quality of Life impairment, measured using the Quality of Life assessment of Growth Hormone Deficiency in Adults (QoL-AGHDA) questionnaire, score has to be 11 or greater (out of 25).

3. The patient must be on full replacement for any other pituitary hormone deficiencies

Once on a maintenance dose, the patient continues for a 6-month trial period of GH replacement, followed by a repeat AGHDA (usually 9 months after after treatment initiation). If the patient's score improves by 7 or more (that is a decrease of at least 7 ), they qualify to continue long-term $\mathrm{GH}$ replacement. If not then it is recommended to stop.

Contraindications include tumour activity, critical illness, pregnancy and lactation.

N.B. in young adults ( $<25 \mathrm{yrs}$, linear growth completed but not reached peak bone mass) with confirmed severe GH deficiency, GH is recommended until peak bone mass is achieved and then reassess using the 3 criteria above

Treatment is self-administered by a daily subcutaneous injection. Start at a low dose $(0.1 \mathrm{mg}-0.2 \mathrm{mg}$ daily) and titrate up (by $0.1 \mathrm{mg}$ ) at monthly intervals, by monitoring IGF-1, and response to adverse effects, until a maintenance dose is achieved, ideally within 3 months. The current median maintenance dose is $0.4 \mathrm{mg}$ daily. We aim for an IGF-1 level in the middle of the reference range (age and sex matched). Women may require a higher dose than men (and higher doses if on HRT). The dose requirement may decrease with age. 
If side effects develop, reduce dose by $0.1 \mathrm{mg}$ for at least 2 weeks then titrate back up according to IGF-1 and symptoms.

The IGF-1 may be within reference range pre GH replacement, and some centres aim for the median or upper half of the reference range on treatment.

\section{SIDE EFFECTS MAY INCLUDE}

headache, arthralgia, myalgia, fluid retention, mild hypertension, carpal tunnel syndrome, visual problems, nausea and vomiting, paraesthesia, antibody formation, reactions at the injection site, rarely benign intracranial hypertension (reverses off treatment).

\section{CONTRAINDICATIONS FOR GH}

Evidence of tumour activity

Critically ill patients

Known hypersensitivity to $\mathrm{GH}$ or any of the excipients

Pregnancy and lactation

Preproliferative or proliferative diabetic retinopathy

PRACTICALITIES REgARDING PRESCRIBING GH (patient information http://www.imperialendo.co.uk/GH\%20replacement.pdf)

1. An application (http://source/pharmacy/pbrexcludeddrugs/fundingforms/index.htm) for funding must be made for each patient. Contact Debbie (Endocrine Nurse Specialist debbie.peters@imperial.nhs.uk) who will organise this as well as patient education.

2. Trust guidance is to use the most cost-effective option which currently is Omnitrope (Sandoz).

\section{MONITORING OF TREATMENT IN OPD (see http://meeran.info/ for pro-forma)}

- $\quad B P, I G F-1$, glucose initially monthly until on stable maintenance dose.

- AGHDA at baseline, and at 9-12 months post-treatment initiation (as per NICE guidelines).

- Weight, BMI, waist;hip ratio 3 monthly.

- Lipids, fasting glucose, HbA1c at baseline and at 9-12 months.

- Pituitary profile including TFT and Cortisol axis or HCDC at 9-12 months (GH replacement may reveal deficiency of T4 or cortisol).

- $\mathrm{BMD}$ at 2 years if osteopenia/osteoporosis pre treatment.

- MRI pituitary pre-treatment (within last year) and at 6 months to 1 year post treatment (depending on previous MRI findings).

\section{VERSION HISTORY}

Emma Hatfield 08/08, Alexander Comninos 09/15, Tony Goldstone 09/15 


\section{EXERCISE TEST}

\section{INDICATION}

1. Used in a child with definite growth retardation preferably as assessed by reduced growth velocity and a random serum growth hormone $(\mathrm{GH})$ of $<15 \mathrm{mU} / \mathrm{L}$. It is a physiological screening test used before formal testing of GH secretion (e.g. insulin tolerance test, arginine stimulation test).

\section{METHOD}

1. If child has difficult veins, cannulate before the test (butterfly is sufficient).

2. Take blood sample for $\mathrm{GH}$ (into a red top Vacutainer) at $\mathrm{T}=0$.

3. Take child to the outpatients staircase and note the time

4. Child should then run up and down the first flight of stairs, as hard and as fast as possible, for at least 10 mins and until the child becomes breathless and moderately fatigued

5. Take blood sample for $\mathrm{GH} 30$ mins after the onset of exercise $(T=30)$

\section{INTERPRETATION}

- A normal GH response of $>15 \mathrm{mU} / \mathrm{L}(5.7 \mathrm{ng} / \mathrm{mL})$ absolves the endocrinologist of any further investigation of GH deficiency. It excludes the need for proceeding to the more laborious and hazardous formal tests.

- A subnormal response $(\mathrm{GH}<15 \mathrm{mU} / \mathrm{L})$ means the child should be considered for a formal test though a repeat exercise test may be valuable (see below).

\section{SENSITIVITY AND SPECIFICITY}

A child with $\mathrm{GH}$ deficiency will not respond to this test. The percentage of children who are not GH deficient and who show a normal response varies depending on the test used and the peak GH value taken as "normal". Values vary from $68-91 \%$. Repeating the test can also improve the detection rate of normals from $80-92 \%$.

\section{REFERENCE}

Milner and Burns (1982) 57:944

\section{VERSION HISTORY}

Maria Barnard 12/89 


\section{GHRH-ARGININE STIMULATION TEST}

\section{INDICATION}

Used to confirm GH deficiency:

1. In transition, after achievement of final height, to confirm persistence of childhood GH deficiency in late adolescence/early adulthood if insulin tolerance test is contraindicated or patient is overweight which may limit interpretation of insulin tolerance test or glucagon stimulation test.

2. In adults, if glucagon stimulation test or insulin tolerance test shows GH deficiency (peak $\mathrm{GH}<5 \mathrm{mcg} / \mathrm{L}$ ), and $2^{\text {nd }}$ confirmatory test is needed before commencing GH treatment, especially if overweight, or ITT contraindicated such as after traumatic brain injury.

\section{PREPARATION}

Fasting overnight from midnight (except water)

Arrive by 9 am

At least 1 month off $\mathrm{GH}$ treatment if in transition.

7 red top Vacutainers

\section{METHOD}

1) Cannulate in both arms, and leave to rest for 45 minutes.

2) Take blood into a plain tube (red top Vacutainer) for baseline GH and IGF-1 measurement (-15 mins), and GH at $0 \mathrm{~min}$.

3) Inject GHRH (Somatorelin, Ferring) $1 \mathrm{mcg} / \mathrm{kg}$ (maximum dose $100 \mathrm{mcg}$ ) as bolus injection.

4) Infuse $0.5 \mathrm{~g} / \mathrm{kg} \mathrm{L}$-arginine monohydrochloride (maximum dose $30 \mathrm{~g}$ ) as a $10 \%$ solution $(30 \mathrm{~g} / 300 \mathrm{~mL}$ ) in normal saline over $30 \mathrm{~min}$.

5) Take blood for further GH estimation in red top Vacutainer (but not IGF-1) at + 30, 45, 60, 90, 120 and 150 min after start of arginine infusion.

6) Can eat lunch at +150 min after last blood test.

7) Stay in bed until +240 min.

8) Monitor pulse \& BP every $15 \mathrm{~min}$ until $+150 \mathrm{~min}$, and every $30 \mathrm{~min}$ from $+150 \mathrm{~min}$ to $+240 \mathrm{~min}$.

\section{SIDE EFFECTS}

Facial flushing is common after GHRH (most patients).

Paraesthesia, nausea, and abnormal taste sensation after GHRH (5-10\%). 


\section{INTERPRETATION}

Cut-offs for diagnosis of GH deficiency depends on peak GH, age and BMI (Colao et al. 2009):

$$
\text { Age }(\mathrm{yrs}) \quad 15-25 \quad 26-65 \quad>65
$$

$\operatorname{BMI}\left(\mathrm{kg} / \mathrm{m}^{2}\right)$

$\begin{array}{llll}<25 & 15.6 & 11.8 & 9.2 \\ 25-30 & 11.7 & 8.1 & 6.1 \\ >30 & 8.5 & 5.5 & 4.0\end{array}$

In transition (adolescence and young adults $<21 \mathrm{y}$ ), other studies have used cut-off for peak $\mathrm{GH}<19 \mathrm{mcg} / \mathrm{Lto}$ confirm GH deficiency if lean. If overweight or obese, cut-offs in transition are unclear and may be higher than in adults. However while using BMI cut-offs given in the Colao et al. study, which did include some subjects down to 15 years old, may pass some patients with GH deficiency as normal, it should correctly identify transition patients who do have GH deficiency.

\section{REFERENCES}

Biller BMK et al. J Clin Endocrinol Metab 87: 2067-2079, 2002

Baxter D et al. Ann Neurol 74:527-36, 2013

Colao A et al. J Clin Endocrinol Metab 94:4414-22, 2009

Clayton PE et al. Eur J Endocrinol 152:165-70, 2005

Corneli G et al. Eur J Endo 153: 257-264, 2005

Ho KKY et al. Eur J Endo 157 695-700, 2007

Corneli G et al. Eur J Endo 157: 701-708, 2007

Gasco V et al. Eur J Endo 159:S45-S52, 2008

\section{VERSION HISTORY}

Tony Goldstone and Nicola Bridges 07/15 


\section{ARGININE STIMULATION TEST}

This is rarely, if ever used but has been included for historical interest.

\section{INDICATION}

Used in a child with definite growth retardation and a subnormal physiological growth hormone $(\mathrm{GH})$ stimulation test (i.e. $\mathrm{GH}<15 \mathrm{mU} / \mathrm{Lor} 5.7 \mathrm{ng} / \mathrm{ml}$ ).

\section{PREPARATION}

Child should be fasting overnight

If the child's bone age is $>10$ years, the test should be done after sex steroid hormone priming:

M: $100 \mathrm{mg}$ testosterone i.m. 3 days before testing.

F: 100 mcg ethinyloestradiol p.o. each for three days before the test.

\section{METHOD}

1) Cannulate child.

2) Take blood into a plain tube (red or yellow top Vacutainer) for baseline GH measurement (0 mins).

3) Infuse $0.5 \mathrm{~g} / \mathrm{kg} \mathrm{L}$-arginine monohydrochloride (maximum dose $40 \mathrm{~g}$ ) as a $10 \%$ solution in normal saline over 30 minutes.

4) Take blood for further GH estimation 30, 60, 90, 120 and 150 mins after start of arginine infusion.

\section{INTERPRETATION}

- A normal $\mathrm{GH}$ response of $>15 \mathrm{mU} / \mathrm{L}(>5.7 \mathrm{ng} / \mathrm{ml})$ excludes $\mathrm{GH}$ deficiency.

- A GH response of 7-15 mU/Lmay indicate partial GH deficiency and should be investigated by a second formal stimulation test.

- A GH response of $<7 \mathrm{mU} / \mathrm{L}(<2.7 \mathrm{ng} / \mathrm{ml})$ should also generally be confirmed by a second test. However, if there are other compatible clinical and auxiliary findings, the child may be directly considered for GH replacement therapy.

- A child with pubertal growth delay may show a subnormal GH response if the test is performed without sex hormone priming. However, there should be a normal response after priming.

\section{SENSITIVITY AND SPECIFICITY}

A child with $\mathrm{GH}$ deficiency will not respond to this test.

The percentage of children who are not $\mathrm{GH}$ deficient and who show a normal response varies from 45 - $93 \%$. Generally, $20 \%$ of normal children fail to respond to a formal test and this is the reason for doing 2 tests before proceeding to $\mathrm{GH}$ therapy. For example, $71 \%$ of normals will respond to both insulin tolerance and arginine stimulation tests. However, the others will respond to at least one test: $13 \%$ to insulin, $16 \%$ to arginine.

\section{REFERENCE}

Raiti et al., (1967) Lancet 2:1182 


\section{ORAL GLUCOSE TOLERANCE TEST FOR ACROMEGALY}

\section{INDICATION}

Used where a clinical diagnosis of acromegaly is suspected.

\section{PREPARATION}

- Fasting from midnight.

- 18-20g cannula.

- 6 red or yellow top Vacutainers.

- 6 grey top fluoride oxalate Vacutainers.

\section{METHOD}

1. Take blood sample for GH and IGF-1 (into a red or yellow top Vacutainer) and glucose (into grey top tube) at $\mathrm{T}=0$.

2. Administer 75 grams oral glucose in $300 \mathrm{ml}$ water over about 10 minutes.

3. Take blood for $\mathrm{GH}$ and glucose at $\mathrm{T}=30,60,90$ and 120 minutes.

4. In the occasional patient who needs an OGTT for acromegaly and assessment of their cortisol reserve (NOT in the early post-operative period), a synacthen test can be carried out at the end of this test, with samples for cortisol taken at $T=120,150$ and 180 minutes. Synacthen $250 \mathrm{mcg}$ is administered at $\mathrm{T}=120$ minutes.

\section{INTERPRETATION}

- In normal individuals, GH levels are suppressed following oral glucose,.At least one of the samples during the test should have undetectable GH levels (i.e. $<1 \mathrm{mcg} / \mathrm{L}$ ).

- Failure of suppression or a paradoxical rise in GH suggests acromegaly.

\section{SENSITIVITY AND SPECIFICITY}

False positives may occur in patients with anorexia nervosa or other causes of chronic starvation, diabetes mellitus, liver or renal failure.

\section{REFERENCES}

Acromegaly: An Endocrine Society Clinical Practice Guideline. (2014) J Clin Endocrinol Metab 99:3933 


\section{FOLLOW UP POST PITUITARY SURGERY AND RADIOTHERAPY}

Following irradiation, endocrine testing should be performed on a yearly basis for at least 10 years, and then 5 yearly until failure of a cortisol response is apparent. Once failure is clear, the patient should be put on hydrocortisone replacement and further insulin tolerance tests (or other appropriate test) are not required.

Patients who have undergone pituitary radiotherapy for acromegaly are often on somatostatin analogues following radiotherapy, and once it appears that the radiotherapy has worked, reassessment (IGF-1 +/- OGTT) off these analogues is essential.

\section{SCREENING COLONOSCOPY IN ACROMEGALY}

A meta-analysis (published in 2008) of 9 case-control studies with a total of 701 acromegaly patients and 1573 controls reported that the pooled odds ratio (OR) for colonic adenomas in acromegaly was approximately $2.5(p<0.0001)$, pooled OR for hyperplastic colonic polyps was about $3.6(p<0.0001)$, and the pooled OR for colon cancer was $4.35(p=0.0006)$. Other authors have reported an increased risk of colon neoplasia in patients with acromegaly. Therefore current guidelines recommend screening for colon cancer in acromegaly.

1. Patients with acromegaly should have a baseline colonscopy at the time of diagnosis of acromegaly, and all patients should be offered regular colonoscopic screening starting at the age of 40 years.

2. The frequency of repeat colonoscopy should depend on the findings at the original screening and the activity of the underlying acromegaly. The Endocrine Society Guidelines advise:

- After treatment, repeat colonoscopy is suggested every 5 years in those found to have a polyp or with persistently elevated IGF-1

- Every 10 years in those without a polyp and with normal IGF-1

3. Total colonoscopy is required rather than sigmoidoscopy, although the colonoscopy is associated with technical difficulties

4. These patients have increased length of colon, as well as increased circumference. In addition, these patients have colonic transit time that is more than twice that of normal subjects and thus standard bowel preparation is usually inadequate. Therefore, bowel preparation should involve twice the "standard" preparation, eg.one satchet of Kleanprep ${ }^{\circledR} 4$ times a day for the two days preceding colonoscopy with a liquid only diet for 24 hours beforehand (actual details of bowel preparation should be confirmed according to local Trust policy).

5. Ensure hydrocortisone $100 \mathrm{mg}$ i.m. on day of procedure if on steroid replacement for associated cortisol deficiency. 


\section{REFERENCES:}

Jenkins and Fairclough (2002) Gut 51(SV):v13

Rokkas et al., (2008) World J Gastroenterol 14:3484

Cairns et al., (2010) Gut 59:666

Katznelson L et al., (2011) Endocr Prac 17:1

Melmed S et al. (2013) Pituitary 16:294

Acromegaly: An Endocrine Society Clinical Practice Guideline. (2014) JCEM 99:3933

\section{VERSION HISTORY}

Karim Meeran 01/01, Niamh Martin 7/08, updated Chioma Izzi-Engbeaya 11/13, reviewed by Alexander Comninos and Niamh Martin 09/15.

\section{HISTORICAL METHODS OF ASSESSING EXCESS GROWTH HORMONE}

\section{FINGER SIZE ASSESSMENT}

\section{INDICATION}

Finger size is an objective measure of soft tissue over growth. It can be used to follow the response to treatment in Acromegaly.

\section{METHOD}

Measurement should be between 0900h and 1000h before any intravenous cannula is inserted. Ring size is assessed on the proximal surface of the proximal interphalangeal joint of the fourth finger. The size is that of the tightest fit. A recording is made from each hand and clearly recorded in the notes. If the finger is too large for size $Z$ then the fifth finger is used.

\section{VERSION HISTORY}

Andrew Hattersely 11/89

\section{MEASURING SKIN FOLD THICKNESS}

\section{INDICATION}

Skin-fold thickness can be used in acromegaly and Cushing's syndrome as an index of skin involvement and therefore disease activity. 


\section{METHOD}

1. The skin is measured using the skin-fold calliper on the dorsum of the hand over the mid-point of the third metacarpal bone.

2. Set the scale on the callipers to zero.

3. Place the patient's hand flat on the table with the wrist in a neutral or extended position.

4. A small skin-fold in the long axis of the hand is lifted up and placed between the blades of the calliper so the fold reaches exactly to the top of the jaw-blades.

\section{INTERPRETATION}

- Skin thickness has only a limited role in the diagnosis and the monitoring of acromegaly and Cushing's.

- Mean skin thickness (see reference) in men is $2.8 \mathrm{~mm}$ when $20 \mathrm{yrs}$ old decreasing to $1.75 \mathrm{~mm}$ when $70 \mathrm{yrs}$. Women's skin is approximately $0.2 \mathrm{~mm}$ thinner than similarly aged men.

- $77 \%$ of acromegalics have abnormally thick skin (mean $+2 \mathrm{~s} . \mathrm{d}=$. in 40 year old males $>3.4 \mathrm{~mm}$ ).

- All patients with Cushing's had skin-fold thickness below the mean value but only $42 \%$ were abnormally thin (mean -2 s.d. $=$ in 40 year old females $<1.5 \mathrm{~mm}$ ).

\section{REFERENCE}

Wright and Joplin (1969) Acta Endocrinologia 60:705

\section{VERSION HISTORY}

Andrew Hattersley 12/89 


\section{PITUITARY RADIOTHERAPY \\ POLICY ON SPERM STORAGE PRIOR TO PITUITARY RADIOTHERAPY}

See Andrology section

\section{ASSESSMENT OF HYPOPITUITARISM FOLLOWING CRANIAL IRRADIATION}

Hypothalamo-pituitary dysfunction is a frequent complication of radiation treatment that involves these structures, described in up to $80 \%$ of adults. Hence, pituitary dysfunction should be screened for not only in patients who have received pituitary radiotherapy for pituitary disease, but also in patients who have undergone cranial irradiation for other tumours eg primary brain tumours, nasopharyngeal carcinoma, whereby the treatment field includes the hypothalamus and pituitary. Significant hypopituitarism has rarely been reported following radiotherapy doses of less than 20Gy.

Onset of post-radiation pituitary dysfunction is variable and prevalence increases with time. Since this has been reported as early as a year following radiation treatment, Society for Endocrinology guidelines recommend that pituitary function should be assessed annually on the anniversary of completion of radiotherapy for ten years. Thereafter, the patient should be assessed every five years or in the event of relevant symptoms. If the primary lesion is in close proximity to the hypothalamus and/or pituitary an additional assessment should be undertaken six months following completion of radiotherapy. It is helpful to document the radiation therapy dose and number of fractions received at the first endocrine consultation with particular reference to the dose delivered to the pituitary (this will be provided by the Clinical Oncologist using the details from the radiotherapy treatment plan).

Typically, following radiation treatment, GH deficiency is the earliest reported pituitary hormone deficiency and TSH deficiency is often the last pituitary dysfunction to manifest. Hyperprolactinaemia has been reported in cancer survivors receiving cranial irradiation. Posterior pituitary dysfunction ie cranial diabetes insipidus is unusual following pituitary radiotherapy.

Assessment of pituitary function should consist of:

- Clinical history and examination.

- Serum urea and electrolytes, plasma glucose

- Serum insulin-like growth factor-1 (IGF-1)

- Serum FSH and LH

- Serum testosterone and sex hormone binding globulin in men

- Serum TSH and free thyroxine (fT4)

- HPA axis assessment - this can be Short Synacthen test (SST), glucagon stimulation test or metyrapone stimulation test. Annual ITTs are not recommended to follow up these patients. 
- Progesterone challenge in amenorrheoic women of premenstrual age

If there are concerns regarding GH deficiency, a dynamic assessment of the growth hormone axis should be performed and an AGHDA score recorded to establish whether the patient meets NICE criteria for $\mathrm{GH}$ replacement ( $\mathrm{p} 47-8$ ). It is important to note that $\mathrm{GH}$ replacement is contraindicated in patients with active malignancy. Hence, $\mathrm{GH}$ replacement therapy should only initiated in adult cancer survivors following discussion with the oncologist responsible for the patient's cancer treatment and monitoring. To date, there are no data on the safety of GH replacement in adult cancer survivors and this should be explained to the patient before GH therapy is initiated. If the patient chooses to proceed with $\mathrm{GH}$ replacement, it is prudent to start with a low dose eg 0.1 or $0.2 \mathrm{mg}$. This can be increased in line with the patient's clinical response, aiming to keep the serum IGF-1 within the age specific normal range.

All other pituitary hormone deficiencies should be treated in the standard way.

\section{REFERENCES:}

Guidance of the Late Endocrine Effects of Cancer Treatment (in press) Ball S et al

\section{VERSION HISTORY}

Niamh Martin and Matt Williams 09/15 


\title{
POSTERIOR PITUITARY
}

\author{
DIABETES INSIPIDUS \\ WATER DEPRIVATION TEST
}

\section{INDICATION}

1. Used in differential diagnosis of polyuria, separating central diabetes insipidus (CDI), nephrogenic diabetes insipidus (NDI) and primary polydipsia/compulsive water drinking (PP).

2. If in the basal state plasma osmolality $>295$ mosmol $/ \mathrm{kg}$, plasma $\mathrm{Na}>145 \mathrm{mmol} / \mathrm{L}$ and urine is hypotonic $(<300 \mathrm{mosmol} / \mathrm{kg}$ ), PP is excluded and investigation goes straight to DDAVP (1deamino-8-D-arginine vasopressin) administration.

\section{CONTRAINDICATIONS}

Exclude other causes of polyuria (e.g. diuretics, chronic renal failure, hypercalcaemia, hypokalaemia, hyperglycaemia). Anterior pituitary hormone deficiency: renders results meaningless as, in particular, steroid and thyroxine deficiencies impair excretion of a free water load.

\section{PREPARATION}

\section{IT IS ESSENTIAL THAT THIS TEST IS SUPERVISED BY A DOCTOR EG F1 OR F2} Up to $08.30 \mathrm{~h}$ on day of water deprivation test:

1. No tobacco/alcohol for $24 \mathrm{hrs}$ before the test and avoid caffeine on day of test.

2. Stop interfering medication (e.g. DDAVP (last dose 24 hours before the start of the test), diuretics) but not other hormone replacement.

3. Light breakfast (do not fast).

4. DO NOT limit fluids until the test begins.

Equipment:

- Blood is taken into yellow top Vacutainers, urine into Sterilin universal containers.

- Urine measuring jug.

- Weighing scales.

- DDAVP: if given intranasally, must acquaint yourself with the spray as it is not easy to use.

\section{SIDE EFFECTS}

If true CDI or NDI, risk of excessive dehydration, therefore careful monitoring of the patient is required. 


\section{GENERAL APPROACH}

Principle: dehydrate till ADH secretion concentrates urine. Observe the patient for the entire duration of the test, in order to ensure no surreptitious drinking and to ensure results are not confused by nonosmotic stimulants of AVP secretion such as smoking, postural hypotension, vaso-vagal reflexes, or nausea or hypotension. Dehydration may develop rapidly if the patient has severe central or nephrogenic DI. Stop test if body weight decreases by $3 \%$ or if plasma osmolality $>300 \mathrm{mOsm} / \mathrm{kg}$.

\section{METHOD (see figure below)}

Please contact duty biochemist on 30348 at least 24 hours in advance if real time osmolalities will be required, as otherwise samples will be run as a batch 1-2 times per day.

\section{Stage 1 (exclusion of PP): 8.30 - 16.30h}

1. No fluid allowed but dry food permitted (e.g. toast).

2. Weigh patient at time 0 . Weight should be measured at hourly intervals: stop test if $>3 \%$ weight loss (positive test).

3. Urine passed and discarded at time 0; urine then passed hourly and hourly volume estimated.

4. Urine specimen taken for osmolality from the total hourly sample passed over $8.30-9.30 \mathrm{~h}$ (U1), 11.30 - 12.30h (U2), 14.30 - 15.30h (U3), 15.30 - 16.30h (U4).

5. Blood taken for osmolality and plasma sodium at 9.00 (P1), 12.00h (P2), 15.00h (P3), 16.00h (P4). Plasma sodium measurement is very important and must be done on ALL blood samples.

6. Note down urine volumes in chart as shown below (U1-U4).

Stage 2 (differential diagnosis CDI from NDI): $16.30-20.30 \mathrm{~h}$

7. Patient may now eat and drink freely

8. At $16.30 \mathrm{~h}$, administer DDAVP: $20 \mathrm{mcg}$ intra-nasally or $2 \mathrm{mcg}$ i.m.

9. Continue to measure hourly urine volumes and take samples for osmolality from each hourly sample. There is no point measuring plasma samples (or taking any blood), as the patient are now eating and drinking freely, and we are only interested in the effects of the administered DDAVP on urine volume and osmolality.

10. Note down urine volumes in chart as shown below (U5-U8). 


\section{Stage 1:}

Exclusion of PP

08.30am to $16.30(\mathrm{pm})$

Time 8.30am $(\mathrm{t}=0)$

Calculate $97 \%$ of body weight, pass urine and discard.

\begin{tabular}{|c|c|c|}
\hline TIME & URINE / VOLUME & PLASMA \\
\hline 0830 & Discard urine & \\
\hline 0900 & $\Rightarrow$ & Collect P1 - osmolality, U \& Es \\
\hline 0930 & & \\
\hline 1130 & $\begin{array}{l}\text { Collect U1 } \\
\text { Discard urine }\end{array}$ & \\
\hline 1200 & $\Rightarrow$ & Collect P2 - osmolality, U \& Es \\
\hline 1230 & & \\
\hline 1430 & Discard urine & \\
\hline 1500 & $\Rightarrow$ & Collect P3 - osmolality, U \& Es \\
\hline 1530 & $\mathrm{ml}$ & \\
\hline 1600 & $\Rightarrow$ & Collect P4 - osmolality, U \& Es \\
\hline 1630 & $\mathrm{ml}$ & \\
\hline
\end{tabular}

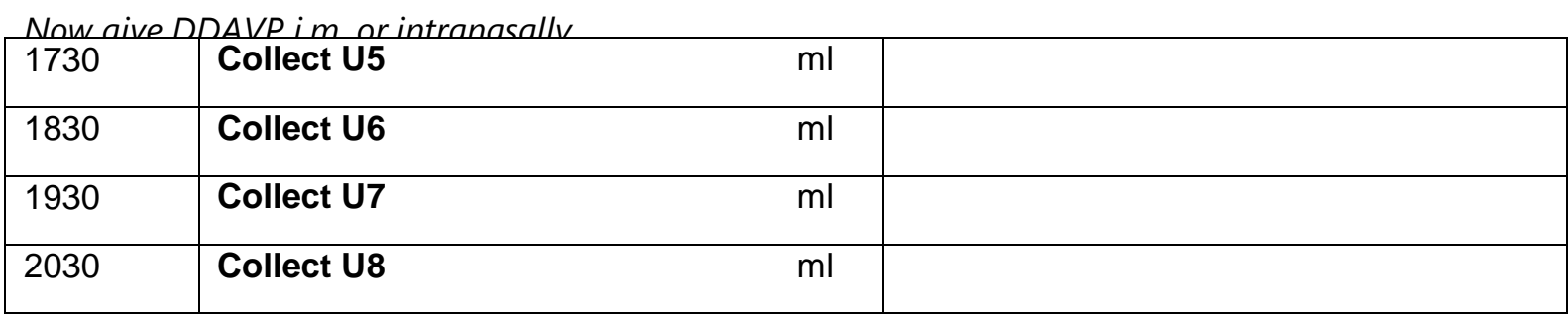

\section{INTERPRETATION}

Complete table (see http://www.meeran.info) for urine volumes, weight, urine and plasma osmolalities, plasma sodium to assist interpretation of results.

1. Normal

With dehydration, plasma is concentrated but to $<300 \mathrm{mOsmol} / \mathrm{kg}$. Urine also concentrates to $>600 \mathrm{mosmol} / \mathrm{kg}$.

2. PP or partial DI

Start with a low plasma osmolality, which concentrates to normal during stage 1. Urine concentrates, though may be subnormal response (see below).

3. $C D I$

Patient excessively concentrates plasma to $>300 \mathrm{mOsmol} / \mathrm{kg}$ with inappropriately hypotonic urine (U3:P3 or U4:P4 = <1.9). After DDAVP: CDI patient, deficient in ADH, is still able to concentrate urine to $>150 \%$ of previous highest level. In NDI, patient is unable to respond to ADH or DDAVP, and concentrates urine to $<150 \%$ of previous highest value. 


\begin{tabular}{|l|l|l|}
\hline Diagnosis & After dehydration & After DDAVP \\
\hline Normal & $>750$ & $>750$ \\
\hline PP or partial CDI & $300-750$ & $<750$ \\
\hline CDI & $<300$ & $>750$ \\
\hline NDI & $<300$ & $<300$ \\
\hline
\end{tabular}

Many patients fall in the range $300-750$ following water deprivation and it is often difficult to differentiate between PP and partial DI, especially following pituitary-surgery. In this instance, the plasma sodium may be helpful, since in PP, this is often low at the start of the test.

If there is a partial response, this test does not reliably differentiate between PP and partial CDI or NDI because the response to dehydration and DDAVP may be very similar for a variety of reasons:

- Polyuria of any origin (e.g. PP or CDI) washes out medullary concentration gradient, blunting maximal urinary concentration

- $\quad C D I$ may increase renal sensitivity to very low levels of AVP. If patient has only a partial deficiency of AVP, dehydration may therefore rapidly increase urine osmolality to maximum of which they are capable.

- Some patients with NDI can concentrate urine if plasma AVP increases to supra-physiological levels, e.g. with exogenous DDAVP.

- With PP patients avoid excess water/fluid at discharge as there is a small chance that following DDAVP and subsequent excess water intake of developing hyponatraemia.

IF THERE IS A PARTIAL RESPONSE, FURTHER INVESTIGATION IS INDICATED (see Prolonged Water Deprivation Test below)

\section{SENSITIVITY AND SPECIFICITY}

When well performed, the WDT has a sensitivity and specificity of $95 \%$ for diagnosing and differentiating severe CDI and NDI. The incidence of false positive and false negative results for PP or partial $\mathrm{CDI} / \mathrm{NDI}$ is $30-40 \%$ (therefore investigate further).

\section{REFERENCE}

Vokes et al., (1988) Endo. Metab. Clin. N. Amer. 17:281

\section{VERSION HISTORY}

Revised Karim Meeran and Niamh Martin 9/08, Sheba Jarvis 11/13, reviewed by Niamh Martin 04/14

\section{PROLONGED WATER DEPRIVATION TEST (MILLER AND MOSES)}

\section{INDICATION}


This is only to be performed if there is doubt distinguishing partial DI e.g. in a patient who has had pituitary surgery, from a patient with primary polydipsia following a standard water deprivation test.

\section{METHODS}

\section{THIS TEST SHOULD BE SUPERVISED BY A DOCTOR EG F1 OR F2}

1. Liaise with the Duty Biochemist on $\times 30348$ the day before the test.

2. The patient must be nil by mouth from 18:00 the day before the test and arrive on Clinical Investigation Unit by $7: 45$.

3. Weigh patient at time 0 . Weight should be measured at hourly intervals: stop test if $>3 \%$ weight loss (positive test)

4. Collect urine for osmolality hourly.

5. Collect plasma for osmolality every 2 hours.

6. All osmolalities should be measured immediately.

7. Water deprivation should be continued until three consecutive urine osmolalities show $<30$ $\mathrm{mOsm} / \mathrm{kg}$ increase (ie has reached a plateau).

8. When a plateau has been reached, give $2 \mathrm{mcg}$ i.m. DDAVP. Patient is then allowed to drink.

\section{INTERPRETATION}

1). Normal response: urine osmolality rises to reach a plateau and does not increase further in response to DDAVP. Plasma osmolality is maintained within the normal range. U:P $>2$ at the end of dehydration.

2). Primary psychogenic polydipsia:before DDAVP urine maximum osmolality $>290 \mathrm{mOsm} / \mathrm{kg}$ with no further rise in urine osmolality after DDAVP. Baseline plasma osmolality is usually low.

3) Partial cranial DI: a rise in urine osmolality of $9 \%$ or more after DDAVP suggests partial cranial DI ie endogenous maximal AVP secretion is insufficient to maximally concentrate the urine.

Adapted from Bart's Endocrine Protocols

\begin{tabular}{|c|c|c|c|c|}
\hline Time & Hours & Urine Osm & Plasma Osm & Weight \\
\hline $08: 00$ & 0 & U1 & P1 & yes \\
\hline $09: 00$ & 1 & U2 & - & \\
\hline $10: 00$ & 2 & U3 & P3 & yes \\
\hline $11: 00$ & 3 & U4 & - & \\
\hline $12: 00$ & 4 & U5 & P5 & yes \\
\hline etc & etc & etc & etc & etc \\
\hline
\end{tabular}

\section{REFERENCE:}

Miller et al., (1970) Arch Intern Med 73:721 


\section{THERAPEUTIC TRIAL OF DDAVP}

\section{INDICATION}

Used when partial response to water deprivation test to differentially diagnose Primary Polydipsia (PP) and partial Cranial Diabetes Insipidus (CDI) or Nephrogenic Diabetes Insipidus (NDI).

\section{SIDE EFFECTS}

Water intoxication in PP.

\section{METHOD}

1. Admit to hospital. Monitor daily: fluid input and output, body weight, $U+E s$ and urine osmolality.

2. Patient observed for 2 days and then $10 \mathrm{mcg}$ DDAVP given intranasally od for at least 2-3 days.

\section{INTERPRETATION}

- Partial CDI: prompt improvement in thirst and polyuria.

- NDI: no effect; can be treated for further 2-3 days with a 10 fold increased dose to see if defect partial or complete.

- PP: decreased polyuria with no change in polydipsia. Causes weight gain, increased urine osmolality and progressive dilutional hyponatraemia, which may develop rapidly and severely (hence need for hospitalisation).

\section{SENSITIVITY AND SPECIFICITY}

Small possibility of false diagnosis of PP as hyponatraemia may occur in $5 \%$ of CDI who continue to drink excessively on DDAVP because of associated abnormal thirst or prolonged habit

\section{REFERENCE}

Vokes et al., (1988) Endo. Metab. Clin. N. Amer. 17:281

\section{VERSION HISTORY}

Maria Bernard 10/89, revised Bernard Khoo 07/00 


\section{ADRENAL INVESTIGATIONS}

\section{SHORT SYNACTHEN TEST (SST)}

\section{INDICATION}

1. Used in the diagnosis of hypoadrenalism as a screening test.

2. It is an increasingly used alternative to the insulin tolerance test to diagnose secondary hypoadrenalism due to pituitary hypofunction. However, it should not be used in the early post-operative assessment of the hypothalamic-pituitary-adrenal axis as response may be normal (an insulin tolerance/glucagon stress test should be used instead).

3. May also be used to ascertain that the adrenals are functioning normally after a prolonged course of corticosteroids, or after suppression by Cushing's syndrome (e.g. after removal of a unilateral Cushing's adrenal adenoma).

4. Diagnosis of 21-hydroxylase deficiency and other causes of adrenal hyperplasia.

5. Diagnosis of non-classical congenital adrenal hyperplasia in the context of a hyperandrogenic woman, if the morning follicular-phase baseline 17-hydroxyprogesterone is $>6.0 \mathrm{nmol} / \mathrm{L}$.

\section{CONTRAINDICATIONS}

Definitely not required for assessment of hypoadrenalism if random cortisol $>450 \mathrm{nmol} / \mathrm{L}$.

If a random cortisol $>400 \mathrm{nmol} / \mathrm{L}$, patients are very likely to pass the test, and some feel that in this circumstance, the test is not usually warranted.

\section{SIDE EFFECTS}

None

\section{PREPARATION}

- If on hydrocortisone the final dose of hydrocortisone should be at midday, on the day prior to the test.

- HRT or any oestrogen should be discontinued for 6 weeks before the test.

- In patients in whom the test is being used to screen for 21-hydroxylase deficiency, the test should be done in the follicular phase because progesterone levels rise substantially in the luteal phase, and there is some cross reaction between the 17-OHP assay and the Progesterone assay.

- Admission is required if there is a risk of Addisonian crisis (rare).

- $18-20 g$ cannula.

- Saline flush.

- $10 \mathrm{ml}$ syringes $\times 4$.

- 3 red or yellow top Vacutainers for cortisol (same samples for 17-OH progesterone)

- 1 EDTA tube (purple top Vacutainer) for ACTH basal sample + ice. 
- 1 ampoule of 250 micrograms tetracosactrin (Synacthen).

\section{METHOD}

1. 0900h: take $7 \mathrm{ml}$ blood for cortisol (red or yellow top Vacutainer) and ACTH (purple top, on ice to lab immediately).

2. Give 250 micrograms tetracosactride i.m. (ideally) or i.v.

3. 0930h: Take $3 \mathrm{ml}$ blood for cortisol.

4. 1000h: Take $3 \mathrm{ml}$ blood for cortisol.

5. For the diagnosis of congenital adrenal hyperplasia the samples taken for cortisol are also analysed for $17-\mathrm{OH}$ progesterone to exclude 21 -hydroxylase deficiency. In some cases $17-\mathrm{OH}$ pregnenolone is measured to differentiate between $21-\mathrm{OH}$ and 3 B-HSD deficiency.

\section{INTERPRETATION}

- Normal response if test done at 0900h (considerable diurnal variation):

Stimulated plasma cortisol $450 \mathrm{nmol} / \mathrm{L}$ or above at 30 minutes

AND/OR

Incremental rise of at least $150 \mathrm{nmol} / \mathrm{L}$

Please note that these cortisol values are based on the cortisol assay at Imperial College Healthcare NHS Trust. Other centres must take into account the specific local assay as the values stated above may not apply to other assays.

- If impaired cortisol response, and ACTH $>200 \mathrm{ng} / \mathrm{L}$ then diagnosis is primary adrenal failure.

- If $A C T H<10 n g / L$ then diagnosis is secondary adrenal failure.

- Response of 17-OH progesterone in suspected 21-hydroxylase deficiency (non-classical): marked rise after ACTH stimulation ( $>30 \mathrm{nmol} / \mathrm{l}$ ), which varies according to whether the patient is homozygous or heterozygous. Reference for nomogram: New et al. (1983) JCEM 57:320-326.

- Response of 11-deoxycortisol in suspected CAH due to $11 \beta$-hydroxylase defect:

\begin{tabular}{|c|c|}
\hline Suggestive of CAH due to $11 \beta$ hydroxylase defect & $\begin{array}{l}\text { 11-Deoxycortisol } \\
\text { following synacthen } \\
\text { stimulation test }\end{array}$ \\
\hline $\begin{array}{c}\text { Highly suggestive of CAH due to } 11 \beta \text {-hydroxylase } \\
\text { defect }\end{array}$ & $>200 \mathrm{nmol} / \mathrm{L}$ \\
\hline
\end{tabular}

\section{SENSITIVITY AND SPECIFICITY}

A normal cortisol response does not exclude adrenal failure, since impending adrenal failure might be 
associated with a much greater loss of zona glomerulosa function. The latter would be suggested by an elevated plasma renin activity.

If equivocal result and no urgency, repeat test after a few weeks.

An abnormal response is consistent with primary or secondary adrenal failure, and should be investigated further. Consider long synacthen test or pituitary function testing.

\section{REFERENCES}

Burke (1985) Clin Endocrinol Metab 14:947

Savage (1985) Clin Endocrinol Metab 14:893

Clayton (1989) BMJ 298:271 (

Azziz et al., (1994) J. Clin. Endo. Metab. 78:810

\section{VERSION HISTORY}

John Wilding 12/89, Karim Meeran 07/01, Tricia Tan and Niamh Martin 08/08, Ben Jones and Chioma Izzi-Engbeaya 11/13, reviewed by Niamh Martin 08/14 


\section{LONG SYNACTHEN TEST}

\section{INDICATION}

1. Confirmation of diagnosis of hypoadrenalism.

2. Differentiating primary and secondary hypoadrenalism (note that measurement of basal 0900h ACTH levels is far more sensitive than cortisol response in the long synacthen test).

3. The first 3 samples should give the same result as the short synacthen test.

\section{SIDE EFFECTS}

None

\section{PREPARATION}

- Patients who have already been taking corticosteroids should have the last dose 24 hours before the start of the test.

- Admit the patient if there is a risk of an Addisonian crisis (virtually never).

- Patients with pituitary disease are usually safe if they have an intact renin-angiotensin (aldosterone) axis.

- Once the test has commenced, dexamethasone will not interfere with the cortisol result. (Do not use hydrocortisone or prednisolone, which will interfere with the cortisol assay). Use $0.75 \mathrm{mg}$ for $5 \mathrm{mg}$ prednisolone equivalent.

- $1 \mathrm{mg}$ depot synacthen (tetracosactride) (depot preparation). This is not the same as ordinary Synacthen!

- $18-20 \mathrm{~g}$ cannula.

- 6 red or yellow top Vacutainers.

- 1 purple top Vacutainer for ACTH.

- Syringes.

- Saline flush.

\section{METHOD}

0900h Insert cannula and flush

Take blood for baseline cortisol and ACTH

Administer $1 \mathrm{mg}$ depot synacthen i.m.

0930h

1000h \} Take blood

$1100 \mathrm{~h}\}$ for cortisol

1300h \} measurement

$1700 \mathrm{~h}\} \quad$ (i.e. additional 2, 4, 8 and 24h)

0900h \} 


\section{INTERPRETATION}

- Normal response: baseline cortisol $>170 \mathrm{nmol} / \mathrm{L}$ with rise to $>900 \mathrm{nmol} / \mathrm{L}$ (peak) Samples at 0900h, 0930h and 1000h can be interpreted as for a short synacthen test.

- Primary adrenal insufficiency: little or no response throughout test.

- Secondary adrenal insufficiency: some patients may show a rise in cortisol, which may be delayed (but a subnormal response does not exclude this - measure ACTH levels).

- Patients with a subnormal response can still have their steroids weaned (e.g. prednisolone by $1 \mathrm{mg} /$ month).

\section{SENSITIVITY AND SPECIFICITY}

More sensitive than short synacthen test for primary adrenal insufficiency (for nomogram see Burke et al 1985).

\section{REFERENCE}

Burke C.W. et al., (1985) Clin. Endo. Metab 14:947

\section{VERSION HISTORY}

Karim Meeran 01/97 updated Karim Meeran 07/01, reviewed by Niamh Martin 08/14 


\section{ADRENAL TUMOURS}

All patients should be referred to Mr Fausto Palazzo, Consultant Endocrine Surgeon, at Hammersmith Hospital.

These patients will need to be discussed at the ICHNT Endocrine MDT.

In the case of the following indications for adrenalectomy:

- An adrenal mass associated with Cushing's syndrome

- Bilateral adrenalectomy as primary treatment for hypercortisolaemia

The patient may need to be treated for 6 weeks prior to surgery with either metyrapone/ketoconazole to achieve a serum cortisol of $150-300 \mathrm{nmol} / \mathrm{L}$. First-line medical treatment to lower cortisol is ketoconazole (200mg bd) however due to issues accessing ketoconazole following concerns about hepatotoxicity, we are now using metyrapone first line with the dose titrated to achieve a serum cortisol of 150-300 nmol/L. If you are using ketoconazole, note that ketonconazole requires an acid $\mathrm{pH}$ environment for adequate absorption, therefore patients need to avoid PPIs if possible.

\section{OPERATIVE MANAGEMENT OF ADRENALECTOMY}

Discuss with surgeon and/or anesthetists in advance.

\section{STEROID REPLACEMENT AFTER ADRENALECTOMY}

Historically, $100 \mathrm{mg}$ hydrocortisone IM qds has been used for early hydrocortisone cover. However, the majority of patients now undergo minimal access (laparoscopic or retroperitoneoscopic) rather than open adrenalectomy and therefore have a lesser physiological insult. Intramuscular boluses are preferred as with intravenous boluses plasma cortisol levels fall to undetectable levels in between doses due to the short half-life of cortisol. These are very different from asthmatics, where IV boluses are given in ADDITION to normal adrenal function.

\section{UNILATERAL ADRENALECTOMY}

All patients undergoing unilateral adrenalectomy must have an overnight dexamethasone suppression test performed and results reviewed prior to their admission for adrenalectomy.

Patients who pass the overnight dexamethasone suppression test do NOT need any steroid perioperatively. Patients that fail the overnight dexamethasone suppression test (i.e. 9am cortisol fails to suppress to $<50 \mathrm{nmol} / \mathrm{L}$ ) need glucocorticoid replacement in the following way:

1. Hydrocortisone administered at the end of the operation (100 $\mathrm{mg} I \mathrm{IM})$.

2. Patient reviewed by the endocrine team post-op on the day of surgery.

3. If the patient is eating and drinking prescribe $10 \mathrm{mg} P O$ prednisolone (at 4-6pm on evening of surgery). 
4. If the patient is not eating and drinking prescribe $50 \mathrm{mg} \mathrm{IM} \mathrm{hydrocortisone} \mathrm{(at} \mathrm{4-6pm)} \mathrm{and}$ continue $50 \mathrm{mg} \mathrm{IM}$ qds until the patient is eating and drinking.

5. If the patient is eating and drinking, from day 1 post-op prescribe $10 \mathrm{mg}$ PO prednisolone for 2 days followed by maintenance dose of $3-5 \mathrm{mg}$ od.

6. Arrange for patient to have a short Synacthen test at the earliest opportunity (but this should not delay patient discharge).

7. In patients who fail the short Synacthen test, continue prednisolone and repeat the short Synacthen test.

8. Be aware that the above protocol will overtreat many patients, but this is safer than allowing any patients to have an Addisonian perioperative period. Once patients with one remaining adrenal have passed a synacthen test, supportive prednisolone can be stopped. The maintenance dose is probably closer to $3 \mathrm{mg}$ daily than $5 \mathrm{mg}$ daily. Clearly lower doses of replacement are less likely to suppress the remaining adrenal. Prednisolone levels may be helpful, and are now carried out by tandem mass spectrometry at Charing Cross.

\section{BILATERAL ADRENALECTOMY}

- Glucocorticoid replacement as above (steps 1-5).

- Start fludrocortisone $50 \mathrm{mcg}$ from day one post-op

These patients require life long glucocorticoid and mineralocorticoid replacement. Doses can be adjusted in the endocrine clinic as required.

\section{IMPORTANT ISSUES FOR PATIENTS NEWLY COMMENCED ON STEROIDS}

- They should be given a steroid card (available at http://www.imperialendo.com/for-doctors/toolkitfor-doctors/steroid-card) and understand 'sick day rules' for hydrocortisone replacement (http://www.imperialendo.com/for-doctors/hydrocortisone-replacement/hydrocortisonereplacement-patient-information). Contact Endocrine Nurse Specialist Debbie Peters (debbie.peters@imperial.nhs.uk) to request a Nurse Specialist clinic appointment in which steroid education will be covered in further detail.

- They need a Medic Alert badge/bracelet: contact details should be given. Bracelet is free if on benefits ( $£ 30$ otherwise). Full address in index.

- Ensure the patient has OPD follow up appointments with Endocrinology and Endocrine Surgery (Mr Palazzo).

\section{VERSION HISTORY}

Fausto Palazzo 03/15; Amir Sam 02/16 


\section{CUSHING'S SYNDROME (CS) IN BILATERAL ADRENAL DISEASE}

Bilateral nodules are seen in $10 \%$ of adrenal CS $(<2 \%$ of all CS) and include:

- Primary pigmented nodular adrenal disease (PPNAD)

- Bilateral macronodular adrenal hyperplasia (BMAH)

- Bilateral adenomas or carcinomas

Note: $10 \%$ of incidentally discovered adrenal lesions are bilateral.

\section{PRIMARY PIGMENTED NODULAR ADRENAL DISEASE (PPNAD)}

Consider PPNAD:

- Confirmed CS and suppressed plasma ACTH

- Young age (<30 years)

- Family history (66\% of patients)

- Spotty pigmentation (in patients with associated Carney complex)

- CT/MRI: adrenal size usually not enlarged, nodules $<1 \mathrm{~cm}$

\section{INVESTIGATIONS}

- $2 \times 24$-hour urine free cortisol at baseline (days $0 \& 1$ ), and on day 6 after sequential LDDST (0.5 mg every 6 hours for 48 hours) followed by HDDST (2mg every 6 hours for 48 hours). A paradoxical rise $(50 \%)$ is seen in approximately $70 \%$ of patients.

- Refer for genetic testing for PRKAR1A, PDE11A, PDE8B, MYH8.

- Screen for other tumours in patients with suspected Carney complex.

\section{TREATMENT}

Bilateral adrenalectomy is recommended.

\section{VERSION HISTORY}

Amir Sam and Julian Waung 09/15 


\section{BILATERAL MACRONODULAR ADRENAL HYPERPLASIA (BMAH)}

Hypercortisolism is secondary to activation of aberrant G-protein coupled receptors, which stimulate local adrenal ACTH production. Identification of aberrant hormone receptors may allow targeted pharmacological therapy as an alternative to adrenalectomy e.g. beta-blockers for patients with BMAH and aberrant beta-adrenergic receptors.

Consider BMAH in patients with:

- Confirmed CS and suppressed ACTH

- Age: $40-60$

- $\mathrm{CT} / \mathrm{MRI}$ : bilateral adrenal enlargement, multiple nodules $>1 \mathrm{~cm}$

\section{PREPARATION}

Stop medications that may interfere with testing for at least 1 week.

\section{METHOD}

- Admit the patient on Monday afternoon, insert cannula and take midnight cortisol (day 1)

- Dexamethasone $0.5 \mathrm{mg}$ every 6 hours for 48 hours (days $2 \& 3$ ) to suppress pituitary ACTH (last dose is at 0300 on the morning of day 4).

- Patient must be fasted overnight before prescribed meals on days 4 and 5 .

- Patient must be supine for at least 1 hour on mornings of days 4 and 5 .

- $\quad \mathbf{X}$ in the table below indicates times of blood sampling for cortisol and recording of pulse and blood pressure.

\begin{tabular}{|c|c|c|c|c|}
\hline $\begin{array}{l}\text { Time } \\
(\min )\end{array}$ & Day 4 & $\begin{array}{l}\text { Pulse } \\
\& \text { BP }\end{array}$ & Day 5 & $\begin{array}{l}\text { Pulse } \\
\& \text { BP }\end{array}$ \\
\hline-15 & $\mathrm{X}$, plus ACTH sample & & $x$ & \\
\hline 0 & $\begin{array}{l}X, \text { patient stands after sample \& } \\
\text { remains ambulatory }\end{array}$ & & $\begin{array}{l}\text { X, GnRH (100 microgram IV) after } \\
\text { sample }\end{array}$ & \\
\hline+30 & X (Upright) & & $x$ & \\
\hline+60 & X (Upright) & & $\mathrm{x}$ & \\
\hline+90 & $\mathrm{X}$ (Upright) & & $\mathrm{x}$ & \\
\hline+120 & X (Upright), patient supine after sample & & X, Breakfast & \\
\hline+150 & $x$ & & X, Synacthen (250 micrograms IV) & \\
\hline+180 & X, Mixed meal (Ensure Plus, $220 \mathrm{ml}$ ) & & $x$ & \\
\hline+210 & $\mathrm{x}$ & & $x$ & \\
\hline+240 & $\mathrm{X}$ & & $\mathrm{X}$ & \\
\hline+270 & $x$ & & X, Lunch & \\
\hline+300 & $X$ & & & \\
\hline
\end{tabular}




\section{INTERPRETATION}

- Partial response: increase in cortisol of $25-49 \%$ from baseline.

- Positive response: increase in cortisol of $\geq 50 \%$ from baseline.

\section{TREATMENT}

- Trial of beta-blockers (propranolol) for patients with BMAH and suspected aberrant betaadrenergic receptors.

- $\mathrm{GnRH}$ agonists (and sex steroid replacement) for patients with BMAH and suspected $\mathrm{LH} / \mathrm{hCG}$ receptors.

- In patients with no identified aberrant hormone receptors or no specific pharmacologic treatment:

- Bilateral adrenalectomy when UFC $>2 \times$ ULN.

- Unilateral adrenalectomy may be considered when UFC $<2 \times$ ULN.

- BMAH may be familial and up to $50 \%$ of apparent sporadic cases carry a germline mutation of armadillo repeat containing 5 gene (ARMC5). Biochemical screening of first-degree relatives over age 25 years using $1 \mathrm{mg}$ overnight dexamethasone suppression test is recommended.

\section{REFERENCES}

1. Lacroix A. Best Pract Res Clin Endocrinol Metab, 2009. 23(2): p. 245-59.

2. Mircescu H et al. J Clin Endocrinol Metab, 2000. 85(10): p. 3531-6.

3. Lacroix A et al. Cushing's syndrome due to primary bilateral macronodular adrenal hyperplasia. UpToDate. Topic 148 Version 11.0. Accessed 31 ${ }^{\text {st }}$ May 2015.

\section{VERSION HISTORY}

Amir Sam and Julian Waung 09/15 


\section{HYPERALDOSTERONISM}

\section{PLASMA ALDOSTERONE AND PLASMA RENIN ACTIVITY}

\section{INDICATIONS}

1. Accelerated hypertension.

2. Drug resistant hypertension.

3. Hypertension and adrenal incidentaloma.

4. Hypertension with hypokalaemia, spontaneous or easily provoked, i.e. by diuretics or sodium loading - consider if plasma potassium is $<3.6 \mathrm{mmol} / \mathrm{L}$. As the treatment of hyperaldosteronism is far more effective in correcting hypokalaemia rather than the hypertension extensive investigation in normokalaemic patients is not justified.

5. Family history or young age $<40$ years.

\section{CONTRAINDICATIONS.}

None

\section{SIDE EFFECTS}

None

\section{FIRST LINE INVESTIGATION OF PRIMARY HYPERALDOSTERONISM (CASE DETECTION):}

It is important to remember that normokalaemic hypertension constitutes the most common presentation of this disease. Therefore, hypokalaemia alone has a low positive predictive value for primary hyperaldosteronism.

\section{RANDOM PLASMA ALDOSTERONE/RENIN RATIO}

Outpatient procedure.

Stop beta blockers for 2 weeks prior to the sample (as beta blockers prevent renin release) and stop mineralocorticoid receptor antagonists (spironolactone, eplenerone) 6 weeks before sample. Calcium channel antagonists and doxazosin may be used in the interim to control BP.

Other drugs need not be stopped unless further investigations are required (see below) although stopping other drugs will give a clearer result.

Supply details of all therapy on request form.

Ensure adequate salt intake - NOT loading.

Correct severe hypokalaemia $(<3.0 \mathrm{mmol} / \mathrm{L})$ first, as a low potassium directly will reduce aldosterone secretion. 


\section{METHOD}

1. Sit patient quietly for at least 10 minutes.

2. 1 X EDTA sample (purple top vacutainer).

3. Send urgently to lab (within half an hour) - NO ice: Ice will cause cryoactivation (conversion of pro-renin into renin), resulting in an artifically high apparent renin activity.

\section{ANALYSIS}

Carried out on 12th Floor, Charing Cross Hospital.

Contact: Mrs Sophie Barnes or Mr Mike Scanlon: Ext 15181 or 15183 for advice.

If clinical details and list of medications are provided then full interpretation of results will be provided.

\section{INTERPRETATION OF RESULTS}

Aldosterone/renin ratio

$\begin{array}{ll}>1700 & \text { Conn's likely if renin }<0.3 \mathrm{pmol} / \mathrm{mL} / \mathrm{h} \\ -850-1700 & \text { Possibly Conn's, investigate further } \\ <680 & \text { Conn's unlikely }\end{array}$

For diagnosis of Conn's: low renin expected

Plasma renin $\leq 0.3 \mathrm{pmol} / \mathrm{ml} / \mathrm{hr}$ (ref. 0.5-3.1)

Aldosterone usually $>275 \mathrm{pmol} / \mathrm{L}$ (ref. 90-700) ie. may be normal or high

Please note: all reference ranges are method specific. These ranges apply to methods currently in use at Imperial College Healthcare NHS Trust.

\section{SECOND LINE INVESTIGATION: CONFIRMATION OF PRIMARY HYPERALDOSTERONISM}

\section{SALINE INFUSION TEST PREPARATION}

- Stop mineralocorticoid receptor antagonists (spironolactone and epelerone) for 6 weeks before the test.

- Stop beta blockers, calcium channel antagonists, ACE inhibitors and AT2 blockers for 2 weeks before the test.

- Can continue to use alpha blockers to manage hypertension e.g. doxazosin.

- Ensure plasma $\mathrm{K}$ in normal range (ideally $>4 \mathrm{mmol} / \mathrm{L}$ ) prior to performing test.

- Examine patient for signs of cardiac failure. This test should not be performed in patients with severe uncontrolled hypertension, renal insufficiency, cardiac insufficiency, cardiac arrhythmia, or severe hypokalemia. 


\section{METHOD}

1. Cannulate and take blood for plasma aldosterone, plasma renin activity, $U$ \& Es.

2. Patient should be in the seated position for at least 30 mins before infusion begins

3. Infuse 2 litres of $0.9 \%$ saline over 4 hours, starting at 9.00 a.m.

4. Blood pressure, oxygen saturation and heart rate are monitored throughout the test.

5. After 4 hours (i.e. $13: 00 \mathrm{pm}$ ), take further blood sample for aldosterone, $U$ \& Es (i.v. saline infusion can promote hypokalaemia).

\section{INTERPRETATION}

Principle of test is that the lack of suppression of aldosterone excretion with intravascular expansion indicates primary hyperaldosteronism.

Post-infusion plasma aldosterone

$<120 \mathrm{pmol} / \mathrm{L}$ make the diagnosis of primary hyperadosteronism unlikely $>240 \mathrm{pmol} /$ Lvery probable sign of primary hyperaldosteronism

Values between $120-240 \mathrm{pmol} / \mathrm{Lare}$ indeterminate

\section{REFERENCES:}

Rossi et al (2007) Journal of Hypertension 25:1433

Funder et al (2009) J Clin Endocrinol Metab 93:3266

\section{VERSION HISTORY}

Ben Jones 11/13, updated Sophie Barnes 05/15

\section{ADRENAL VENOUS SAMPLING FOR ALDOSTERONE}

\section{INDICATION}

Once primary hyperaldosteronism has been confirmed biochemically, this procedure allows distinction between unilateral and bilateral disease.

\section{CONTRAINDICATIONS}

- The patient is aged < 40 years with marked primary hyperaldosteronism, and has a clear unilateral adrenal adenoma and a normal contralateral adrenal gland on imaging.

- The patient carries unacceptably high risks for adrenal surgery or does not wish to have surgery.

- The patient is suspected of having an adrenocortical carcinoma, based on size or FDG PET uptake.

- The patient has proven glucocorticoid remediable hyperaldosteronism (Familial Hyperaldosteronism Type I) or has FH Type III (KCNJ5 mutations). 
Discuss with radiologist at Adrenal MDT if any of the following factors exist: Bleeding tendency (including intercurrent treatment with warfarin and other anticoagulants), Accelerated hypertension, Allergy to contrast, Significant ischaemic heart disease.

\section{SIDE EFFECTS}

Bleeding.

Adrenal infarction rarely.

\section{PREPARATION}

- Remember liquorice ingestion and carbenoxolone may mimic hyper-aldosteronism.

- Discontinuation of Clopidogrel for 5-7 days is generally recommended, although AVS can be done on this medication if discontinuation is not possible.

- Patients can remain on aspirin.

- Discontinue mineralocorticoid receptor antagonists. Spironolactone and amiloride can cause de-suppression of renin, leading to aldosterone secretion from the contralateral adrenal gland. Spironolactone/Eplerenone discontinue 6 weeks prior to procedure.

Amiloride discontinue at least 4 weeks prior to procedure.

\section{WHAT DRUGS CAN BE USED TO CONTROL BP?}

If possible, the BP should be controlled with the following classes of antihypertensives alone, as they negligibly affect renin production.

- Peripherally acting alpha blockers (prazosin, doxazosin, terazosin)

- Long acting calcium channel antagonists (nifedipine LA, amlodipine, verapamil, diltiazem)

Other antihypertensives with the potential to affect renin secretion should be stopped for the following periods of time:

- ACE inhibitors: 2 weeks

- Angiotensin II receptor inhibitors: 2 weeks

- Diuretics (except spironolactone or amiloride): 1 week

- Beta-blockers: 1 week

If there is difficulty in controlling the BP to acceptable levels, ACE inhibitors, angiotensin II receptor inhibitors, diuretics and beta-blockers can be used as long as the renin activity remains suppressed, although interpretation may be guarded if the AVS results do not support lateralisation.

\section{ENSURE THAT THE PATIENT IS EUKALAEMIC}

Sando-K tablets should be prescribed and potassium levels checked (see below). 


\section{THE DAY BEFORE THE PROCEDURE}

- $\quad$ Check FBC, U \& Es, INR, $G+S$.

- Consent (risks of bleeding from sheath sites, venous thrombosis - done by radiology).

- Fast overnight.

- Prepare 6 plain tubes (red top Vacutainers).

- Arrangements for immediate transfer of samples to laboratory.

\section{METHOD}

1. Catheter inserted via femoral vein and adrenal veins selectively cannulated under X-ray control.

2. Samples are taken for aldosterone and cortisol from left adrenal vein, right adrenal vein and lower IVC, below level of the renal veins.

3. Some centres use bolus of tetracosactrin $250 \mathrm{mcg}$ (Synacthen) 20 minutes prior to sampling in which case interpretation cut-offs are different, see below.

\section{INTERPRETATION:}

- Cortisol is measured to check catheterization of the adrenal vein.

- Aldosterone/cortisol ratios (ACR) are calculated to correct for variable dilution between samples.

- AVS is interpretable only with successful cannulation of the adrenal veins. To confirm correct catheter placement the cortisol values in each adrenal vein should be at least two times greater than that in the lower IVC (without tetracosactrin stimulation).

Endocrine Society guidelines suggest unilateral disease is demonstrated where the ACR of the dominant adrenal vein is greater than two times the ACR of the contralateral adrenal vein. This may be termed the lateralisation index (LI), i.e., $A C R_{\text {dominant }} / A C R_{\text {contralateral }}$ and if $>2.0$ suggests unilateral disease.

Additionally in our own centre we are more confident in identifying unilateral disease when there is suppression of the contralateral adrenal vein ACR to below half of that of the IVC. This may be

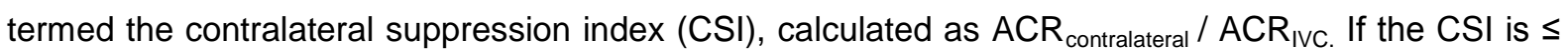
0.5 it is strongly supportive of unilateral disease.

(Note Endocrine Society guidelines are less strict suggesting a contralateral suppression index $<1$ is sufficient as long as $A C R_{\text {dominant }} / A_{C C R_{I V C}}$ is > 2.5.) 


\section{SENSITIVITY and SPECIFICITY}

While published guidelines agree on principles of lateralization and contralateral suppression in interpretation of AVS results, there is little consensus on where the optimal cut-offs should be. A lateralization index (LI) of $>2.0$ for unilateral disease is suggested in Endocrine Society guidelines first published in 2008 and is further supported in a consensus statement in 2014. The original study cited suggested optimal $\mathrm{LI}$ of $>2.0$, reporting over $80 \%$ success in identifying the aetiology of primary hyperaldosteronism (see reference Rossi et al., 2001).

The concept of contralateral suppression is described in principle in the same Endocrine Society guidelines whereby the ACR for the contralateral adrenal should suppress to less than that of the IVC, but there are few published data to support an optimal cut-off. Our own retrospective analysis using a cut-off of $\leq 0.5$ for CSI was $95 \%$ sensitive in identifying unilateral disease with specificity of $100 \%$. This is with our method without tetracosactrin stimulation and without sequential sampling of the adrenal veins and lower IVC.

Note if using tetracosactrin stimulation then cut-offs are suggested as follows: For catheter placement investigators use at least 3:1 ratio for cortisol concentration in the adrenal vein relative to peripheral sample.

Unilateral disease may be diagnosed using an LI cut-off $>4.0$ (Rossi et al 2014). One study has suggested CSI $<1.4$ as $90 \%$ sensitive and $94 \%$ specific for unilateral disease, with tetracosactrin stimulation (see reference Kline et al., 2015).

\section{EXAMPLE 1}

\begin{tabular}{|c|c|c|c|}
\hline & Aldosterone pmol/L & Cortisol nmol/L & ACR \\
\hline Right Adrenal Vein & 870 & 2432 & 0.36 \\
\hline Left Adrenal Vein & 33000 & 1013 & 32.6 \\
\hline IVC & 603 & 253 & 2.38 \\
\hline
\end{tabular}

Ratios of cortisol (adrenal vein to IVC) show both adrenal veins successfully cannulated. In this case $\mathrm{LI}$ is $32.6 / 0.36=90.6$ (this is $>2.0$ ). The contralateral suppression index $=0.36 / 2.38=0.15$ (which is $\leq 0.5$ ).

Results therefore supportive of unilateral disease. 
EXAMPLE 2

\begin{tabular}{|c|c|c|c|}
\hline & Aldosterone $\mathbf{~ p m o l / L}$ & Cortisol nmol/L & ACR \\
\hline Right adrenal vein & 4900 & 1695 & 2.9 \\
\hline Left adrenal vein & 6500 & 410 & 15.9 \\
\hline IVC & 300 & 93 & 3.2 \\
\hline
\end{tabular}

Ratios of cortisol (adrenal vein to IVC) show both adrenal veins successfully cannulated.

$\mathrm{LI}$ is 15.9/2.9 $=5.5$ (>2.0 therefore on this criterion alone supportive of unilateral disease.

HOWEVER, contralateral suppression index is 2.9/3.2 $=0.91$ (this in not $\leq 0.5$ ). Therefore on the basis of incomplete contralateral suppression we would classify this as most likely bilateral disease.

\section{REFERENCES:}

Funder et al., (2008) J Clin Endocrinol Metab 93:3266

Rossi et al., (2014) Hypertension 63:151

Rossi et al., (2001) J Clin Endocrinol Metab 86:1083

Gordon (2001) In: Zanchetti A, ed. Clinical medicine series on hypertension. Maidenhead, UK: McGraw-Hill International; 101-111

Graham et al., (2012) Clin Endocrinol (Oxf) 76:26

Kline et al., (2015) Clin Endocrinol (Oxf) 83:20

\section{VERSION HISTORY}

Updated Matthew Allum, Tricia Tan James Jackson and Sophie Barnes 03/15 


\section{SELENIUM CHOLESTEROL SCANNING FOR CONN'S TUMOURS}

\section{INDICATIONS}

We are no longer performing this but details are given below for historical interest.

\section{CONTRAINDICATIONS}

Caution if diabetic.

\section{METHOD}

1. Admit. Start dexamethasone $2 \mathrm{mg}$ daily at Day -2 , i.e. two days before the injection. Monitor blood glucoses qds. Continue dexamethasone to Day +11 .

2. On day 0 , nuclear medicine will inject $8 \mathrm{MBq}$ of 75 Se Scintadren and image.

3. Start $5 \mathrm{mg}$ bisacodyl for 2 days.

4. Discharge home once dexamethasone completed.

5. Nuclear medicine will arrange for further images on Day 4,7 and 11 .

6. A cortisol on any morning should be undetectable if the dexamethasone the previous day is suppressing the HPA axis adequately, and may be useful to check compliance. Without adequate dexamethasone suppression, one can wrongly diagnose bilateral adrenal hyperplasia, which is simply an indication of normal cortisol production. Remember that cortisol secretion rates are 1000 times higher than aldosterone secretion rates, so even a single missed dose of dexamethsone can jeapordise the results.

\section{INTERPRETATION}

The images will be reported by nuclear medicine, but a Conn's tumour should take up label with no uptake on the contralateral side. Bilateral uptake suggests bilateral adrenal hyperplasia. 


\section{PHAEOCHROMOCYTOMAS AND PARAGANGLIOMAS PLASMA/URINE METANEPHRINE MEASUREMENT}

\section{INDICATION}

To diagnose excess secretion of catecholamines in patients with possible secondary hypertension or in patients with paroxysmal sweating, headaches, anxiety and hypertension.

The initial biochemical testing for Phaeochromocytomas and Paragangliomas should include measurement of plasma free metanephrines or urinary fractionated metanephrines. Measurements of metanephrines in plasma or urine using liquid chromatography with spectrometric or electrochemical detection methods provides the highest diagnostic sensitivities for detection of phaeochromocytomas and paragangliomas.

\section{CONTRAINDICATIONS}

No absolute contraindications.

\section{SIDE EFFECTS}

None.

\section{PREPARATION}

Before testing, ensure that patients are not taking any medications that could cause false positive elevations in metanephrine levels (see table below).

Urine can be collected in the same bottles with acid preservatives as catecholamines. The 24-hour urine collection should include measurement of urinary creatinine to ensure a complete collection. The blood sample is collected in an EDTA (purple) tube (not lithium heparin tubes as with catecholamines). 
MAJOR MEDICATIONS THAT MAY CAUSE FALSELY ELEVATED TEST RESULTS FOR

PLASMA AND URINARY METANEPHRINES (from Lenders et al. JCEM 2014)

\begin{tabular}{|l|l|l|l|l|}
\hline & Plasma & & Urine & \\
\hline & NMN & MN & NMN & MN \\
\hline Acetaminophen $^{\mathrm{a}}$ & ++ & - & ++ & - \\
\hline Labetalol $^{\mathrm{a}}$ & - & - & ++ & ++ \\
\hline Sotalola $^{\mathrm{a}}$ & - & - & ++ & ++ \\
\hline alpha-Methyldopa $^{\mathrm{a}}$ & ++ & - & ++ & - \\
\hline TCAs $^{\mathrm{b}}$ & ++ & - & ++ & - \\
\hline Buspirone $^{\mathrm{a}}$ & - & ++ & - & ++ \\
\hline Phenoxybenzamine $^{\mathrm{b}}$ & ++ & - & ++ & - \\
\hline MOA-inhibitors $^{\mathrm{b}}$ & ++ & ++ & ++ & ++ \\
\hline Sympathomimetics $^{\mathrm{b}}$ & + & + & + & + \\
\hline Cocaine $^{\mathrm{b}}$ & ++ & + & ++ & + \\
\hline Sulphasalazine $^{\mathrm{a}}$ & ++ & - & ++ & - \\
\hline Levodopa $^{\mathrm{c}}$ & + & + & ++ & + \\
\hline
\end{tabular}

Abbreviations: TCAs, tryciclic antidepressants; MAO, monoamine oxidase; MN, metanephrine; NMN, normetanephrine;

++ , clear increase; +, mild increase; -, no increase.

${ }^{a}$ Analytical interference for some but not all methods employing LC-ECD

${ }^{b}$ Pharmacodynamic interference leading to increased levels affecting all analytical methods

${ }^{c}$ Analytical interference with some LC-ECD assays, and also pharmacodynamic interference increase the dopamine metabolite 3-methoxytyramine affecting all analytical methods 


\section{INTERPRETATION}

Metanephrines are the products of COMT (catecholamine O-metheyltransferase) metabolism of adrenaline (producing metanephrine) and noradrenaline (producing normetanephrine) within adrenal chromaffin cells or tumours derived from these cells. Phaeochromocytomas and paragangliomas frequently over-express COMT. Sympathetic nerves, the major site of initial norepinephrine metabolism lack COMT, making O-methylated metabolites specific markers of chromaffin tumours. For measurement of the dopamine metabolite 3-methoxytyramine, sampling should be carried out following an overnight fast.

Importantly, metanephrines are being produced in a continous manner within tumours. This process is independent of catecholamine release, which can be episodic or can occur at low rates in certain tumours.

REFERENCE RANGES FOR PLASMA METANEPHRINES in seated position (Newcastle Upon Tyne, Freeman Hospital)

\begin{tabular}{|l|l|}
\hline Normetanephrine & $120-1180 \mathrm{pmol} / \mathrm{L}$ \\
\hline Metanephrine & $80-510 \mathrm{pmol} / \mathrm{L}$ \\
\hline 3-Methoxytyramine & $<180 \mathrm{pmol} / \mathrm{L}$ \\
\hline
\end{tabular}

\section{REFERENCE RANGES FOR URINARY METANEPHRINES (ICHNT)}

\begin{tabular}{|l|l|}
\hline Normetadrenaline & $<3.14 \mu \mathrm{mol} / 24 \mathrm{hrs}$ \\
\hline Metadrenaline & $<1.02 \mu \mathrm{mol} / 24 \mathrm{hrs}$ \\
\hline Total urine metanephrines & $<4.16 \mu \mathrm{mol} / 24 \mathrm{hrs}$ \\
\hline
\end{tabular}

\section{SENSITIVITY AND SPECIFICITY}

Urine metanephrines have a sensitivity of $86-97 \%$ and specificity of $69-95 \%$.

Plasma metanephrines have a sensitivity of $90-100 \%$ and specificity of $79-98 \%$

\section{REFERENCES}

Lenders et al., (2014) JCEM 99: 1915

Boyle et al., (2007) JCEM 92:4602

D'Herbomez et al., (2007) EJE 156:569

Eisenhofer et al., (2003) JCEM 88:2656

Willemsen et al., (2006) Clin Chem 53:268

deJong et al., (2009) JCEM 94:2841 


\section{VERSION HISTORY}

Tricia Tan 5/08, Updated Ben Jones and Chioma Izzi-Engbeaya 11/13, Alexander Comninos and Tricia Tan 09/15, Florian Wernig 11/15 


\section{URINE/PLASMA CATECHOLAMINE MEASUREMENT}

\section{INDICATION}

To diagnose excess secretion of catecholamines in patients with possible secondary hypertension or in patients with paroxysmal sweating, headaches, anxiety and hypertension.

\section{CONTRAINDICATIONS}

No absolute contraindications.

\section{SIDE EFFECTS}

None.

\section{PREPARATION}

Certain drugs can cause elevations of catecholamines: catecholamine infusions, SSRIs and SNRIs, cocaine. Certain drugs can interfere with urine catecholamine measurements: e.g. labetalol elutes close to adrenaline on HPLC. Labetalol, however, does not interfere with plasma catecholamines. Please look at table for further examples.

MEDICATIONS THAT INCREASE URINE CATECHOLAMINE MEASUREMENTS

\begin{tabular}{|l|l|l|l|l|}
\hline Alpha-blockers & Aminophylline & Amphetamine & Benzodiazepines & Buspirone \\
\hline Beta-blockers & Caffeine & $\begin{array}{l}\text { Catecholamines eg } \\
\text { decongestants }\end{array}$ & Chlorpromazine & Diazoxide \\
\hline Domperidone & Ethanol & Glyceryltrinitrate & Hydralazine & Levodopa \\
\hline $\begin{array}{l}\text { Labetalol (does not } \\
\text { interfere with plasma } \\
\text { catecholamine } \\
\text { measurement) }\end{array}$ & Lithium & Metaclopromide & Methyldopa & $\begin{array}{l}\text { Nicotinic acid / } \\
\text { Nicotine }\end{array}$ \\
\hline $\begin{array}{l}\text { Nitroglycerin } \\
\text { Sodium }\end{array}$ & Sotalol & Theophylline & $\begin{array}{l}\text { Tricyclic } \\
\text { antidepressants }\end{array}$ \\
\hline
\end{tabular}


MEDICATIONS THAT DECREASE URINE CATECHOLAMINE MEASUREMENTS

\begin{tabular}{|l|l|l|l|l|}
\hline Clonidine & Disulfiram & $\begin{array}{l}\text { Guanethidine + } \\
\text { adrenergic blockers }\end{array}$ & Imipramine & MAO inhibitors \\
\hline $\begin{array}{l}\text { Methylglucamine } \\
\text { (present in } \\
\text { radiocontrast) }\end{array}$ & Methyltyrosine & Phenothiazines & Reserpine & Salicylates \\
\hline
\end{tabular}

MEDICATIONS THAT HAVE VARIABLE EFFECTS ON URINE CATECHOLAMINE MEASUREMENTS

\begin{tabular}{|l|l|l|l|l|}
\hline Levodopa & $\begin{array}{l}\text { Tricyclic } \\
\text { antidepressents }\end{array}$ & $\begin{array}{l}\text { Calcium channel } \\
\text { blockers }\end{array}$ & ACE inhibitors & Bromocriptine \\
\hline
\end{tabular}

PATIENTS SHOULD AVOID THE FOLLOWING FOR 3 DAYS BEFORE THE TEST AND WHILST COLLECTING THE URINE SAMPLE

\begin{tabular}{|l|l|l|l|l|}
\hline Coffee & Tea & Bananas & Chocolate & Cocoa \\
\hline Citrus fruit & Vanilla & Coke & Pineapple & \\
\hline
\end{tabular}

The patient should be given urine bottles with acid preservative as catecholamines deteriorate without this. They should also be given a disposable jug to urinate into and instructions to collect (http://www.imperialendo.com/for-doctors/toolkit-for-doctors/urine-collections-24hr-hormone-tests). At least two 24 hour urine collections should be performed.

Blood for plasma catecholamine measurement needs to be taken into Lithium heparin, kept on ice, spun at $4^{\circ} \mathrm{C}$, frozen until assay. Note - plasma catecholamines are stable for $\sim 1$ month at $-20^{\circ} \mathrm{C}$ and $\sim 1$ year at $-80^{\circ} \mathrm{C}$. 
INTERPRETATION

Reference ranges for urine catecholamines (ICHNT)

\begin{tabular}{|l|l|}
\hline Noradrenaline & $<0.690 \mu \mathrm{mol} / 24 \mathrm{hrs}$ \\
\hline Adrenaline & $<0.080 \mu \mathrm{mol} / 24 \mathrm{hrs}$ \\
\hline Dopamine & $<3.120 \mu \mathrm{mol} / 24 \mathrm{hrs}$ \\
\hline
\end{tabular}

Reference ranges for plasma catecholamines (St Helier)

\begin{tabular}{|l|l|l|}
\hline Noradrenaline $\mathbf{~ n m o l} / \mathbf{L}$ & Adrenaline $\mathbf{~ n m o l} / \mathbf{L}$ & Interpretation \\
\hline 5 & $<0.8$ & low probability \\
\hline $5-7.7$ & $0.8-1.2$ & medium probability \\
\hline$>7.7$ & $>1.2$ & high probability \\
\hline
\end{tabular}

\section{SENSITIVITY AND SPECIFICITY}

Urine catecholamines have a sensitivity of $85 \%$ and specificity of $86 \%$. Sensitivity can be improved by repeating the test (traditionally 3 times).

Plasma catecholamines have a sensitivity of $76-81 \%$ and specificity of $81-88 \%$ and their role in the diagnosis of phaeochromocytoma therefore remains limited.

\section{VERSION HISTORY}

Tricia Tan 8/08, Updated Ben Jones and Chioma Izzi-Engbeaya 11/13, Tricia Tan 08/14, Florian Wernig 11/15 


\section{CLONIDINE SUPPRESSION TEST}

\section{INDICATION}

To exclude the diagnosis of phaeochromocytoma in patients with hypertension and borderline raised catecholamines or catecholamine metabolites.

\section{CONTRAINDICATIONS}

Frail patient with a history of hypotensive episodes/ severe coronary/ carotid disease.

\section{SIDE EFFECTS}

Hypotension and sedation

\section{PREPARATION}

- Order the clonidine from pharmacy (readily obtainable).

- Stop sympatholytic medications (eg. beta blockers) for at least 48 hours before the test.

- Fast overnight.

- Quiet environment.

- Cancel test if baseline blood pressure is $<110 / 60 \mathrm{mmHg}$ or in volume-depleted patients.

- Sphyngomanometer or Critikon monitor.

- i.v. Cannula, 18-20g.

- Ice.

- EDTA (purple) tubes.

- Contact biochemistry laboratory before doing the test, enquire how they would like the samples taken and arrange for their delivery.

\section{METHOD}

1. Insert i.v. cannula.

2. Rest for $1 / 2$ hour in supine position.

3. Monitor BP and pulse at onset and every time blood taken.

4. Take 2 baseline samples at 5 minute intervals.

5. Give, at time zero, 300 micrograms $(3 \times 100 \mathrm{mcg}$ tablets $)$ clonidine hydrochloride orally.

6. Take blood for plasma metanephrines at 1,2, 3 hours. Blood needs to be taken into EDTA, kept on ice, spun at $4^{\circ} \mathrm{C}$, frozen until assay. 


\section{INTERPRETATION}

- Clonidine (alpha2-adrenoceptor agonist) acts via the alpha pre-ganglionic receptors to reduce catecholamine secretion in patients without phaechromocytoma or paraganglioma, but not in patients with autonomous tumoural secretion of catecholamines by a phaeochromocytoma or paraganglioma.

- An abnormal result indicative of a phaechromocytoma or paraganglioma consists of an elevation of plasma normetanephrine at 3 hours after clonidine administration and a less than $40 \%$ decrease in plasma normetanephrine levels compared with baseline

\section{SENSITIVITY AND SPECIFICITY (Eisenhofer, et al):}

${ }^{*}$ Elevated norepinephrine after clonidine AND lack of suppression ( $\left.>50 \%\right)$ :

Sensitivity $67 \%$, Specificity $98 \%$

Elevated normetanephrine after clonidine AND lack of suppression ( $>40 \%)$ :

Sensitivity $96 \%$, Specificity $100 \%$

Elevated normetanephrine after clonidine OR lack of suppression $(>40 \%)$ :

Sensitivity $96 \%$, Specificity $67 \%$

${ }^{*}$ No longer recommended for diagnosis

\section{REFERENCES}

Bravo et al., (1981) NEJM 305:623

Grossman et al., (1991) Hypertension 17:733

Eisenhofer et al. (2003) JCEM $88: 2856$

\section{VERSION HISTORY}

Stephen Gilbey 1/90; revised Tricia Tan 5/08. Florian Wernig 11/15 


\section{PENTOLINIUM SUPPRESSION TEST}

This test is nearly obsolete as it is difficult to obtain pentolinium.

\section{INDICATION}

1. To exclude the diagnosis of phaeochromocytoma in patients with hypertension and borderline changes in plasma catecholamines or 24 hour urinary catecholamines.

\section{CONTRAINDICATIONS}

No absolute contraindications but beware frail patient and patients with severe coronary or carotid vascular disease.

\section{SIDE EFFECTS}

May cause severe transient hypotension.

\section{PREPARATION}

- Order the Pentolinium from pharmacy allowing a week for pharmacy to order in (difficult to obtain). It comes as $10 \mathrm{mg}$ in $2 \mathrm{ml}$.

- Stop hypotensive treatment (incuding labetalol) for at least 24 hours before the test, especially centrally acting drugs such as methyldopa.

- Fast overnight. (Large meals can cause variation in catecholamines).

- Quiet environment.

- Sphygmomanometer or Critikon BP monitor.

- Cannula, 18-20g.

- Ice.

- Lithium heparin tubes (green top Vacutainer).

- Contact biochemistry laboratory before doing the test, enquire how they would like the samples taken and arrange for their delivery.

\section{METHOD}

1. Patient should empty bladder before lying down as they might not be allowed to stand for a while.

2. Insert cannula and flush.

3. Rest for $1 / 2$ hour.

4. Monitor BP and pulse at onset and every time blood taken.

6. Take 2 baseline samples at 5 minute intervals for catecholamines. Blood needs to be taken into Lithium heparin, kept on ice, spun at $4^{\circ} \mathrm{C}$, frozen until assay.

7. At time 0 , give $2.5 \mathrm{mg}$ Pentolinium i.v.

8. Take blood at one hour. 


\section{INTERPRETATION}

- Pentolinium is a sympathetic ganglion blocker. Normal subjects may show an initially elevated plasma adrenaline and noradrenaline but these will fall to within the normal plasma range with Pentolinium.

- In contrast the autonomous secretion of a phaeochromocytoma will not suppress.

\section{SENSITIVITY AND SPECIFICITY}

This test has a low false positive and false negative rate as determined in series of known phaeochromocytomas and normals but published information is very scanty. The most likely theoretical problem is a fall in plasma catecholamine levels in a phaeochromocytoma patient whose tumour is only secreting episodically.

\section{REFERENCES}

Brown et al., (1981) Lancet 1:174

\section{VERSION HISTORY}

Stephen Gilbey 1/90; revised Bernard Khoo, Karim Meeran, Rachel Batterham and Jeannie Todd $7 / 00$.

\section{${ }^{123}$ I- META-IODOBENZYLGUANIDINE (MIBG) SCAN}

\section{INDICATION}

The MIBG scan is a useful, qualitative, method of locating the site of a phaeochromocytoma.

It should not be undertaken without biochemical evidence for a tumour being present (urine or plasma catecholamines/metanephrines), and should be backed up by ultrasound, CT scanning, and, where indicated, venous sampling. It is particularly useful for extra-adrenal and metastatic or residual phaeochromocytoma.

\section{CONTRAINDICATIONS}

No absolute contraindications except pregnancy, allergy to iodine.

Caution in any patient with any drug allergies.

Many drugs may interfere with the study - nuclear scanning have a list. These include tricyclic antidepressants, SSRIs, calcium channel antagonists, catecholamine receptor agonists and antagonists, phenothiazines, butyrophenones (e.g. haloperidol etc.), guanethidine and reserpine.

\section{PREPARATION}

- Liase with nuclear medicine at least 1 week in advance of planned scan. 
- Avoid i.v. phenoxybenzamine (may lead to false negative result), although oral phenoxybenzamine is OK.

- Thyroid uptake should be blocked by potassium iodide $60 \mathrm{mg}$ bd for 48 hours beforehand and for 5 days afterwards.

\section{METHOD}

1. [123]I-MIBG is injected intravenously (this molecule is similar to noradrenaline, transported in similar fashion and stored in catecholamine vesicles).

2. The patient is scanned twice at 24 and 48 hours.

\section{INTERPRETATION}

- Spots of increased uptake on scanning are the tumours.

- Most common sites: adrenals, organ of Zuckerkandl (usually pelvis).

- Tumours can be anywhere from base of skull to bifurcation of aorta. Sometimes found near bladder and rarely in the prostate.

- May be multiple.

- If the MIBG is negative but there is compelling biochemical evidence of a catecholamine secreting tumour, consider [18]F-FDG or [68]Ga-DOTATATE PET scanning.

\section{SENSITIVITY AND SPECIFICITY}

In patients with a proven phaeochromocytoma but uncertain site the scan has $90-96 \%$ sensitivity and 98-99\% specificity. More recent data with a large series of patients shows that the sensitivity is only $75 \%$. Tumour detection was lower for extra-adrenal paragangliomas (58\%) versus adrenal (85\%) phaeochromocytomas.

\section{REFERENCES}

Sisson et al., (1981) New Engl J Med 305:12

Shapiro et al., (1985) Cardiology 72 suppl. 1:137

Win et al., (2007) Nuclear Medicine Communications 28:359

Bhatia et al., (2008) Clin Endo 69:181

\section{VERSION HISTORY}

Stephen Gilbey 11/89, revised Tricia Tan 05/08 


\section{GENETIC SCREENING FOR PHAEOCHROMOCYTOMAS}

\section{INDICATION}

At least $30 \%$ of patients with phaeochromocytoma/paraganglioma (PH/PGL) disease have a germline mutation in SDHB (10\%), SDHD (9\%), VHL (7\%), RET (6\%), and NF1 (3\%). Frequencies of less than $2 \%$ of germline mutations are found for SDHC, SDHA, MAX, and TMEM127. SDHB mutations lead to metastatic disease in $40 \%$ or more of affected patients.

The following clinical details are useful:

- Family history: especially with VHL, RET, NF1, SDHD. There is genomic imprinting of SDHD: the disease phenotype is only apparent in patients who have inherited the mutant allele from their father, as a rule (although there is one exception in the literature). Family history may not be apparent as most of the genes except NF1 (and possibly RET) are not fully penetrant. All disorders have the potential to be de novo, so the absence of family history does not reduce risks.

- Age at presentation: Hereditary catecholamine-producing tumours typically present at a younger age than sporadic neoplasms. Sporadic phaeochromocytomas are often diagnosed on the basis of symptoms or following incidental discovery on imaging, whereas hereditary phaeochromocytomas are frequently diagnosed earlier in the course of the disease because of biochemical screening/surveillance or genetic testing. This of course is only the case if the individual is known to have a predisposition.

- Bilateral and multifocal disease: bilateral PH disease is associated with c-Ret or VHL disease. Multifocal PGL disease is associated with SDHB and SDHD disease. Head and neck tumours are associated with SDHD disease.

- Malignancy: defined as metastases to non-chromaffin tissue (e.g. bone, lungs, liver, lymph nodes). This is particularly associated with SDH-B disease.

- Clinical features of neurofibromatosis: NF1 disease (autosomal dominant) is a clinical diagnosis based on the presence of multiple café-au-lait spots, neurofibromas, Lisch nodules (iris hamartomas), central nervous system gliomas, and axillary freckling. DNA analysis is not routinely required.

- Clinical features of VHL disease: CNS and retinal haemangioblastomas, renal cell carcinomas, pancreatic neuroendocrine tumours, endolymphatic sac tumours of the middle ear, serous cystadenomas of the pancrease, and papillary cystadenomas of the epididymis and broad ligament.

- Clinical features of MEN 2: Medullary thyroid carcinoma, parathyroid hyperplasia (2A), mucosal neuromas (2B), marfanoid phenotype (2B). 


\section{REFERRAL TO THE JOINT ENDOCRINE/GENETICS CLINIC}

Can be done directly for any patients (though patients who live far from Hammersmith should be given a choice to be seen more locally):

- Patients presenting with phaeochromocytoma $\leq 50$ years old.

- Patients with extra-adrenal PGL, metastatic disease or multiple tumours at any age.

- Patients with tumour at any age, with a personal or family history of similar, or of related tumours (eg MTC, haemangioblastoma, renal cell cancer)

- Relatives of an index patient with a known mutation, for cascade screening.

Genetic counselling and sampling will be handled by the clinic. It is not possible to offer primary genetic testing in the relative of an individual with $\mathrm{PH} / \mathrm{PGL}$ if that person is not themselves affected.

\section{METHODS}

If you want to arrange your own genetic testing rather than going through the Genetic clinic, Birmingham offer a panel of genes SDHB, SDHC, SDHD, SDHAF2, RET, TMEM127, MAX, VHL and $\mathrm{FH}$ for $£ 750$, with results in around 4 months of receipt of sample. Exeter and some other labs offer a similar panel for similar cost and turn-around-time. Single gene mutation analysis is not typically available any longer (except in the case of a known familial mutation). Samples should be sent to West Midlands Regional Genetics Laboratory, Birmingham Women's Hospital, Metchley Park Road, Edgbaston, Birmingham, B15 2TG. Tel: 01216272710 Fax: 01216272711.

Ensure that you have discussed with the patient the potential of making a diagnosis, which puts them and their children at risk of multiple tumours other than phaeochromocytoma, to guarantee fully informed consent.

SDHA is extremely difficult to analyse due to multiple pseudogenes, and is only offered on consultation with the lab, with very good evidence.

\section{REFERENCES}

Gimenez-Roqueplo et al., (2006) Clin Endocrinol (Oxf) 65:699

Pacak K et al., (2007) Nature Clin Pract Endocrinol Metab 3:92

Lenders et al., (2014) JCEM 99:1915

\section{VERSION HISTORY}

Revised Tricia Tan 5/08, Florian Wernig \& Natalie Canham 11/15 


\section{PERIOPERATIVE MANAGEMENT OF PHAEOCHROMOCYTOMAS}

\section{ALPHA BLOCKADE}

Phenoxybenzamine is a non-competitive, non-selective inhibitor with a relatively long duration of action. Inhibition of alpha-adrenergic receptors by phenoxybenzamine is not overcome by extra catecholamine release intra-operatively. Therefore, there is reduced risk of intra-operative hypertensive crisis. However, this irreversible binding can lead to increased risk of post-operative hypotension.

Doxazosin is a competitive, selective $\alpha-1$ receptor blocker with a relatively short duration of action. Due to its competitive nature, it can be overcome by extra catecholamine release intra-operatively with a potentially increased risk of hypertensive crisis. However, the shorter half-life makes it less likely to cause post-operative hypotension.

There is no conclusive evidence to favour the use of selective $\alpha-1$ adrenergic receptor blockers (e.g. doxazosin/prazosin) over non-selective $\alpha$ receptor blockers (e.g. phenoxybenzamine). A retrospective study of Mayo versus Cleveland experience showed that use of phenoxybenzamine is associated with less intra-operative hypertension and more post-operative hypotension. However, there was no difference in post-operative surgical outcomes or length of hospital stay. Other studies have found no differences in intra-operative or post-operative blood pressures.

\section{BETA BLOCKADE}

There is no evidence to support the preference of selective $\beta 1$ adrenergic receptor blockers over nonselective $\beta$ receptor blockers.

Beta-blockers must NOT be started before alpha blockade because of the risk of hypertensive crisis. This is due to $\alpha$-adrenergic receptor mediated vasoconstriction without the opposition of the $\beta 2$ adrenergic receptor mediated vasodilation.

\section{PRE-OPERATIVE MANAGEMENT}

Patients require pre-operative treatment for a minimum of 14 days to normalise blood pressure (BP) for elective surgery. Where surgery for whatever reason is urgent, one needs to balance the risk of shorter pre-op treatments with the benefits of earlier surgery. Phentolamine (see below) can be used for very rapid control of blood pressure, but be aware of the risks of sudden acute falls in blood pressure. Modern non-ionic IV contrast does not cause a significant increase in catecholamine levels, so blockade is usually not necessary for CT scanning.

- All patients should have an ECG and an echocardiogram (to evaluate for the presence of cardiomyopathy).

- Start Phenoxybenzamine $10 \mathrm{mg}$ once nocte. Increase every 3 days by $10-20 \mathrm{mg}$. 
Aim for:

Target BP: Sitting BP $<130 / 80$ and Standing Systolic BP $>90 \mathrm{mmHg}$.

Target HR: $60-80 \mathrm{bpm}$.

Aim for a final dose of phenoxybenzamine of $1.5 \mathrm{mg} / \mathrm{kg}$ per day prior to surgery.

Warn patients about postural dizziness, nasal stuffiness, fatigue and retrograde ejaculation in men.

- On the second day of alpha-adrenergic blockade, patients need to start a high sodium intake ( $>5 \mathrm{~g}$ daily) and adequate oral hydration ( $3 \mathrm{~L}$ per day) to reverse catecholamine-induced blood volume contraction and prevent hypotension. Caution in patients with heart or renal failure. Occasionally patients may require intravenous $0.9 \%$ saline if they continue to have postural hypotension.

- Start Propranolol $20 \mathrm{mg}$ tds, once heart rate $>80 \mathrm{bpm}$. This can be titrated up to $40 \mathrm{mg}$ tds. An alternative is to use Atenolol $(25-50 \mathrm{mg})$.

Warn patients about side effects including cold peripheries, fatigue and dizziness

- Calcium channel blockers (e.g. Amlodipine 5-10 mg od) may be added if BP is not controlled.

- Intravenous $0.9 \%$ saline (2-3 L over $24 \mathrm{hr}$ period) should be commenced on admission (2 days pre-operatively, hence if surgery is on Monday, this should start on Saturday). Caution in patients with heart or renal failure.

- Continue intravenous fluids post-operatively, as hypotension may result due to residual effects of pre-operative alpha blockade for 24 to 48 hours.

- Monitor BP, HR and capillary blood glucose (to detect rebound hypoglycaemia) for up to 48 hours post-operatively.

NB. Patients may remain hypertensive for a few days post-operatively.

- Lifelong biochemical follow-up is necessary. Measure 24-hour urine metanephrines at 6 weeks, 6 months and then annually thereafter.

\section{HYPERTENSIVE CRISIS}

In the event of a crisis, use intravenous phentolamine $(0.5-1 \mathrm{mg})$ boluses, which can be repeated until BP controlled. Note that phentolamine is supplied as $10 \mathrm{mg}$ per $\mathrm{ml}$, so very tiny volumes are required to bring down blood pressure. This works rapidly. If patients are not well filled, this can precipitate severe hypotension and a watershed cerebral infarction. Rehydration with crystalloids MUST therefore be started at the same time. 


\section{REFERENCES}

Kinney et al., (2002) J Cardiothorac Vasc Anesth 16:359

Kocak et al., (2002) Int Surg 87:191

Weingarten et al., (2010) Urology 76:508.e6-11

Fishbein et al., (2013) J Clin Hypertens 15:428

Lenders et al., (2014) J Clin Endocrinol Metab 99:1915

\section{VERSION HISTORY}

Amir Sam and Sarah Ali 06/15 


\section{THYROID}

\section{PROTOCOL FOR RADIO-IODINE TREATMENT}

A recent study carried out in our centre demonstrated that the likelihood of cure following radio-iodine treatment was $60 \%$ higher in hyperthyroid patients that received adjuvant lithium (Martin et al., (2012) Clin Endo 77:621). The protocol below includes lithium, however the use of lithium is not essential and the protocol can be followed with lithium omitted.

\begin{tabular}{|l|l|}
\hline Day -7 & $\begin{array}{l}\text { Thyroid function tests. Information session \& signing of consent form in } \\
\text { Department of Nuclear Medicine, Charing Cross Hospital. Send information } \\
\text { letter to patient's GP. Stop anti-thyroid medication. }\end{array}$ \\
\hline Day -3 & Start Lithium carbonate (Priadel) 800 mg nocte. \\
\hline Day $\mathbf{0}$ & Thyroid function tests. Lithium level. Radio-iodine treatment. \\
\hline Week +1 & Thyroid function tests. Lithium level. STOP lithium treatment. \\
\hline Week +3 & Thyroid function tests. Lithium level. \\
\hline Week +6 & Thyroid function tests. \\
\hline Week +9 & Thyroid function tests. \\
\hline Week $\mathbf{+ 1 2}$ & Thyroid function tests. \\
\hline Week $\mathbf{+ 1 4}$ & Outpatient clinic visit. \\
& \\
\hline
\end{tabular}

\section{WHAT DO YOU NEED TO GIVE THE PATIENT?}

1. Information sheet on Radio-iodine treatment available at http://www.imperialendo.com/for-patients/patent-information

2. Give the patient an appointment for list Meeran D5 Endo Radioiodine F/UP at Charing Cross. Everything else (below) is for information only, and will be carried out from that clinic.

3.

They will be given:

1. An X-Ray request form to Nuclear Medicine for I-131 Therapy.

2. Seven (7) request forms for TFTs (TSH, fT4, fT3 :Weeks $-1,0,+1,+3,+6,+9,+12$ as above).

4. 2 request forms for a lithium level (week 0 and +1 as above).

5. A prescription for lithium $800 \mathrm{mg}$ (specify Priadel) nocte for 10 days.

6. A prescription for thyroxine $100 \mu \mathrm{cg}$, NOT to be started until they are telephoned.

7. An appointment for the out-patient clinic, 14 weeks after treatment.

8. Make sure to note the patients' telephone number in the notes and on the X-Ray form. If they need to ring and enquire regarding results/treatment they should be given the switchboard number and bleep4998. 


\section{PROTOCOL FOR THE POST-RADIOIODINE TREATMENT TELEPHONE CLINIC}

\section{AIM:}

Our aim following radio-iodine treatment is to render patients euthyroid with hypothyroidism acceptable. The purpose of the telephone clinic is to rapidly determine when thyroxine replacement should be started, thus avoiding unnecessary outpatient appointments or leaving patients with untreated hypothyroidism, which has many undesirable effects, including possible worsening of thyroid eye disease. See http://radioiodine.info.

\section{WHO IS SUITABLE FOR TELEPHONE FOLLOW-UP?}

This service is only available to patients who;

- Are contactable by telephone during office hours (9am - 5pm).

- Speak reasonable English and are able to follow instructions regarding medications.

- Consent to regular blood tests, preferably at the hospital phlebotomy department.

\section{HOW DO I ARRANGE FOR RADIO-IODINE TREATMENT?}

If you think that a patient might be suitable for radioiodine they should be referred to $\mathrm{Dr}$ Zarni Win (Consultant Radiologist, Charing Cross Hospital) by cc-ing him a copy of your clinic letter or sending him an email (zarni.win@imperial.nhs.uk). This does not mean that the patient will have radioiodine but they should have an expert consultation to discuss this treatment option. In particular, radiation protection issues are not generalisable and should therefore be discussed with each patient on a case by case basis.

Anti-thyroid drugs should be stopped as soon as the decision to use radioiodine is made. Ideally they will be stopped for at least a week. If you know roughly when the patient wants radioiodine, further planning can be made. If it is clear that the patient will defer treatment for more than 2 months, then the antithyroid drugs should be continued until closer to the date of radioiodine. As a guide, the antithyroid drugs should be stopped at least 1 week and at most 2 months before radioiodine. Betablockers can be used to control symptoms.

If patient has active thyroid eye disease, see also section on thyroid eye disease for information on steroid cover for radioiodine treatment.

Give the patient an appointment for list Meeran D5 Endo Radioiodine F/UP at Charing CrossHospital as soon as possible. If you are at Hammersmith Hospital, you will need to give the patient an appointment on Meeran D5 Endo Radioiodine F/UP and also write on the frontsheet to actually book this on the Charing Cross system.

Send a referral letter (or fill in web form on http://meeran.info) to:

Radioiodine clinic (c/o Prof. Meeran),

c/o Dept of Endocrinology

$9^{\text {th }}$ Floor, East Wing, Charing Cross Hospital (Fax: 02033 111862). 
Make sure to include as many contact telephone numbers as possible in the letter.

\section{WHO WILL FOLLOW PATIENTS UP BY TELEPHONE?}

All computerised results are updated and reviewed on a weekly basis by a designated Doctor and patients telephoned if they become either biochemically hypo- or hyperthyroid following treatment.

\section{WHAT HAPPENS IF A PATIENT DEVELOPS SIGNIFICANT SYMPTOMS AFTER RADIOIODINE?}

If at any stage a patient becomes symptomatic or develops Grave's ophthalmopathy the Department of Endocrinology can be contacted by either the patient or the GP and arrangements made to review the patient urgently at the next outpatient clinic.

\section{WHEN WILL THYROXINE BE STARTED?}

Blood samples will be checked on the day of radioiodinel, and 1 week later for lithium levels. Thyroid function tests will also be monitored, but no action taken (as the fT4 may be lowered by the lithium). When the fT4 falls to $14.5 \mathrm{pmol} /$ Lor less, then thyroxine will be commenced by telephone. Samples will be collected at 3, 6, 9 and 12 weeks, and the patient attend clinic at about 14 weeks. If they are still toxic, further telephone appointments can be made at 15, 18 and 21 weeks.

If at review (after 12 weeks), the TSH is still not detectable, then this is either due to excess thyroxine, or due to failed radioiodine. A fT3 $>5$ pmol/Lsuggests autonomy, and the thyroxine should be discontinued. If the fT3 $<5.0 \mathrm{pmol} / \mathrm{L}$, then the dose of thyroxine can be slowly lowered with 3 weekly phone reviews. 


\section{INSTRUCTIONS FOR THOSE RUNNING THE TELEPHONE CLINIC}

Patients will be expecting phonecalls to tell them whether or not to start thyroxine.

First look on computer for results of fT3/fT4/TSH.

Ask the patient their weight in kilograms (or stone/lbs and convert).

Find out how they feel. Ask specifically about nausea. Check that they have been compliant with the lithium. How many tablets did they take? Which ones did they miss?

If the patient feels toxic (tremor, tachycardia etc), and the fT4 $>40 \mathrm{pmol} / \mathrm{L}$, then suggest propranolol e.g. 20-40 mg tds daily until next ( 3 weeks) review, as they might still rapidly become hypothyroid.

If $\mathrm{fT} 4<14.6 \mathrm{pmol} / \mathrm{L}$, then start thyroxine $100 \mathrm{mcg}$ daily. The patient should have a supply of these at home, and should be able to start these the day you make the phonecall.

After week 12, if TSH suppressed, then check fT3. If fT3 $>5 \mathrm{pmol} / \mathrm{L}$, then stop thyroxine. If fT3 < $5 \mathrm{pmol} / \mathrm{L}$, then reduce thyroxine slowly.

This page to be filled in with each phonecall in the thyroid clinic made and stored in the thyroid file.

Name:

Hospital Number:

Date of phone call:

Date of blood test:

Date of radioiodine $(\mathrm{RAl})$ :

Weeks since RAI:

Results: $\quad$ fT4

fT3

TSH

Lithium level checked (yes/no). Do NOT get result. 
Phone call:

Comments about how patient feels:

Weight of patient (at home).

How many lithium tablets did you take and how many did you forget? Which ones did you forget? (Get exact dates).

Do you smoke? How many per day?

What tablets are you CURRENTLY taking:

If fT4 $<14.6 \mathrm{pmol} / \mathrm{L}$, then start thyroxine $100 \mathrm{mcg}$ once daily. Advice given: start thyroxine or wait until further samples taken:

If fT4 > 30pmol/Land patient feels unwell (tremor, tachycardia etc), then consider propranolol.

After week 12, if TSH suppressed, then check fT3. If fT3 $>5 \mathrm{pmol} / \mathrm{L}$, then stop thyroxine. If $\mathrm{fT} 3<5$ $\mathrm{pmol} / \mathrm{L}$, then reduce thyroxine slowly. 


\section{THYROID EYE DISEASE AND RADIOIODINE}

Worsening of thyroid eye disease mainly occurs in smokers, and they have an approximately $25 \%$ risk of worsening opthalmopathy. In a large RCT, smokers had an increased risk of progression or de novo development of thyroid eye disease independently of the treatment modality for hyperthyroidism, but smokers treated with radio-iodine had the highest risk. Low doses of prednisolone $(0.2 \mathrm{mg} / \mathrm{kg}$ body weight), started 1 day after radio-iodine administration and continued for 6 weeks, were shown to be effective with very little side effects in a retrospective matched cohort study. It is preferable to avoid steroids in the majority, and treat the few who develop worsening eye signs with steroids at that stage.

There is thus no indication for the use of prophylactic steroids in non-smokers. If there is any doubt, all patients should be referred to Mrs Veronica Ferguson (Consultant Ophthalmologist at Charing Cross Hospital).

\section{REFERENCES}

Bartalena et al., (1998) Ann Int Med 129:632

(Traisk F,et al., (2009) J Clin Endocrinol Metab 94:3700

Lai et al., (2010) J Clin Endocrinol Metab 95:1333

\section{VERSION HISTORY}

Elaine Murphy 07/01, Karim Meeran 01/03, Florian Wernig and Chioma Izzi-Engbeaya 11/13, Saira Hameed 04/15

\section{PREPARATION OF THYROTOXIC PATIENTS FOR THYROIDECTOMY}

Patients will ideally be rendered euthyroid before surgery. In all cases, one must always balance the risks of delay against the benefit of being euthyroid pre-operatively. In an emergency, the following combination of drugs can be used to try and achieve this in approximately ten days:

1. Beta blockade. Propranolol $80 \mathrm{mg}$ tds is favoured historically. Atenolol $100 \mathrm{mg}$ or Nadolol $16 \mathrm{mg}$ can be administered only once daily and hence might improve compliance

2. Propylthiouracil (PTU) $250 \mathrm{mg}$ qds. This is a higher dose than used normally, but in emergency higher doses more frequently are required in view of the fact that the liver increases the metabolism of these drugs. The PTU should be administered an hour before any iodide treatment as the PTU will prevent organification of the administered iodine.

3. An excess of iodide or iodine ( $\mathrm{Kl} 60 \mathrm{mg}$ tds or $0.3 \mathrm{ml}$ Lugols iodine tds). Potassium iodide $60 \mathrm{mg}$ tds 
is by far the easiest to administer and is not foul tasting like Lugol's NEJM (1980) 302;883-885)

\section{STARTING THYROXINE POST-TOTAL OR COMPLETION THYROIDECTOMY}

After a total or completion thyroidectomy we commence thyroxine based on a weight-guided estimation. The typical dose is $1.5-2 \mathrm{mcg} / \mathrm{Kg}$. In the elderly we err towards $1.5 \mathrm{mcg} / \mathrm{Kg}$ to minimise the risk of atrial fibrillation.

\section{PROTOCOL FOR THE MANAGEMENT OF THYROID EYE DISEASE (TED)}

\section{REFER URGENTLY TO OPHTHALMOLOGY IF ANY OF THE FOLLOWING ARE PRESENT \\ Symptoms:}

- Unexplained deterioration in vision

- Awareness of change in intensity/quality of colour vision in one or both eyes

- History of eye(s) suddenly 'popping out' (globe subluxation)

Signs:

- Obvious corneal opacity

- Cornea still visible when eyelids are closed

- Optic disc swelling

\section{REFER NON-URGENTLY TO OPHTHALMOLOGY IF ANY OF THE FOLLOWING ARE PRESENT} Symptoms:

- Eyes abnormally sensitive to light (photophobia): troublesome or deteriorating over past 12 months

- Eyes excessively gritty and not improving after 1 week of topical lubricant

- Pain in or behind the eyes: troublesome or deteriorating over past 12 months

- Progressive change in appearance of the eyes and/or eyelids over the past 1-2 months

- Diplopia

Signs:

- Troublesome eyelid retraction

- Abnormal swelling or redness of eyelid(s) or conjunctiva

- Restriction of eye movements or manifest strabismus

- Tilting of the head to avoid double vision 


\section{CLINICAL ACTIVITY SCORE (CAS)}

Pain at rest-1

Pain on Extra Ocular Eye Movement-1

Redness of the conjunctiva-1

Redness of the eyelids- 1

Swelling of the caruncle-1

Swelling of the conjunctiva (chemosis)-1

Swelling of the eyelid (oedema)-1

$C A S$ of $\geq 3$ indicates active disease likely to warrant first line therapy

\section{SEVERITY GRADING}

Grade 1 - Ocular irritation

Grade 2 - Soft tissue swelling or proptosis

Grade 3 - Any restriction of Extra Ocular Movement

Grade 4 - Optic Neuropathy or Exposure Keratopathy

MANAGEMENT PROTOCOL (from EUGOGO) 


\section{GENERAL MANAGEMENT OF TED}

- Smoking cessation programme

- Restore euthyroidism

- Monitor thyroid status closely

- If thyroid eye disease is active radioiodine treatment should be accompanied by steroid cover which should be started on the day that radioiodine is administered:

- We advocate a prednisolone at a dose of $0.2 \mathrm{mg} / \mathrm{kg}$.

- Continue this same dose for 6 weeks and stop dead (ie no tapering)

- Inactive stable thyroid eye disease does not require steroid cover

- Avoid post radioiodine hypothyroidism

- Selenium supplementation

\section{MILD TED (GRADE I/II SEVERITY)}

- Symptoms

- Ocular irritation with signs of mild lid retraction and or proptosis $(<3 \mathrm{~mm})$.

- Mild activity where clinical activity score is below 3/7 including mild soft tissue swelling (intermittent diplopia, saccadic discord).

- If active, does not usually warrant systemic immunosuppression and can often be managed with improvememt of the ocular surface.

- Regarding choice of lubricant Clinitas, Hyloforte, Xailin HA are all appropriate.

- If you are stuck, simple carmellose (Celluvisc for example) will do. For night time paraffin based ointment such as Xailin Night or Lacrimal Lube are good.

\section{MODERATE TO SEVERE TED (GRADE III SEVERITY)}

- Clinical activity $>3 / 7$ :

- Proptosis $>3 \mathrm{~mm}$, soft tissue swelling (oedema or erythema of lids, conjunctival chemosis or injection and caruncular swelling), pain (at rest on or extraocular movements), diplopia (constant, inconstant).

- If active, warrants systemic immunosuppression (e.g. intravenous glucocorticoid - see below) when significant impact on activities of daily living.

- Inactive disease may warrant surgical rehabilitation (lid lowering, strabismus surgery or orbital decompression) 


\section{SIGHT THREATENING TED (GRADE IV)}

Optic neuropathy or corneal breakdown secondary to exposure keratopathy requires immediate intervention - medical or surgical decompression.

\section{MEDICAL MANAGEMENT}

The below is for information/guidance only.

All systemic immunosuppression must be guided by ophthalmology colleagues with a specialist interest in TED with support from rheumatology when appropriate.

Pulsed methylprednisolone $1 \mathrm{~g}$ i.v. daily for three consecutive days (usually on PIU) then continue either $250 \mathrm{mg}$ i.v. weekly or oral prednisolone $0.7-1 \mathrm{mg} / \mathrm{kg}$.

$+/-2^{\text {nd }}$ line immunosuppression.

\section{FOR MODERATE TO SEVERE TED}

Pulsed methylprednisolone $500 \mathrm{mg}$ i.v. weekly for 6 weeks followed by $250 \mathrm{mg}$ weekly for further 6 weeks. Not suitable in children.

Early response to steroid predicts treatment outcome. Outcome is inversely related to duration of disease.

Depending on severity $2^{\text {nd }}$ line immunosuppression may be considered by ophthalmology with rheumatology support.

\section{RADIOTHERAPY}

Although radiotherapy in combination with steroids is more effective in treating active thyroid eye disease than steroids alone, it is not known if $2^{\text {nd }}$ line immunosuppression in combination with steroid is more effective than radiotherapy combined with steroid. The results of the CIRTED study will perhaps provide further evidence supporting one or the other treatment regime.

\section{SURGICAL MANAGEMENT}

Orbital decompression.

\section{REFERENCES}

EUGOGO (2008) Eur J Endocrinol 158:273

Bartlena et al., (1997) Clin Endocrinol (Oxf) 47:9

Mourits et al., (2011) New Engl J Med 364:1920

\section{VERSION HISTORY}

Mano Sira 04/15 


\section{PENTAGASTRIN TEST FOR MEDULLARY THYROID CARCINOMA}

\section{CALCITONIN (CT)}

Calcitonin may be secreted by C-cells on the thyroid gland. High levels may suggest medullary thyroid carcinoma. In very early disease (e.g. on screening for familial syndromes), levels may not be raised, but may be stimulated either by calcium or pentagastrin. It is suggested that borderline baseline levels (which no longer need be fasting) are further investigated by a stimulation test.

\section{INDICATIONS}

1. Suspected medullary carcinoma of thyroid.

2. Screening of families with medullary carcinoma of the thyroid.

3. Patients with suspected MEN type 2. Remember to inform the MEN2 registry.

4. Patients with basal CT level ( $<11.8$ (male) and $<4.8$ (female) $\mathrm{ng} \mathrm{LI}) / \mathrm{L} / \mathrm{L}$

\section{CONTRAINDICATIONS}

Allergy/anaphylaxis

\section{SIDE EFFECTS}

Severe short lasting nausea, epigastric discomfort

\section{PREPARATION}

1. Check electrolytes and serum calcium.

2. i.v. Cannula, $18-20 \mathrm{~g}$.

3. Pentagastrin $0.5 \mathrm{mcg} / \mathrm{kg}$ body weight. Pentagastrin is available as $500 \mathrm{mcg}$ in $2 \mathrm{ml}$. So for a $100 \mathrm{~kg}$ patient, you need $50 \mathrm{mcg}$, which is only $0.2 \mathrm{ml}$.

4. $6 \times$ red or yellow top tubes.

5. Centrifuge.

6. Ice or facilities to transfer samples immediately to lab

\section{METHOD}

1. Patients should be fasted, as food can increase calcitonin.

2. Insert cannula and flush.

3. Take baseline sample for calcitonin.

4. Ensure the patient is lying down before administering pentagastrin, which makes some patients feel very unwell for a few seconds.

5. Give bolus i.v. of pentagastrin $0.5 \mathrm{mcg} / \mathrm{kg}$ body weight and flush cannula.

6. Take samples at 1, 2, 3, 5 and 10 minutes for calcitonin.

7. Take immediately to lab on ice.

\section{INTERPRETATION}

In patients with a stimulated CT 30-100 ng/L- follow-up screening recommended. 
In patients with a stimulated CT 100-200 ng/L- probable C-cell hyperplasia or early MTC.

In patients with a stimulated CT > $200 \mathrm{ng} / \mathrm{L}-$ MTC very likely.

\section{SENSITIVITY AND SPECIFICITY}

Pentagastrin stimulates calcitonin best in medullary carcinoma, whereas calcium infusion is best in normals.

Combining two studies only two out of 25 patients with medullary thyroid carcinoma had normal responses to pentagastrin. Many normals have been described with an exaggerated response to pentagastrin and the reproducibility of this test is poor.

Surgical treatment should be considered especially if there is a family history. Potentially affected family members should be screened biennially until aged 65 years.

\section{REFERENCES}

McLean et al., (1984) Metabolism 33:790

Karges et al., (2004) Exp Clin Endocrinol Diabetes 112:52

\section{CALCIUM INFUSION TEST FOR MEDULLARY THYROID CANCER}

\section{INDICATIONS}

1. Suspected acalcitoninaemia.

2. Suspected medullary carcinoma of thyroid.

3. Screening of families with medullary carcinoma of the thyroid.

4. Patients with suspected MEN type 2.

\section{CONTRAINDICATIONS}

Bleeding disorders

\section{SIDE EFFECTS}

Unpleasant flushing sensation

No major side effects

\section{PREPARATION}

- Patient should fast overnight.

- Check electrolytes and serum calcium.

- i.v. Cannula, 18-20g.

- Saline flush.

- Calcium gluconate 10\% (10 - $20 \mathrm{ml}$ required).

- $6 \times$ red or yellow tubes.

- Syringes. 
- Ice and facilities to transfer samples immediately to lab.

\section{METHOD}

1. Insert cannula and flush.

2. Take baseline sample for calcitonin.

3. Give calcium gluconate $0.2 \mathrm{ml} / \mathrm{kg}$ body weight i.v. over 1 minute.

4. Flush cannula.

5. Take samples at 1, 2, 3, 5 and 10 minutes for calcitonin.

6. Send immediately on ice to the lab for centrifugation and freezing.

\section{INTERPRETATION}

- In medullary carcinoma of the thyroid there is often a raised fasting serum calcitonin $(>90 \mathrm{ng} / \mathrm{L})$ but this may be in the normal range.

- Provocative tests improve the sensitivity of calcitonin measurement.

- Normal range for peak calcitonin following calcium infusion is 100 to $200 \mathrm{ng} / \mathrm{L}$.

\section{SENSITIVITY AND SPECIFICITY}

In the study quoted below $8 / 12$ subjects with medullary thyroid carcinoma had increased responses to calcium infusion. Two of the four who failed to respond had a raised baseline calcitonin. There is a high false positive rate especially in young men. The pentagastrin test is better in this situation.

\section{REFERENCES}

Charib et al., (1987) Mayo Clinic Proc 62:373

\section{VERSION HISTORY}

John Wilding 12/89, Ben Jones 11/13 


\section{GENETIC SCREENING FOR MEN-2}

The current local policy is referral of anyone in whom a diagnosis of MEN2 is suspected to the joint Endocrine/Genetics clinic (can be done directly for local patients for out of area patients request a referral from the GP). Genetic counselling and sampling will be handled by the clinic.

An alternative laboratory for MEN1 and MEN2 genetic screening runs at Exeter University Clinical Enquiries: Professor Andrew Hattersley. Tel : +44 (0) 1392 408260. Fax: 01392403027.

E-mail: A.T.Hattersley@ex.ac.uk:

Laboratory Enquiries: Professor Sian Ellard Tel: +44 (0) 1392 408529) Email: $\underline{\text { Sian.Ellard@ @nhs.net }}$ A request form is available via http://www.imperialendo.co.uk/men.htm

\section{VERSION HISTORY}

Karim Meeran 01/03, Niamh Martin 9/08, Saira Hameed 03/15

\section{FINE NEEDLE ASPIRATION OF A THYROID NODULE}

\section{INDICATION}

Investigation of thyroid nodule(s). The prime aim of FNA is to exclude malignancy.

\section{METHOD}

\section{METHOD}

1. All thyroid nodules suspicious of cancer should be referred to the Hammersmith Thyroid Clinic (clinic code THCI/THEM) to Prof Graham Williams or Mr Palazzo also has a clinic in parallel with Prof Williams on the same day.

2. It may be useful to arrange an US guided FNA at the time of the referral so long as the patient is biochemically euthyroid. 
INTERPRETATION AND ACTION

Guidelines for the management of Thyroid Cancer. British Thyroid Association (2014) Clinical Endocrinology 81(S1) 1-122

\begin{tabular}{|c|c|c|}
\hline Thy Grade & Cytological description & Action taken \\
\hline 1 & Non-diagnostic & $\begin{array}{l}\text { Repeat FNA to obtain a sample that is } \\
\text { adequate for diagnosis. }\end{array}$ \\
\hline 2 & $\begin{array}{l}\text { Non-neoplastic } \\
\text { Samples are adequately cellular and suggest } \\
\text { a non-neoplastic lesion such as normal } \\
\text { thyroid tissue, a colloid nodule or a thyroidits. } \\
\text { Cyst samples containing abundant colloid can } \\
\text { be categorized as Thy2c }\end{array}$ & $\begin{array}{l}\text { Correlate with clinical and radiological } \\
\text { (US) findings. If no suspisious } \\
\text { associated clinical/radiological } \\
\text { findings then no further biopsy } \\
\text { required. }\end{array}$ \\
\hline 3 & $\begin{array}{l}\text { Neoplasm possible } \\
\text { This is subdivided into: } \\
\text { Thy3a - when there are atypical } \\
\text { features present but not enough to } \\
\text { place into any of the other categories. } \\
\text { Thy3f - when a follicular neoplasm is } \\
\text { suspected. The histological possibilities } \\
\text { then include a hyperplastic nodule, } \\
\text { follicular adenoma or follicular } \\
\text { carcinoma. These cannot be } \\
\text { distinguished on cytology alone and a } \\
\text { histology sample (e.g. diagnostic } \\
\text { hemithyroidectomy) will be required for } \\
\text { diagnosis. }\end{array}$ & $\begin{array}{l}\text { DISCUSS IN ICHNT MDT } \\
\text { Thy3a - further investigation, usually } \\
\text { US assessment and repeat FNAC } \\
\text { Thy3f - diagnostic hemithyroidectomy }\end{array}$ \\
\hline 4 & Suspicious for malignancy & $\begin{array}{l}\text { DISCUSS IN ICHNT MDT } \\
\text { Diagnostic hemithyroidectomy with or } \\
\text { without frozen section or total } \\
\text { thyroidectomy when the degree of } \\
\text { suspicion is particularly high }\end{array}$ \\
\hline 5 & Diagnostic of malignancy & $\begin{array}{l}\text { DISCUSS IN ICHNT MDT } \\
\text { Therapy appropriate to tumour type, } \\
\text { usually surgery for papillary or } \\
\text { medullary thyroid carcinomas }\end{array}$ \\
\hline
\end{tabular}




\section{HOW TO REFER TO THE WEST LONDON CANCER NETWORK THYROID CANCER MDT}

For information see: $\underline{h t t p: / / w w w . l o n d o n c a n c e r a l l i a n c e . n h s . u k / i n f o r m a t i o n-f o r-h e a l t h c a r e-~}$

professionals/forms,-protocols-and-guidance/north-west-london-cancer-network/

Contact details available from:

http://www.imperial.nhs.uk/services/cancerservices/thyroidcancer/index.htm

\section{VERSION HISTORY}

Stephen Gilbey 10/89, Karim Meeran 07/01, Tricia Tan 8/08, Florian Wernig and Chioma IzziEngbeaya 11/13, Saira Hameed 02/15, Fausto Palzzo 10/15

\section{PERFORMING A THYROID FNA}

This is no longer done in the general endocrine clinics at either site as patients are referred to the clinics above. Outlined below is the procedure for historical purposes.

\section{PREPARATION}

None

\section{SIDE EFFECTS}

Rarely: local bleeding. Avoid by applying local pressure

\section{METHOD}

1. Contact cytology department who will come almost immediately and bring their prepared slides.

2. Lie patient in supine position with neck flexed backwards.

3. Insert 25 gauge needle into nodule and aspirate (usually more than one pass). Local anaesthesia is usually necessary. The needle should just be passed in and out. Don't draw back as this results in a bloody tap. 


\section{PARATHYROID}

\section{HYPERPARATHYROIDISM}

\section{DIAGNOSIS OF HYPERPARATHYROIDISM}

- Elevated corrected $\mathrm{Ca}^{2+}$.

- Low $\mathrm{PO}_{4}^{3-}$.

- Normal alkaline phosphatase.

- Normal or elevated serum PTH.

- Exclude vitamin D deficiency

- High $24 \mathrm{hr}$ urinary $\mathrm{Ca}^{2+}$ excretion.

- To exclude Familial Hypocalciuric Hypercalcaemia (FHH), the calcium clearance to creatinine clearance ratio should be $>0.01$. This is calculated as follows (for easy calculation see http://www.imperialendo.com/for-doctors/toolkit-for-doctors for on-line calculator).

\section{Calcium Clearance}

[Urine Calcium $(\mathrm{mmol} / \mathrm{L}) \times$ urine volume $(\mathrm{ml})$ ] / [ Serum calcium $(\mathrm{mmol} / \mathrm{L}) \times 1440$ ]

Creatinine Clearance (This may be calculated already)

[Urine Creatinine $(\mathrm{mmol} / \mathrm{L}) \times$ urine volume $(\mathrm{ml})$ ] / [ Serum creatinine $(\mathrm{mmol} / \mathrm{L}) \times 1440$ ]

Serum creatinine is normally expressed in $\mu \mathrm{mol} / \mathrm{L}$ and needs to be converted to $\mathrm{mmol} / \mathrm{Lby}$ dividing by 1000.

However, this ratio can be reduced to:

Urine Calcium (mmol/L) $\times$ [Serum creatinine $(\mu \mathrm{mol} / \mathrm{L}) / 1000]$

Serum calcium $(\mathrm{mmol} / \mathrm{L}) \times$ Urine Creatinine $(\mathrm{mmol} / \mathrm{L})$

For example

FHH

Urine calcium $1.0 \mathrm{mmol} / \mathrm{L}$

$$
\text { Ratio }=\underline{1.0 \times[130 / 1000]}=0.0079
$$

Urine creatinine $6.2 \mathrm{mmol} / \mathrm{L}$

Serum creatinine $130 \underline{\mu} \mathrm{mol} / \mathrm{L}$

Serum calcium $2.65 \mathrm{mmol} / \mathrm{L}$

Primary Hyperparathyroidism

Urine calcium $2.2 \mathrm{mmol} / \mathrm{L}$

$$
\text { Ratio }=\underline{2.2 \times[74 / 1000]}=0.035
$$

Urine creatinine $1.4 \mathrm{mmol} / \mathrm{L}$

$3.3 \times 1.4$

Serum creatinine $74 \underline{\mu} \mathrm{mol} / \mathrm{L}$

Serum calcium $3.3 \mathrm{mmol} / \mathrm{L}$ 


\section{WHO TO CONSIDER FOR PARATHYROIDTHYROID SURGERY}

- All symptomatic patients (neuropsychiatric, nephrolithiasis, bone disease, cardiovascular disease including hypertension).

- Asymptomatic patients who might benefit from surgery include:

- Those at risk for disease progression,

- Those who have features of the disease that may improve following parathyroidectomy.

The Fourth International Workshop on the Management of Asymptomatic Primary Hyperthyroidism (2014) identified the following features in asymptomatic patients who might benefit from surgery:

J Clin Endocrinol Metab (2014) 99(10):3561-3569

Age $<50$ years.

Bone density at the hip, lumbar spine, or distal radius $>2.5$ standard deviations below peak bone mass ( $T$ score $<-2.5$ ) and/or previous fragility fracture.

Calcium concentration $\geq 0.25 \mathrm{mmol} / \mathrm{Labove}$ the upper limit of normal, (i.e. $2.85 \mathrm{mmol} / \mathrm{L}$ )

Creatinine clearance $<60 \mathrm{~mL} / \mathrm{min}$ (or $24 \mathrm{~h}$ urine calcium excretion $>10 \mathrm{mmol} /$ day with increased risk of stone formation).

\section{LOCALISATION OF PARATHYROID ADENOMA}

\section{Localisation studies are only required if the patient is being considered for parathyroid} surgery

None of the techniques are reliable and often a combination of methods are used.

- Ultrasound of neck.

- Sesta-MIBI scanning.

- Usually no additional tests are performed but selected patients may undergo a 4DCT neck (+ upper mediastinum).

- Selective venous sampling for PTH is not routinely used and reserved for re-operations only. Patient requires hospital admission, and investigation needs to be booked with Dr Jackson well in advance.

- All patients with primary hyperparathyroidism needing surgery should be referred to the endocrine surgical department to Mr Fausto Palazzo or Mr Neil Tolley. 


\section{MANAGEMENT PRIOR TO PARATHYROIDECTOMY}

- Is the patient $<40$ years? Could the patient have MEN-1 ? If so discuss screening for MEN-1 mutations.

- Usual pre-operative bloods, including U\&Es, $\mathrm{Ca}^{2+}, \mathrm{PO}_{4}$, alkaline phosphatase, albumin.

- Maintain adequate hydration.

- Replace deficit and maintain 3-4 L fluids /day i.v. and then orally if patient able to drink.

- If above measures do not reduce corrected $\mathrm{Ca}^{2+}<3.0 \mathrm{mmol} /$ Lgive a bisphosphonates (e.g. pamidronate $30 \mathrm{mg}$ in 1 litre $0.9 \%$ saline over $4 \mathrm{hrs}$ or IV zolendroic acid $4 \mathrm{mg}$ in $100 \mathrm{ml} 5 \%$ glucose or $0.9 \&$ sodium chloride over 15 minutes). This will not start to work for 24 hours, with maximum effect 5-6 days. Plan in advance to avoid severe post-operative hypocalcaemia following bisphosphonate therapy.

\section{A NOTE ON VITAMIN D DEFICIENCY AND HUNGRY BONES}

Vitamin $\mathrm{D}$ deficiency is a risk factor for the development of the hungry bone syndrome which presents as marked hypocalcaemia (corrected $\mathrm{Ca}^{2+}<2.1 \mathrm{mmol} / \mathrm{L}$ ) following parathyroidectomy for severe hyperparathyroidism. The mechanism is unclear but it is thought that the abrupt cessation of the PTH stimulus results in rapid bone remineralisation sequestering circulating calcium into bone. It occurs most often in patients with pre-operative bone disease resulting from a chronic increase in bone resorption induced by high levels of PTH. It is recommended that Vitamin D levels be normalised prior to parathyroidectomy. For information on Vitmain $D$ replacement see: http://www.imperialendo.com/for-doctors/vitamin-d-guidelines

\section{MANAGEMENT AFTER PARATHYROIDECTOMY}

- Enquire for symptoms of hypocalcaemia (paraesthesiae, cramps etc.).

- U\&Es, corrected $\mathrm{Ca}^{2+}$ \& PTH tested at 9pm post op and 6am so that results ready for surgical ward round.

- Rarely are patients symptomatically hypocalcaemic after a parathyroidectomy. If symptoms occur and corrected $\mathrm{Ca}^{2+}>1.9 \mathrm{mmol} / \mathrm{l}$, give effervescent $\mathrm{Ca}^{2+}$ (Sandocal 10002 tablets bd suggested, alternatives include Adcal 3 tablets bd or cacichew forte 2 tablets bd).

- Intravenous calcium is almost never required after a parathyroidectomy (never used in 1400 parathyroidectomies for primary hyperparathyroidism at Hammersmith Hospital since 2005-2015) and if considered should be discussed with the consultant surgeon. If the symptoms are severe, PTH unrecordable, the patient not responding to oral medication and the corrected $\mathrm{Ca}^{2+}<1.9 \mathrm{mmol} / \mathrm{l}$ consider $10-20 \mathrm{ml} 10 \%$ calcium gluconate in $50-100 \mathrm{ml}$ of $5 \%$ dextrose i.v. over 10 minutes with ECG monitoring. This can be repeated until the patient is asymptomatic.

- Hazards of i.v. calcium administration: uncommon but include local thrombophlebitis, cardiotoxicity, hypotension, calcium taste, flushing, nausea, vomiting and sweating. Patients with cardiac 
arrhythmias or on digoxin therapy need continuous ECG monitoring during i.v. calcium replacement.

- Monitor PTH. If detectable and parathyroid recovery occurs, wean off alfacalcidol. If PTH remains undetectable, it is likely that they will stay on alfacalcidol for life. In that situation, the long term risk is nephrocalcinosis as the urinary calcium-phosphate product will be high. Thus long term aim is for a low-normal calcium.

\section{REFERENCES}

Witteveen et al., (2013) Eur J Endocrinol.168:R45-53

Emergency Endocrine Guidance, Society for Endocrinology (2013) Acute Hypocalcaemia for use in adult patients.

\section{VERSION HISTORY}

Arshia Panahloo 1/98 updated Sarah Stanley 07/01 updated Alexander Comninos and Saira Hameed 09/15, Fausto Palazzo 10/15 


\section{METABOLIC BONE}

\section{OSTEOPOROSIS}

A condition of low bone mass and micro-architectural deterioration of bone tissue. The clinical significance of osteoporosis lies in the morbidity and mortality associated with fracture.

\section{DIAGNOSIS OF OSTEOPOROSIS}

Patients are identified on the finding of a previous fragility fracture or the presence of significant clinical risk factors (see below).

All patients seen in secondary and tertiary care should undergo assessment of bone mineral density (BMD) by dual energy X-ray absorptiometry (DXA) prior to FRAX assessment (www.shef.ac.uk/FRAX).

Diagnostic assessment of individuals with osteoporosis should include not only the assessment of BMD but also the exclusion of diseases that mimic osteoporosis e.g. myeloma, osteomalacia.

NB. Secondary causes of osteoporosis are commonly found amongst men, so this population requires thorough investigation. Consideration should be given to referring men with osteoporosis to specialist centres, particularly younger men or those with severe disease.

\section{STRONG RISK FACTORS FOR OSTEOPOROSIS}

Parental history of hip fracture

Prior fracture

Alcohol intake $\geq 4$ units/day

Poor diet (especially low calcium intake)

Low BMI $\leq 19 \mathrm{~kg} / \mathrm{m}^{2}$

Long-term immobility

Current smoking (in association with other risk factors)

Rheumatoid arthritis

\section{OTHER SITUATIONS IN WHICH TO SUSPECT OSTEOPOROSIS}

History of multiple atraumatic/minimal trauma fracture

Previous episodes of severe back pain

Radiological appearances of osteoporosis eg. previous unknown vertebral collapse

Marked loss of height, thoracic kyphosis (after radiological confirmation of vertebral collapse) 


\section{Secondary causes of osteoporosis}

\section{Untreated \\ Hypogonadism \\ Premature ovarian \\ failure (surgical, drug or}

diseas- induced)

\begin{abstract}
Early menopause $(<45$
\end{abstract} years)

Chronic liver/kidney

disease

Malabsorption Diseases
eg Coeliac, Crohn's

administration especially

Severe malnutrition

Prolonged amenorrhoea

(>1year)

\begin{abstract}
Primary, secondary or
tertiary testicular failure
\end{abstract}

\section{Major Gl surgery}

including bariatric

surgery

Anorexia

nervosa/bulimia

Primary and secondary
hypogonadism

Rheumatoid arthritis -

(increases fracture risk

independently of BMD

and the use of

glucocorticoids)

Cushing's

Myeloma

Chronic heparin

during pregnancy.

\section{Systemic Disease}

High dose or long term

oral corticosteroids,

( $>7.5 \mathrm{mg} / \mathrm{d}$ or more of

prednisolone or

equivalent dose or

another corticosteroid

for 6 months or more or

about to commence

long-term treatment)

LHRH agonists

Hyperparathyroidism

COPD

(specifically ask for BMD

at the radius on the

request)

Thyrotoxicosis

Type 1 diabetes

Hyperprolactinaemia
Anticonvulsants

Aromatase inhibitors for breast $\mathrm{Ca}$

\section{Vitamin D or Calcium}

deficiencies (only after

checking that Vitamin D

levels are normal)
TSH suppression in Thyroid cancer Immunosuppression Glitazones 


\section{DXA SCANNING}

Osteopenia is defined as a T-score between -1 and -2.5 SD below the mean for a gender and ethnically matched group.

Osteoporosis is defined as a value for BMD 2.5 SD or more below the mean for a gender and ethnically matched group.

BMD at the femoral neck provides the reference site. The spine is not a suitable site for diagnosis in the elderly because of the high prevalence of arthrosis and osteoarthritis, but it is the preferred site for assessing response to treatment.

The radius should be assessed in all cases of primary hyperparathyroidism.

'Severe' or 'established' osteoporosis denotes osteoporosis as defined above in the presence of one or more documented fragility fractures.

N.B. The use of BMD alone to assess risk has a high specificity but low sensitivity. In other words, the risk of fracture is very high when osteoporosis is present, but by no means negligible when BMD is normal. Indeed, the low sensitivity means that the majority of osteoporotic fractures will occur in individuals who do not have osteoporosis as defined by a T-score of $\leq-2.5$. The performance characteristics of assessment can, however, be improved by the concurrent consideration of risk factors that operate independently of BMD. Of particular importance is age, which contributes to risk independently of BMD.

In men and women who require a BMD test, fracture probabilities should be recomputed with FRAX as diagnostic thresholds differ from intervention thresholds because:

1. The fracture risk varies at different ages, even with the same T-score.

2. Other factors that determine intervention thresholds include the presence of clinical risk factors and the cost and benefits of treatment.

Treatment can be considered in those in whom fracture probabilities lie above the intervention threshold.

In addition to its diagnostic use, the assessment of BMD provides information on prognosis i.e. the likelihood of future fractures. The risk of fracture increases approximately twofold for each SD decrease in BMD.

N.B. National Osteoporosis Guideline Group (NOGG) guidance for treatment is integrated into the FRAX score 


\section{GLUCOCORTICOID-INDUCED OSTEOPOROSIS}

Glucocorticoids contribute to the increase in fracture risk over and above the level of low BMD. Therefore, for a given BMD, the risk of fracture is higher in glucocorticoid-induced osteoporosis than in postmenopausal osteoporosis. Measurement of BMD is recommended for the assessment of fracture risk in patients treated with glucocorticoids. Individuals at high risk should start boneprotective therapy at the time of starting glucocorticoids e.g. $\geq 65$ years and those with a prior fragility fracture. In other patients, in whom glucocorticoids will continue for $>3$ months, a DXA scan should be considered. N.B. FRAX assumes an average daily dose of prednisolone of $2.5-7.5 \mathrm{mg} / \mathrm{day}$ or its equivalent and may underestimate fracture risk in patients taking higher doses and overestimate the risk in those taking lower doses. For further information see References Royal College of Physicians (2002) Glucocorticoid induced osteoporosis. Guidelines for prevention and treatment.

\section{TREATMENT OF OSTEOPOROSIS}

General management includes assessment of the risk of falls and their prevention. Maintenance of mobility, regular weight bearing exercise, smoking cessation, reduction of alcohol intake, and correction of nutritional deficiencies, particularly of calcium, vitamin $\mathrm{D}$ and protein.

\section{PHARMACOLOGICAL TREATMENT}

\section{Bisphosphonates}

The bisphosphonates are analogues of inorganic pyrophosphate and inhibit osteoclast mediated bone resorption.

\section{Contraindications.}

Upper GI disorders

Post-bariatric surgery - discuss with surgeon.

Inability to stand or sit upright for at least 30 minutes.

Hypocalcaemia.

Creatinine clearance $<35 \mathrm{ml} / \mathrm{min}$ ).

Pregnancy and lactation.

Both the bisphosphonates and denosumab have been associated with osteonecrosis of the jaw (particularly in cancer patients setting) and atypical fractures.

A guide based on the NICE guidance (2008) (see references) for the use of bisphosphonates in the management of osteoporosis is outlined on the following page. As ever consult the BNF for doses and side effects/contraindications. 


\begin{tabular}{|c|c|c|c|c|c|}
\hline Name & Dose & $\begin{array}{l}\text { Indication in } \\
\text { Women }\end{array}$ & Use in Men & $\begin{array}{l}\text { Use in } \\
\text { glucocorticoid } \\
\text { induced } \\
\text { osteoporosis }\end{array}$ & Notes \\
\hline Alendronate & $\begin{array}{l}\text { PO } 70 \text { mg } \\
\text { once/wk }\end{array}$ & $\begin{array}{l}\text { Postmenopausal } \\
\text { osteoporosis } \\
\text { Prevention of } \\
\text { postmenopausal } \\
\text { osteoporosis (5 } \\
\text { mg daily) }\end{array}$ & $\begin{array}{l}\text { Osteoporosis } \\
70 \mathrm{mg} \\
\text { once/week }\end{array}$ & $\begin{array}{l}\text { Yes. Prevention and } \\
\text { Rx } \\
\text { Treatment of } \\
\text { glucocorticoid- } \\
\text { induced } \\
\text { osteoporosis ( } 5 \mathrm{mg} \\
\text { od or, in } \\
\text { postmenopausal } \\
\text { women not } \\
\text { receiving hormone } \\
\text { replacement therapy } \\
10 \text { mg daily). }\end{array}$ & \\
\hline Ibandronate & $\begin{array}{l}\text { PO } 150 \text { mg } \\
\text { once monthly } \\
\text { Or } \\
\text { IV } 3 \text { mg every } \\
\text { three months }\end{array}$ & $\begin{array}{l}\text { The treatment of } \\
\text { osteoporosis in } \\
\text { postmenopausal } \\
\text { women at } \\
\text { increased risk of } \\
\text { fracture. }\end{array}$ & & & $\begin{array}{l}\text { Intravenous } \\
\text { administration may be } \\
\text { associated with an acute } \\
\text { phase reaction, } \\
\text { characterised by an } \\
\text { influenza-like illness; this } \\
\text { generally is short-lived } \\
\text { and typically occurs only } \\
\text { after the first injection. }\end{array}$ \\
\hline Risedronate & $\begin{array}{l}\text { PO } 35 \text { mg } \\
\text { once weekly }\end{array}$ & $\begin{array}{l}\text { Treatment of } \\
\text { postmenopausal } \\
\text { osteoporosis in } \\
\text { women } \\
\text { unable to comply } \\
\text { with the special } \\
\text { instructions of } \\
\text { alendronate } \\
\text { administration, or } \\
\text { have a Cl or are } \\
\text { intolerant of } \\
\text { alendronate }\end{array}$ & $\begin{array}{l}\text { Treatment of } \\
\text { osteoporosis in } \\
\text { men at high } \\
\text { risk of } \\
\text { fractures. }\end{array}$ & $\begin{array}{l}\text { Prevention and Rx } \\
\text { of glucocorticoid- } \\
\text { induced } \\
\text { osteoporosis in } \\
\text { postmenopausal } \\
\text { women (5mg od) }\end{array}$ & \\
\hline $\begin{array}{l}\text { Zoledronic } \\
\text { acid } 5 \mathrm{mg} \\
\text { intravenously } \\
\text { once/ }\end{array}$ & $\begin{array}{l}\text { IV } 5 \text { mg once } \\
\text { a year }\end{array}$ & $\begin{array}{l}\text { postmenopausal } \\
\text { women at } \\
\text { increased risk of } \\
\text { fracture, including } \\
\text { those with a } \\
\text { recent low trauma } \\
\text { fracture }\end{array}$ & $\begin{array}{l}\text { Men at } \\
\text { increased risk } \\
\text { of fracture, } \\
\text { including those } \\
\text { with a recent } \\
\text { low trauma } \\
\text { fracture }\end{array}$ & $\begin{array}{l}\text { Men \& women: } \\
\text { treatment of } \\
\text { osteoporosis } \\
\text { associated with } \\
\text { long-term } \\
\text { glucocorticoid use }\end{array}$ & $\begin{array}{l}\text { Intravenous } \\
\text { administration may be } \\
\text { associated with an acute } \\
\text { phase reaction } \\
\text { An increase in atrial } \\
\text { fibrillation, reported in } \\
\text { phase III trials }\end{array}$ \\
\hline
\end{tabular}




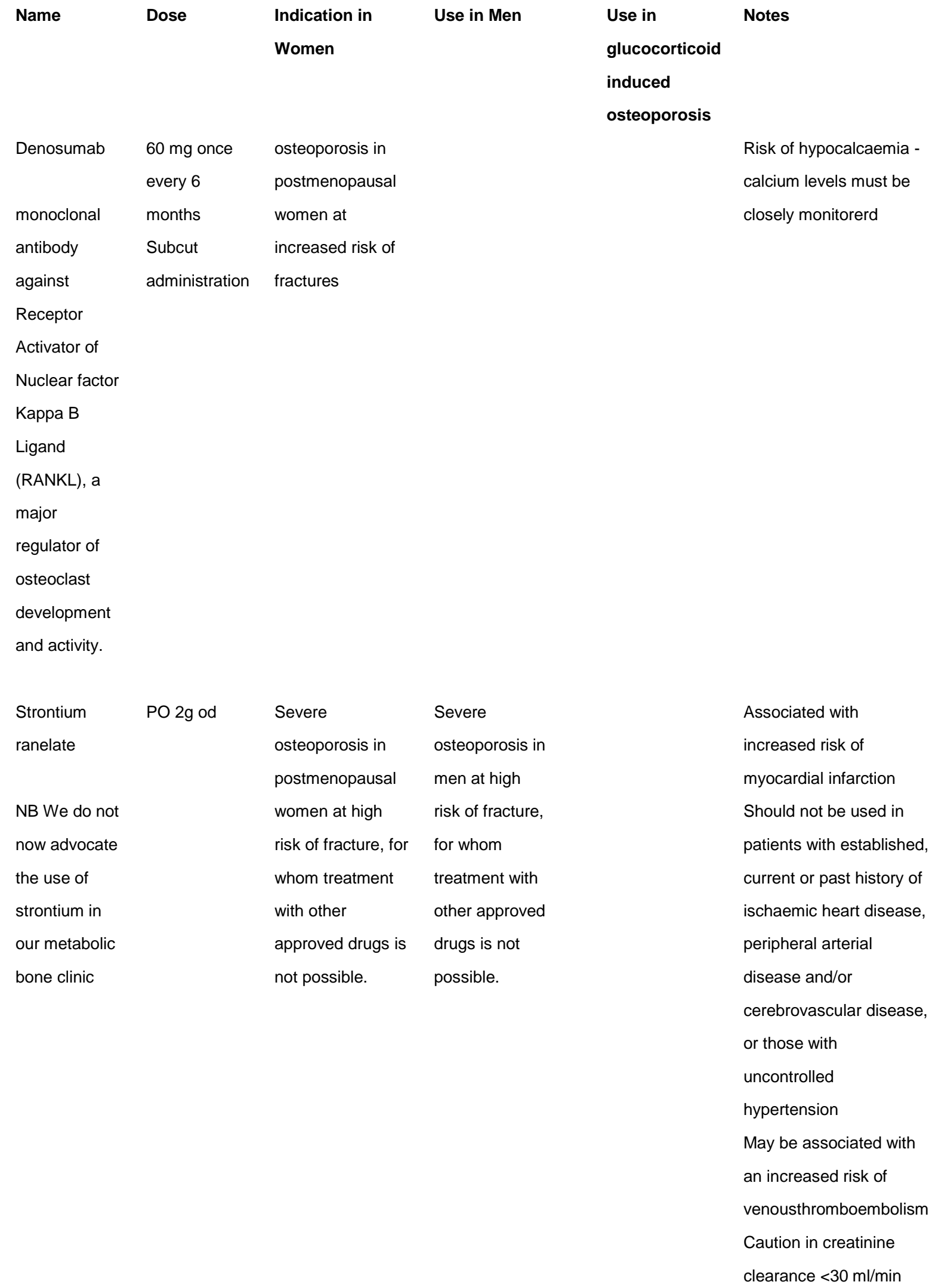




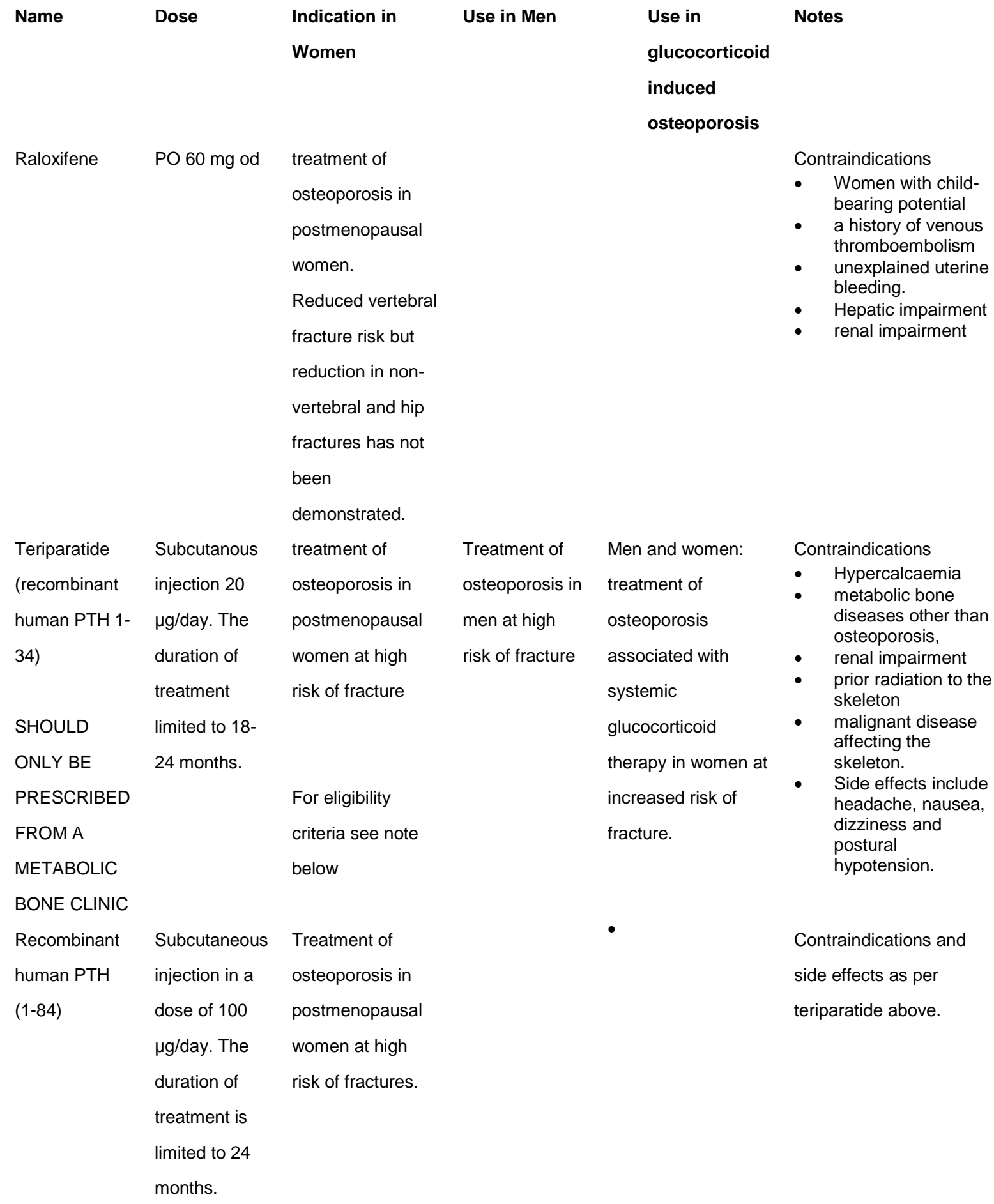

\section{Monitoring treatment using markers of bone turnover:}

National Osteoporosis Guideline Group (NOGG) guidelines state that biochemical indices of skeletal turnover have the potential of aiding in risk assessment as well as for monitoring of treatment but their utility in clinical practice needs to be evaluated. However in our experience, the measurement of NTX 
is indispensable to guide management.

\section{NICE GUIDANCE (2008) ON THE USE OF TERIPARATIDE}

Teriparatide is recommended as an alternative treatment option for the secondary prevention of osteoporotic fragility fractures in postmenopausal women who:

are unable to take alendronate and either risedronate or etidronate

OR have a contraindication to or are intolerant of alendronate and either risedronate or etidronate

OR who have a contraindication to, or are intolerant of strontium ranelate

OR who have had an unsatisfactory response to treatment with alendronate, risedronate or etidronate

\section{AND}

- who are 65 years or older and have a T-score of $-4.0 \mathrm{SD}$ or below, or a T-score of $-3.5 \mathrm{SD}$ or below plus more than two fractures

OR who are aged 55-64 years and have a T-score of -4 SD or below plus more than two fractures.

\section{PRACTICALITIES REGARDING PRESCRIBING TERIPARATIDE}

1. An application (http://source/pharmacy/pbrexcludeddrugs/fundingforms/index.htm) for funding must be made for each patient. Contact Specialist Medicine Pharmacists or Osteoporosis Nurse for assistance with this.

\section{Duration of Bisphosphonate Treatment}

Concerns over possible adverse effects of long-term bisphosphonate therapy, particularly osteonecrosis of the jaw and atypical femoral fractures have raised questions over the optimal duration of bisphosphonate treatment and whether, in some individuals, treatment should be discontinued for a period of time (the so-called "drug holiday").

Based on the available data, it is recommended that a treatment review should be performed after 5 years for alendronate, risedronate or ibandronate and after 3 years for zoledronic acid.

A helpful algorithm from National Osteoporosis Guideline Group (NOGG) clinical guideline for long term treatment monitoring is shown below: 


\section{A guide to long-term bisphosphonate use based on the National Osteoporosis Guideline}

Group (NOGG) clinical guideline for long-term bisphosphonate treatment monitoring is summarised below:

- In general terms 3 years treatment with zoledronic acid and 5 years for other bisphosphonates is advised.

- After this, in order to make a decision whether to continue or to stop bisphosphonate treatment, perform a clinical assessment of the patient. Guidance is given below for the following clinical scenarios:

- $\quad$ Clinical assessment 1:

- The patient is high risk e.g. over 75 years and/or has previously sustained a hip or vertebral fracture, and/or is taking continuous oral glucocorticoids at a dose of $\geq 7.5 \mathrm{mg} /$ day prednisolone and/or has sustained one or more low trauma fractures during treatment.

- Check adherence, exclude secondary causes, re-evaluate treatment choice, continue treatment

- $\quad$ Clinical assessment 2:

- There has been no history of fractures during bisphosphonate treatment

- Guidance:

- Calculate the FRAX score and perform repeat DXA scan

- If the FRAX score is above the NOGG intervention threshold or hip BMD T-score is $\leq-2.5 \mathrm{SD}$ :

- Check adherence, exclude secondary causes, re-evaluate treatment choice, continue treatment

- $\quad$ Clinical assessment 3:

- There has been no history of fractures during bisphosphonate treatment

- Guidance:

- Calculate the FRAX score and perform repeat DXA scan

- If the FRAX score is below the NOGG intervention threshold or hip BMD Tscore is >-2.5 SD: 
- Consider drug holiday. Repeat FRAX and DXA scan in 1.5 to 3 years.

\section{WHEN TO REPEAT DXA}

\section{INDICATIONS AND TIMING OF FOLLOW-UP DXA SCANS}

For comparability these need to be performed on the same manufacturer and model type of DXA scanner and analysed using the same software version.

In patients with normal BMD - there is no indication for a follow-up scan unless something dramatically changes in the patient's clinical history that could cause a reduction in their known normal BMD to the 'at risk' level.

\section{Routine DXA Follow-up/Indication}

For further details see references below NICE (2008) guidance

1. Two years post commencement of treatment or previous DXA measurement:

Monitoring borderline BMD results

Perimenopausal women $=1-2$ years post menopause

Within 10 years of menopause $=2-3$ years post initial DXA scan

2. Following major alteration in treatment type: this provides a new baseline measurement (e.g HRT to bisphosphonates but not from one HRT to another).

3. Patient wishing to stop treatment but with a known reduced BMD or with very strong osteoporosis risk factors.

4. All other groups $=4-5$ years post initial scan

\section{Corticosteroid Follow-up}

1. Patient with known osteoporotic fracture and treated with bisphosphonates for 1 year:

2. One year following commencement of treatment and then every 1-3 years depending upon results. 
3. BMD $T$ score $\leq 1.5+/$ - treatment with bisphosphonates for one year: one year following baseline DXA scan and then depending upon results.

4. BMD T score between -1 and -1.4 : one year following baseline DXA scan and then depending upon results ( $>4 \%$ loss in spine or $7 \%$ at hip after 1 year - start or change in therapy).

\section{USE OF BISPHOSPHONATES IN ACUTE FRACTURE SITUATIONS}

The International Society for Fracture Repair convened a multidisciplinary workshop to assess the current evidence around the interaction between anti-osteoporosis drugs and the healing of incident fractures, with a view to making recommendations for clinical practice. The consensus was that there is no evidence-based reason to withhold anti-resorptive therapy while a fracture heals, whether or not the patient was taking such therapy when the fracture occurred.

\section{REFERENCES:}

Abrahamsen et al., (2010) Cumulative alendronate dose and the long-term absolute risk of subtrochanteric and diaphyseal femur fractures: a register-based national cohort analysis. J Clin Endocrinol Metab. 95:5258-65.

Compston et al., (2013) Diagnosis and management of osteoporosis in postmenopausal women and older men in the UK: National Osteoporosis Guideline Group (NOGG) update 2013 Maturitas 75:392396

Dell et al., (2012) Incidenece of atypical nontraumatic diaphyseal fractures of the femur. J Bone Miner Res 27:2544-50

Goldhahn J and ISFR working group drugs and fracture repair. Evidence for anti-osteoporosis therapy in acute fracture situations--recommendations of a multidisciplinary workshop of the International Society for Fracture Repair. Bone. 46:267-71.

Khan et al., (2015) Diagnosis and management of osteonecrosis of the jaw: a systematic review and international consensus. J Bone Miner Res. 30:3-23

National Osteoporosis Guideline Group (NOGG). Guideline for the diagnosis and management of osteoporosis in postmenopausal women and men from the age of 50 years in the UK. Updated March 2014

NICE technology appraisal guidance 160 (2008) Alendronate, etidronate, risedronate, raloxifene and strontium ranelate for the primary prevention of osteoporotic fragility fractures in postmenopausal women 
NICE technology appraisal guidance 161 (2008) Alendronate, etidronate, risedronate, raloxifene, strontium ranelate and teriparatide for the secondary prevention of osteoporotic fragility fractures in postmenopausal women

Osteoporosis Clinical guideline for prevention and treatment Executive Summary Updated November 2014. National Osteoporosis Guideline Group on behalf of the Bone Research Society, British Geriatrics Society, British Orthopaedic Association, British Orthopaedics Research Society, British Society of Rheumatology, National Osteoporosis Society, Osteoporosis 2000, Osteoporosis Dorset, Primary Care Rheumatology Society, Royal College of Physicians and Society for Endocrinology

Reid (2015) Short-term and long-term effects of osteoporosis therapies Nat Rev Endocrinol 11:418

Royal College of Physicians (2002) Glucocorticoid induced osteoporosis. Guidelines for prevention and treatment

Schilcher et al., (2011) Bisphosphonate use and atypical fractures of the femoral shaft. N Engl J Med. 2011 364:1728-37

Shane et al., (2013) Atypical subtrochanteric and diaphyseal femoral fractures: second report of a task force of the American Society for Bone and Mineral Research. J Bone Miner Res 29:1-23

WHO Scientific Technical Report (2007) Assessment of Osteoporosis at Primary Health Care Level VERSION HISTORY

Saira Hameed 05/15, reviewed Niamh Martin and Duncan Bassett 05/15 


\section{PANCREAS}

\section{DIABETES}

\section{ORAL GLUCOSE TOLERANCE TEST}

\section{INDICATIONS}

1. Suspected diabetes mellitus. With certain caveats (see below), HbA1c is the preferred diagnostic test, a value of $\geq 48 \mathrm{mmol} / \mathrm{mol}(6.5 \%)$ on two occasions is diagnostic of diabetes but caution should be used in people with iron deficiency anaemia and HbA1c should not be used in people with haemoglobinopathy.

2. In acromegaly, to establish the diagnosis and to follow patients after treatment with surgery or irradiation.

3. Suspected reactive hypoglycaemia.

\section{CONTRAINDICATIONS}

None

\section{SIDE EFFECTS}

Nausea and occasional vomiting

\section{PREPARATION}

- The subject should have been on a diet containing an adequate amount of carbohydrate (250 $\mathrm{g} /$ day) for at least 3 days before the test

- Overnight fast.

- $75 \mathrm{~g}$ glucose in $250-350 \mathrm{ml}$ water, equivalent to $440 \mathrm{ml}$ of Lucozade $(70 \mathrm{kCal} / 100 \mathrm{~mL}$ formulation).

- Fluoride oxalate tubes x 3 (grey top Vacutainers).

- 18-20g i.v. cannula.

- Saline flush.

- $\quad$ Syringes $\times 3$.

\section{METHOD}

- Diabetes

Insert cannula.

Take a baseline glucose at time 0 .

Give oral glucose load (75 g glucose in $250-350 \mathrm{ml}$ water, equivalent to $440 \mathrm{~mL}$ of Lucozade [70kCal/100mL formulation]).

Repeat blood samples at 60 and 120 min after glucose load.

- Acromegaly 
See under "growth hormone" above.

\section{INTERPRETATION}

WHO (2011) for diabetes and impaired glucose tolerance

\begin{tabular}{|l|l|l|}
\hline Plasma Glucose (mmol/l) & Fasting & $\begin{array}{l}\mathbf{2} \text { hrs after } \mathbf{7 5} \text { g glucose } \\
\text { load }\end{array}$ \\
\hline Diabetes mellitus & $\geq 7.0$ & $\geq 11.1$ \\
\hline Impaired glucose tolerance & & $\geq 7.8-11.0$ \\
\hline Impaired fasting glucose & $\geq 6.1-6.9$ & \\
\hline Normal & $<6.1$ & $<7.8$ \\
\hline
\end{tabular}

$75 \mathrm{~g}$ oral glucose tolerance test.

In the absence of osmotic symptoms at least 2 abnormal values are necessary to establish a diagnosis of diabetes mellitus

Gestational diabetes: women who have IGT in pregnancy should be treated as if they have GDM, however it is worth noting that there are multiple diagnostic criteria for GDM, not all of which are consistent.

\section{SENSITIVITY AND SPECIFICITY}

These criteria were revised by the WHO in 2011 and reflect the point at which microvascular complications occur in population studies. Remember that acute illness (e.g. myocardial infarction) and drugs may affect glucose tolerance.

In acromegaly it is very rare for GH to suppress to the normal range with a glucose load. In fact there is often a paradoxical rise in GH. Some normal individuals, especially if stressed do not suppress $\mathrm{GH}$. See 'OGTT for acromegaly' on page 53 for further information.

\section{DIABETES UK: SITUATIONS WHERE HBA1C IS NOT APPROPRIATE FOR DIAGNOSIS OF DIABETES:}

ALL children and young people and ALL pregnant people

Patients of any age suspected of having Type 1 diabetes

Patients with symptoms of diabetes for less than 2 months

Patients at high risk who are acutely ill (e.g. those requiring hospital admission)

Patients taking medication that may cause rapid glucose rise e.g. steroids, antipsychotics

Patients with acute pancreatic damage, including pancreatic surgery

Presence of genetic, haematologic and illness-related factors that influence $\mathrm{HbA} 1 \mathrm{c}$ and its 
measurement

\section{REFERENCES}

Use of glycated haemoglobin (HbA1c) in the diagnosis of diabetes mellitus

Abbreviated report of a WHO consultation.14 January 2011

Definition and diagnosis of diabetes mellitus and intermediate hyperglycaemia

Report of a WHO/IDF consultation. 14 January 2006

\section{MANAGEMENT OF PATIENTS WITH DIABETES}

The following ICHNT guidelines have recently been updated and are available from 'The Source':

- Continuous Glucose Monitoring

- Continuous Subcutaneous Insulin Infusion

- Diabetes and Enteral Feeding

- Diabetes and Outpatient Investigations

- Diabetes and Surgery

- Diabetes, Steroids and Hyperglycaemia

- Diabetic Foot Care

- DKA \& HONK

- Glycaemic Management in Acute Stroke

- Hypoglycaemia

\section{VERSION HISTORY}

Revised and updated Nick Oliver 11/13 


\section{SHORT GLUCAGON TEST}

\begin{tabular}{|c|c|c|}
\hline Purpose of test & \multicolumn{2}{|c|}{$\begin{array}{l}\text { Differentiate type } 1 \text { and type } 2 \text { diabetes } \\
\text { Assess } \beta \text { cell reserve in diabetes }\end{array}$} \\
\hline Rationale & \multicolumn{2}{|c|}{$\begin{array}{l}\text { Glucagon is a stimulus for the } \beta \text { cell to produce insulin. Infusion of glucagon } \\
\text { causes insulin secretion both by direct action on the } \beta \text { cell and by inducing } \\
\text { hyperglycaemia. Glucagon has a short half life in plasma ( } 6 \text { minutes). } \\
\text { Measurement of basal and stimulated insulin and c-peptide are therefore a } \\
\text { measure of } \beta \text { cell reserve. }\end{array}$} \\
\hline Patient preparation & \multicolumn{2}{|c|}{$\begin{array}{l}\text { Inform lab the day before the test } \\
\text { Fasting from 10pm } \\
\text { No medication or insulin on the morning of the test } \\
\text { Patients should bring all morning medication (including insulin) to the test to } \\
\text { be taken immediately after the test }\end{array}$} \\
\hline Precautions & \multicolumn{2}{|c|}{ Glucagon can cause nausea } \\
\hline \multirow[t]{4}{*}{ Protocol } & & Cannulate and weigh patient \\
\hline & 0 minutes & $\begin{array}{l}\text { Take blood for Glucose, HbA1c, Lipids, Full renal profile, C- } \\
\text { peptide and insulin } \\
\text { If less than } 90 \mathrm{~kg} \text {, give } 1 \mathrm{mg} \text { Glucagon IV } \\
\text { If greater than } 90 \mathrm{~kg} \text {, give } 1.5 \mathrm{mg} \text { Glucagon IV }\end{array}$ \\
\hline & 6 minutes & Take blood for Glucose, C-peptide and insulin \\
\hline & & $\begin{array}{l}\text { Take bloods to laboratory immediately } \\
\text { Give medication (including insulin) and breakfast }\end{array}$ \\
\hline Interpretation & \multicolumn{2}{|c|}{$\begin{array}{l}\text { Normal stimulation of C-Peptide is } 1.5 \text { to } 3 \text { times the basal level } \\
\text { Basal c-peptide }<0.2 \mathrm{pmol} / \mathrm{L} \text { and stimulated }<0.5 \mathrm{pmol} / \mathrm{L} \text { confirm type } 1 \text { diabetes }\end{array}$} \\
\hline
\end{tabular}

\section{REFERENCES}

Scheen et al (1996) Diabetes Metab.22:397

Castillo et al (1995) JCEM 80:393

Faber et al (1977) 26: 605

Hendriksen et al (1977) Diabetologia. 13:615

\section{VERSION HISTORY}

Nick Oliver 11/15 


\section{AUTONOMIC FUNCTION TESTS}

\section{INDICATIONS}

Suspected diabetic autonomic neuropathy.

Shy-Drager Syndrome (Multisystem Atrophy).

Suspected autonomic failure from other causes.

\section{CONTRAINDICATIONS}

Patients with proliferative retinopathy should not perform the Valsalva manoeuvre because of the risk of retinal haemorrhage.

Atrial fibrillation (tests uninterpretable, except postural hypotension and handgrip tests).

\section{SIDE EFFECTS}

None

\section{PREPARATION}

- Sphygmomanometer.

- Mouthpiece to attach to sphygmomanometer (5ml syringe minus plunger).

- ECG machine with rhythm strips recording function.

\section{TESTS OF CARDIAC PARASYMPATHETIC DAMAGE}

1. Heart rate response to the Valsalva manoeuvre

Start ECG machine (limb leads only, use lead II).

Patient blows into sphygmomanometer and maintains pressure at $40 \mathrm{mmHg}$ for 15 seconds, continue recording for 30 seconds after release of pressure.

Measure shortest R-R interval during manoeuvre and longest after.

Valsalva ratio $=$ longest after/shortest during.

Take mean of three readings.

2. Heart rate variation during deep breathing

Start ECG machine.

Ask patient to breathe quietly at a rate of six breaths over one minute ( 5 seconds in and 5 seconds out).

Mark ECG at start of each inspiration and expiration.

Measure maximum and minimum R-R interval for each cycle and convert to beats/min.

Result is mean difference ( $\max -\mathrm{min}$ ) for heart rate during deep breathing.

3. Heart rate response to standing

Start ECG recording with patient lying.

Ask the patient to stand, continue recording ECG for 1 minute.

Measure shortest R-R interval around the 15th beat after standing and the longest around the 30th beat. Calculate longest/shortest $=30: 15$ ratio. 


\section{TESTS OF SYMPATHETIC DAMAGE}

Blood pressure response to standing

Measure blood pressure lying and then 2 minutes after standing

Record postural difference

\section{INTERPRETATION}

\begin{tabular}{|l|l|l|l|}
\hline TESTS & Normal & Borderline & Abnormal \\
\hline Valsalva ratio & $\geq 1.21$ & $1.11-1.20$ & $\leq 1.10$ \\
\hline (max-min) HR & $>15$ & $11-14$ & $<10$ \\
\hline (30:15 ratio) & $>1.04$ & $1.01-1.03$ & $\leq 1.00$ \\
\hline fall in BP & $\leq 10$ & $11-29$ & $\geq 30$ \\
\hline
\end{tabular}

These tests can be used to determine the degree of abnormality present: if two or more of the parasympathetic tests plus the sympathetic tests are clearly abnormal then this indicates significant autonomic damage, earlier damage is signified by abnormalities in at least two parasympathetic tests.

\section{SENSITIVITY AND SPECIFICITY}

Caution should be taken in interpreting these tests in patients who are poorly co-operative and in the elderly.

\section{REFERENCE}

Clarke and Ewing (1982) BMJ 285:918 


\section{GUT HORMONE TUMOURS}

\section{INSULINOMAS AND POSTPRANDIAL HYPOGLYCAEMIA}

Patients with hypoglycaemic symptoms and demonstrating Whipple's triad (symptoms/signs consistent with hypoglycaemia, a low plasma glucose concentration, and resolution of those symptoms/ signs after the plasma glucose concentration is raised) should be investigated for an insulinoma or post-prandial (reactive) hypoglycaemia. Those under investigation for insulinoma should have a prolonged ( 5 hour) oral glucose tolerance test before their supervised fast. (If both negative, consider EEG and CT brain, as temporal lobe epilepsy also occurs with this presentation). If the patient is on diazoxide it should be discontinued a week before admission.

\section{PROLONGED ORAL GLUCOSE TOLERANCE TEST}

The subject should have been on a diet containing an adequate amount of carbohydrate ( $250 \mathrm{~g} /$ day) for at least 3 days before the test thus the OGTT must NOT follow the prolonged fast.

\section{PREPARATION}

- Overnight fast.

- $75 \mathrm{~g}$ anhydrous glucose.

- Fluoride oxalate tubes x 14 (grey top Vacutainers).

- EDTA (purple) tubes $\times 14$

- $\quad$ red or yellow tubes $\times 14$

- $18-20$ g i.v. cannula.

- Saline flush.

\section{METHOD}

Take blood for glucose, insulin, C-peptide, and gut hormones (to measure GLP-1) at - $15,0,+15,30$, $45,60,90,120,150,180,210,240,270$ and $300 \mathrm{~min}$. The participant should refrain from exercise and smoking during the test.

Samples for Insulin and C-peptide should be kept on ice or taken to the laboratory as soon as possible.

\section{INTERPRETATION}

There is no consensus on the threshold of hypoglycaemia required for diagnosing reactive hypoglycaemia on prolonged OGTT. In practice, the interpretation of the test results is the same as when the tests are done during a spontaneous episode of hypoglycemia or during a 72-hour fast. Therefore inducing symptoms consistent with hypoglycaemia in the presence of a low glucose (usually below $3.0 \mathrm{mmol} / \mathrm{L}$ ), would constitute a positive test finding. 


\section{MIXED MEAL TEST}

Note that the Endocrine Society guidelines (2009) advocate that an oral glucose tolerance test is not recommended for the evaluation of suspected postprandial hypoglycaemia. Patients with a history suggestive of postprandial hypoglycemia should undergo a mixedmeal test. The test meal should include the components recognised by the patient as likely to cause hypoglycemia although a nutritional supplement formula mixed meal can also be used. In our practice we use Ensure Plus (13.8 $\mathrm{g}$ protein, $10.8 \mathrm{~g}$ fat, $44.4 \mathrm{~g}$ carbohydrates, $220 \mathrm{ml}$, Abbott laboratories, Abbott Park, IL). The mixed meal test should be conducted over 5 hours. Blood is collected following the same time points as in a prolonged OGTT.

REFERENCE: Evaluation and Management of Adult Hypoglycemic Disorders: An Endocrine Society Clinical Practice Guideline. J Clin Endocrinol Metab (2009) 94: 709-728

\section{PROLONGED SUPERVISED FAST}

\section{INDICATION}

1. Used to demonstrate fasting hypoglycaemia and diagnose insulinoma if not observed. spontaneously or after an overnight fast.

\section{PREPARATION}

- $\quad$ Admit to perform test under close supervision with glucose (p.o./i.v.) available.

- Leave a copy of this protocol sheet in the nurses' notes and a copy above the patient's bed.

\section{METHOD}

1. Cannulate patient and commence $72 \mathrm{hr}$ fast.

2. Water/non-caloric beverages allowed. Patient should be active during waking hours.

3. Blood glucoses should be done at regular (4-6 hour) intervals and whenever the patient has symptoms suggestive of hypoglycaemia. Decrease to 2 hour intervals if the patient consistently has glucoses $<3.0 \mathrm{mmol} / \mathrm{L}$.

4. Each time a blood glucose is checked a blood ketone level should be measured and recorded in the patient notes.

5. If blood glucoses are $\leq 2.2 \mathrm{mmol} / \mathrm{L}$ or symptoms are convincing:

a. Take blood for glucose, insulin and C-peptide in a red or yellow tube $(7 \mathrm{ml})$ and a fluoride oxalate tube.

b. Take blood for sulphonylurea screen in a red or yellow tube $(7 \mathrm{ml})$ (NB urine screen only useful if prolonged delay in obtaining a plasma sample, all sulphonylureas detected on plasma due to improved radioimmunoassay and HPLC. Therefore, urine superfluous nowadays and more interference in urine vs. plasma makes plasma sulphonylurea analysis more specific)

c. Take to chemistry labs to be separated and frozen within 30 minutes. Ring biochemistry up for an urgent glucose.

d. Do not reverse hypoglycaemia until the lab confirms hypoglycaemia, or unless the 
patient becomes unconscious or fits.

6. If no symptoms during the fast, finish with 15-30 mins exercise, e.g. a brisk walk around the hospital.

7. Take final samples for glucose, insulin, C-peptide, and sulphonylurea screen.

\section{INTERPRETATION}

- Normals do not become hypoglycaemic, although young women can run glucoses in the region of 2.2-3.0 $\mathrm{mmol} /$ Lwithout symptoms.

- True hypoglycaemia must be demonstrated (glucose $\leq 2-2.2 \mathrm{mmol} / \mathrm{L}$ ), before one can interpret insulin results or consider insulinoma.

- If hypoglycaemia with raised insulin but low $C$ peptide, consider self administration of insulin.

- If hypoglycaemia with raised insulin, and raised C-peptide, make sure sulphonylurea screen is negative! Tel (Guildford lab 01483571122 x 4696).

- With hypoglycaemia, insulin and endogenous insulin production (estimated by C-peptide) should be low.

- Insulin $>6 \mathrm{mU} / \mathrm{L}$ ( $>50 \mathrm{pmol} / \mathrm{L}$ ); $\mathrm{C}$ peptide $>300 \mathrm{pmol} / \mathrm{L}=$ insulinoma (check ratio of c-peptide to insulin high enough).

- Insulin >3-6 mU/L (25-50 pmol/L); C peptide 100-300 pmol/L = possible insulinoma but needs further tests.

- Insulin $<3 \mathrm{mU} / \mathrm{L}$ ( $<25 \mathrm{pmol} / \mathrm{L}) ; C$ peptide $<75 \mathrm{pmol} / \mathrm{L}=$ normal response

- Ketones should be suppressed with insulinoma even though patient is fasting because of the excess insulin.

\section{SENSITIVITY AND SPECIFICITY}

By $24 \mathrm{hrs}, 66 \%$ insulinomas develop hypoglycaemia and by $48 \mathrm{hrs}$, >95\% insulinomas can be diagnosed. After 72 hrs fast plus exercise, if no hypoglycaemia, insulinoma is very unlikely.

\section{REFERENCE}

Friesen (1987) Surg. Clin. N. Amer 67:379

\section{VERSION HISTORY}

Maria Bernard and Peter Hammond 10/91, Preeshila Behary and Agnieska Falinszka 11/13, Saira

Hameed and George Tharakan 03/15

\section{MANAGEMENT OF STABLE INSULINOMAS PRIOR TO SURGERY TREATMENT OPTIONS INCLUDE}

1. Dietician review. Multiple, regular, small meals usually help.

2. Guar gum $5 \mathrm{~g}$ tds also helps by slowing gastric absorption.

3. Diazoxide 50-200 mg tds, but beware of hypokalaemia and severe oedema.

4. NG feeding can be considered.

5. Steroids can help for a short period.

6. Octreotide can be helpful but beware hypoglycaemia if glucagon levels are suppressed. 
7. Calcium channel antagonists may be useful for nesidioblastosis.

\section{GASTRINOMA}

\section{GASTRIC ACID SECRETION}

\section{INDICATION}

Used in the diagnosis of Zollinger-Ellison syndrome. Rarely needed now as an endoscopy can give evidence of acid hypersecretion (multiple ulceration) and usually can distinguish with achlorhydria.

Consider syndrome if:

1) Raised gastrin ( $>40 \mathrm{pmol} / \mathrm{L})$ in the absence of other causes (e.g. $\mathrm{H} 2$ antagonists, PPls, pernicious anaemia, other causes of achlorhydria, renal failure).

2) Associated upper gastrointestinal disease, i.e. peptic ulcer disease with poor response to treatment; multiple duodenal or jejunal ulcers; peptic ulcer disease with unexplained diarrhoea; fulminant peptic ulcer disease (perforation, haemorrhage, oesophagitis and stricture); ulcer in upper part of ligament of Treitz.

Measuring gastric output distinguishes secondary hyper-gastrinaemia (due to achlorhydria) from primary hyper-gastrinaemia. Administration of pentagastrin i.v. does not improve the diagnostic accuracy.

\section{PREPARATION}

- Book with endoscopy suite since the end couch next to the apparatus will be required.

- Liase with Gastro research fellow to ensure that equipment is not being used.

- Stop H2 antagonists for 72 hours and stop PPIs for 2 weeks.

- Stop antacids 24 hours before blood sample.

- Patient should be fasting.

- Check that the autotitrator is available, otherwise you will need to obtain a burette, conical flask, $\mathrm{pH}$ meter and $0.1 \mathrm{M} \mathrm{NaOH}$.

\section{METHOD}

1. Pass the special double lumen naso-gastric tube (obtained from sister in endoscopy) with plenty of Xylocaine spray to the nose and throat, and lignocaine jelly to the nose. Pass the NG tube as far as the $50 \mathrm{~cm}$ mark at the nostril.

2. Ask the patient to drink $50 \mathrm{mls}$ of water and then aspirate this via the NG tube to check that it is in the most dependent part of the stomach.

3. Connect NG tube to the pump and collect four samples of gastric juice, each over 15 min into polystyrene cups. Alternatively, aspirate regularly and periodically with a $50 \mathrm{ml}$ syringe to collect gastric juice over each 15 min period. 
4. Measure total volume of each sample. Decant $10 \mathrm{mls}$ of each into a fresh polystyrene cup and titrate against $0.1 \mathrm{M} \mathrm{NaOH}$ with the automated titrating equipment, or carry out a standard neutralisation titration manually.

5. Calculate the acid production of each 15 min collection:

$A=(N / 100) \square V$

$A=$ mmol of acid production

$\mathrm{N}=$ volume $(\mathrm{ml})$ of $0.1 \mathrm{M} \mathrm{NaOH}$ solution needed to neutralise $10 \mathrm{mls}$ of gastric juice

$\mathrm{V}=$ volume $(\mathrm{ml})$ of gastric juice in 15 min collection

A sum of the acid production for each 15 min will give the total hourly production.

\section{INTERPRETATION}

- Spontaneous basal acid outputs of $20-25 \mathrm{mmol} / \mathrm{hr}$ are almost diagnostic, $>10 \mathrm{mmol} / \mathrm{hr}$ is suspicious. Post ulcer surgery $>5 \mathrm{mmol} / \mathrm{hr}$ is indicative.

- Realistically, basal acid output studies may be complex to perform. An alternative is to take a single gastric $\mathrm{pH}$ measurement using a wide bore nasogastric tube and $\mathrm{pH}$ (not litmus) paper. A basal gastric $\mathrm{pH}$ of $>2$ virtually excludes a gastrinoma.

\section{SENSITIVITY AND SPECIFICITY}

Hypergastrinaemia and raised gastric acid are also found with:

1. gastric outlet obstruction: resolves with NG decompression

2. massive small bowel resection: resolves a few months post op

3. antral $\mathrm{G}$ cell hyperplasia: excess cells on histochemistry

\section{REFERENCE}

Deveney et al., (1987) Surg. Clin. N. Amer 67:411

\section{VERSION HISTORY}

Maria Bernard \& Peter Hammond 2/91; corrected equation Bernard Khoo 7/00.

\section{INTRAVENOUS SECRETIN TEST}

We do not use this test routinely, but describe it here for historical purposes.

\section{INDICATION}

The intravenous secretin test should, whenever possible, be performed only after the results of basal plasma gastrin and acid output - both performed off PPIs for 2 weeks, H2 blockers for 3 days and fasted - are available.

The indications for the test are:

1. Strong clinical suspicion of a gastrinoma with equivocal results of acid studies and fasting gastrin. 
2. Inability to wean patients off antisecretory therapy for long enough to perform acid studies and gastrin estimation because of recurrence of severe symptoms.

\section{PREPARATION}

- Warn fasting gut hormone lab (33949) 48 hours in advance.

- Fast overnight. If possible, stop antisecretory therapy for 24 hours.

- Secretin (Kabi) ordered in advance from Pharmacy.

- 7 x EDTA (purple) tubes labelled before the study.

- Syringes.

- Ice.

- Arrangements to transfer for immediate spinning.

\section{METHOD}

1. Site i.v. cannula.

2. Take two baseline samples at $\mathrm{T}=-15$ and 0 mins.

3. Secretin $2 \mathrm{U} / \mathrm{kg}$ injected as bolus at $\mathrm{T}=0 \mathrm{mins}$.

4. Blood samples taken at $T=2,10,15,20$ and 30 mins.

5. Samples stored on ice and spun within 15 mins.

6. All samples assayed for gastrin.

\section{INTERPRETATION}

- The criteria for diagnosing a gastrinoma are based on gastrin assays from other laboratories where results may not be directly comparable.

- The best criterion is a rise in gastrin of $200 \mathrm{pg} / \mathrm{ml}$ - equivalent to about $100 \mathrm{pmol} / \mathrm{L}$.

- This gives a sensitivity of $85 \%$ when performed on all patients with a fasting gastrin of less than $400 \mathrm{pmol} / \mathrm{L}$.

- A rise of $50 \%$ over basal values gives a sensitivity of $78 \%$. Gastrin levels FALL in normal individuals in response to secretin.

- Few false positives have been reported, but massive rises occasionally occur in association with achlorhydria and common duodenal ulcer disease, hence the need to have acid studies and fasting gastrin as the initial investigations, if possible.

\section{REFERENCE}

Frucht et al., (1989) Ann. Intern. Med. 111:713 


\section{LOCALISATION OF GASTRINOMAS AND INSULINOMAS}

IMAGING.

- CT or MRI.

- Octreotide scan.

- Ga 68 DOTATATE.

- Endoscopic ultrasound (performed at the Hammersmith Hospital by Dr Panagiotis Vlavionos)

$\circ \quad$ preparation for endoscopic ultrasound (EUS)

Patients need to fast from 4 am, but insulinoma patients are at risk of hypoglycaemia and will require admission for an i.v. dextrose infusion from midnight.

\section{SELECTIVE ARTERIAL INJECTION}

\section{INDICATION}

This investigation is performed in conjunction with highly selective angiography for patients with proven gastrinomas or insulinomas, whose tumours are too small (usually less than $1 \mathrm{~cm}$ ) to be detected by CT or USS. This comprises about $50 \%$ of patients with these syndromes.

Gastrinomas can be stimulated with intra-arterial secretin or calcium; insulinomas with intra-arterial calcium.

Much better results are obtained with calcium, and secretin is no longer really available.

\section{CONTRAINDICATIONS}

(Discuss with radiologist)

Allergy to contrast dye.

Ischaemic Heart Disease.

Orthopnoea.

Bleeding tendencies (severe).

If patient on aspirin/clopidogrel, discuss with radiology.

\section{PREPARATION}

- Book as Hepatic venous sampling.

- For Hammersmith, liaise with Dawn Chaquico (Superintendent of Angiography) Ext 34943. Radiologist perfoming procedure is Dr James Jackson.

- Order Secretin (Kabi) or $10 \%$ calcium gluconate in advance from Pharmacy.

- Warn fasting gut hormone lab (33949) or endocrinology lab (35914/6/7) 48 hours in advance.

- Stop diazoxide 7 days before procedure. Patients on PPIs or $\mathrm{H} 2$ antagonists do not need to be discontinued (unlike fasting gastrin measurements for diagnosis).

- Consent patient (may have flushing, nausea and hypoglycaemia following calcium injection, risks of bleeding from sheath sites, thrombosis/dissection of femoral artery and visceral arteries, dye allergy). This should be done by the radiologist.

- Blood for FBC, U\&Es, clotting, and $\mathrm{G}+\mathrm{S}$ should be taken the day prior to the procedure.

- Fast for at least 4 hours and infuse $5 \%$ dextrose as required to maintain blood glucose at 
about $3.0 \mathrm{mmol} / \mathrm{L}$.

- 2 endocrine staff to attend to assist sample processing.

- 7 tubes per arterial run (prepare 5 runs and have more tubes to hand):

- EDTA (purple) tubes marked before the study starts for gastrinoma.

- Red or yellow tubes for insulinoma (for insulin AND c-peptide).

- Syringes.

- Ice.

- Stopwatch.

- Arrangements to transfer for immediate spinning.

\section{SIDE EFFECTS}

No serious complications of this procedure have been reported in the 30 patients reported in the literature.

Flushing and nausea may follow calcium injection.

One of our insulinoma patients had a hypoglycaemic episode following injection of calcium and so BMs should be monitored and the glucose maintained at $3-5 \mathrm{mmol} / \mathrm{L}$ with $5 \%$ dextrose infusion if necessary.

The other potential side effects are those of the angiography itself.

\section{METHOD}

1. A catheter is placed in the right hepatic vein prior to routine highly selective visceral angiography.

2. Following angiography each artery (usually proximal gastroduodenal, proximal splenic, hepatic and superior mesenteric) is re-catheterised in turn, preferably starting with the vessels least likely to be supplying the tumour. Occasionally the dorsal pancreatic artery is also catheterised.

3. Take two baselines at $T=-120$ and 0 seconds.

4. At $\mathbf{T}=0$ secretagogue is rapidly injected as a bolus into the artery $-30 \mathrm{U}$ secretin in $5 \mathrm{ml}$ normal saline or $1 \mathrm{ml}$ of $10 \%$ calcium gluconate as appropriate.

5. Blood is sampled at $\mathrm{T}=30,60,90,120$ and 180 seconds (give a 10 second countdown before each sample).

6. Samples for gut hormone assay should be stored in ice and spun within 15 minutes, and samples for insulin assay should be separated within 30 minutes. Do not store insulin samples on ice unless procedure is very prolonged.

7. A Clinical Chemistry form needs to be completed with details of arteries sampled, times and hormones that you want assayed.

8. The proforma below can be used as a guide for labelling the samples (1-35) 


\begin{tabular}{|c|c|c|c|c|c|c|c|}
\hline & $\begin{array}{c}-120 \\
\text { seconds }\end{array}$ & $\mathbf{0}$ second & $\begin{array}{c}30 \\
\text { seconds }\end{array}$ & $\begin{array}{c}60 \\
\text { seconds }\end{array}$ & $\begin{array}{c}90 \\
\text { seconds }\end{array}$ & $\begin{array}{c}120 \\
\text { seconds }\end{array}$ & $\begin{array}{c}180 \\
\text { seconds }\end{array}$ \\
\hline $\begin{array}{c}\text { Proximal } \\
\text { Gastro } \\
\text { Duodenal }\end{array}$ & 1 & 2 & 3 & 4 & 5 & 6 & 7 \\
\hline $\begin{array}{c}\text { Proximal } \\
\text { Splenic }\end{array}$ & 8 & 9 & 10 & 11 & 12 & 13 & 14 \\
\hline $\begin{array}{c}\text { Dorsal } \\
\text { Pancreatic }\end{array}$ & 15 & 16 & 17 & 18 & 19 & 20 & 21 \\
\hline $\begin{array}{c}\text { Superior } \\
\text { Mesenteric }\end{array}$ & 22 & 23 & 24 & 25 & 26 & 27 & 28 \\
\hline Hepatic & 29 & 30 & 31 & 32 & 33 & 34 & 35 \\
\hline
\end{tabular}

\section{INTERPRETATION}

Secretin injection: localisation to a specific region of the pancreas or duodenum (regionalisation) is based on a gradient of greater than $50 \%$ on the 30 second sample. Using these criteria the NIH group successfully regionalized $54 \%$ of tumours and in combination with angiography, $77 \%$ of lesions were localised.

Calcium injection: 4 patients have been reported in the literature (by the NIH group). All were localised using the criterion of a two-fold rise in insulin in the 30 or $60 \mathrm{sec}$ hepatic vein samples. There has also been one report of a PPoma being localised by selective arterial calcium injection.

\section{REFERENCES}

Doppman et al., (1990) Radiology 174:25

Doppman et al., (1991) Radiology 178:237

Fedorak et al., (1993) Surgery 113:242

O'Shea et al., (1996) JCEM 81:1623

Turner et al., (2002): Clin Endocrinol (Oxf). 57:821

Dhillo et al., (2005) Eur. J. Gast Hep. 17:249

\section{VERSION HISTORY}

Peter Hammond 9/93; minor corrections Bernard Khoo 07/00, Karim Meeran 07/02, updated Preeshila Behary and Agnieska Falinska 11/13 


\section{CARCINOID AND NEUROENDOCRINE TUMOURS}

\section{INVESTIGATIONS}

$2 \times 24$ hours urine collections for 5 -HIAA

FOODS TO AVOID DURING 24 HOUR URINE COLLECTION FOR 5-HIAA:

Avocados, bananas, plums, walnuts, pineapples, tomatoes, aubergines, cough medicine.

Fasting Gut Hormones

Imaging: CT scan/ MRI/ EUS

Functional Imaging: Octreotide/Ga 68 DOTATATE/ MIBG

Echocardiogram

Consider Genetics - MEN1 mutation

\section{MANAGEMENT}

Surgery

Symptomatic management with Somatostatin analogue

If liver metastases present - consider hepatic embolization

Targeted radionuclide therapy with ${ }^{131} \mathrm{MIBG} /{ }^{90} \mathrm{Y}$ Octreotide or ${ }^{90} \mathrm{Y}$ Lanreotide

${ }^{177}$ Lu DOTATATE

Chemotherapy

\section{SCHEDULE FOR LUTETIUM-177 DOTA OCTREOTATE TREATMENT}

Patient's case must be discussed in the Neuroendocrine MDT at Hammersmith Hospital. If the agreed MDT outcome is treatment with Lutetium-177 DOTA Octreotate, the following arrangements are made:

- Funding is requested (liaise with Dr Rohini Sharma).

- If the patient is on depot somatostatin analogue preparations, this must be stopped by the referring clinician 4 weeks before Lutetium-177 DOTA Octreotate treatment. Patients may require subcutaneous octreotide (100 microgram tds and increase according to symptom control) in the interim, so Endocrine Specialist Nurse (Debbie Papadopoulou: bleep 7934, email: debbie.peters@imperial.nhs.uk) input may be needed to teach patients to self-inject octreotide.

-

- Patient is referred to the Nuclear Medicine team (Prof Adil Al-Nahhas) with a request placed on CERNER.

- The Nuclear Medicine team:

- approves the request

- arranges for a bed

- books a Cr-51 EDTA test for the assessment of Glomerular Filtration Rate ('NM GFR 2 samples' on CERNER) and informs the patient.

- informs Dr Rohini Sharma and the referring Consultant of the treatment date. 


\section{ASSESSMENT TWO WEEKS BEFORE EACH TREATMENT CYCLE}

A member of Dr Sharma's team reviews patients two weeks before the admission date to carry out the following steps:

- Perform baseline bloods (FBC, U\&Es, LFTs, clotting, chromogranin A) and complete assessment visit in the proforma. Blood results to be reviewed and documented on the proforma.

- Discuss any concerns about patient eligibility with the referring Consultant or a senior clinician (see inclusion criteria below).

- Inform the Nuclear Medicine team (Prof Adil Al-Nahhas) immediately if the patient is unable to proceed with treatment (a minimum notice period of 10 days is required to cancel the dose from Radiopharmacy, otherwise the department will be billed).

\section{TREATMENT CYCLES (ON WARD 6N AT CHARING CROSS HOSPITAL)}

A member of the Oncology team (Dr Rohini Sharma) clerks the patient using set proforma on the morning of admission and carries out the following steps:

- Writes up drug chart:

a. intravenous ondansetron $8 \mathrm{mg}$ stat dose

b. oral ondansetron $4 \mathrm{mg}$ bd for 3 days

c. intravenous amino acid solution $1 \mathrm{~L}$ over $4 \mathrm{~h}$ (provided by the Nuclear Medicine department).

- Informs the Nuclear Medicine team that patient is able to proceed with treatment.

- Inserts 2 venflons in both antecubital fossae.

- Administers intravenous bolus of anti-emetic ondansetron $8 \mathrm{mg} 30 \mathrm{~min}$ prior to therapy.

- Ensures patient's written informed consent (completed by a Nuclear Medicine Consultant or Registrar) is filed in the medical notes.

- Discharges patient the same or the following day with an electronic discharge summary (EDC) for the GP. The EDC should include the bleep number (8082) of the Medical Oncology Registrar oncall, Imperial College NHS Healthcare Trust, if patient becomes unwell at home e.g. severe vomiting, diarrhoea, flushing (NB this is most likely to occur in patients with extensive metastatic disease).

- Informs the referring Consultant that patient has undergone a treatment cycle. Patients must have a follow-up clinic appointment approximately two weeks after treatment for toxicity assessment (in Dr Sharma's clinic), and two weeks before each treatment cycle (in Dr Sharma's clinic) to ensure that they meet the criteria for subsequent treatment. Treatment cycles (3-4) are approximately every 12-16 weeks. Patients should be followed by the referring clinician during the period of treatment according to guidelines for follow-up of patients with neuroendocrine tumours.

- A Ga-68 DOTATATE PET CT scan is booked 8 weeks after the end of the treatment.

Eligibility for therapy for all patients will be discussed in a multidisciplinary setting. 


\begin{tabular}{|c|c|}
\hline Inclusion criteria & Contraindications to treatment \\
\hline $\begin{array}{l}\text { Somatostatin-receptors on tumour demonstrated } \\
\text { by octreotide scan or Ga-68 DOTATATE PET CT } \\
\text { scan within } 6 \text { months of first dose. Tumour } \\
\text { uptake using this imaging should be at least as } \\
\text { high as normal liver uptake on planar imaging. }\end{array}$ & Pregnancy and lactation \\
\hline Primary inoperable or Metastatic disease & $\begin{array}{l}\text { Renal impairment; creatinine clearance (eGFR) } \\
<40 \mathrm{~mL} / \mathrm{min}\end{array}$ \\
\hline Life expectancy at least 3-6 months & $\begin{array}{l}\text { Impaired haematological function; } \mathrm{Hb}<80 \mathrm{~g} / \mathrm{L} \text {, } \\
\mathrm{WCC}<2 \times 10^{9} / \mathrm{L} \text {, platelets }<75 \times 10^{9} / \mathrm{L}\end{array}$ \\
\hline $\begin{array}{l}\text { ECOG Performance Status } 2 \text { or above (see } \\
\text { below) }\end{array}$ & $\begin{array}{l}\text { Severe hepatic impairment; bilirubin }>3 \times \text { ULN, } \\
\text { ALT/AST }>3 \times \text { ULN or albumin }<30 \mathrm{~g} / \mathrm{L} \text { with } \\
\text { increased prothrombin time. }\end{array}$ \\
\hline & Severe cardiac impairment* \\
\hline
\end{tabular}

*In patients where this may be a concern, particularly those with metastatic carcinoid syndrome, a baseline echocardiogram should be performed prior to discussion about patient eligibility for Lu-177 treatment.

\section{ECOG PERFORMANCE STATUS**}

\begin{tabular}{|l|l|}
\hline Grade & ECOG \\
\hline 0 & Fully active, able to carry on all pre-disease performance without restriction \\
\hline 1 & $\begin{array}{l}\text { Restricted in physically strenuous activity but ambulatory and able to carry out work of a light } \\
\text { or sedentary nature, e.g., light house work, office work }\end{array}$ \\
\hline 2 & $\begin{array}{l}\text { Ambulatory and capable of all selfcare but unable to carry out any work activities. Up and } \\
\text { about more than } 50 \% \text { of waking hours }\end{array}$ \\
\hline 3 & Capable of only limited selfcare, confined to bed or chair more than $50 \%$ of waking hours \\
\hline 4 & Completely disabled. Cannot carry on any selfcare. Totally confined to bed or chair \\
\hline 5 & Dead \\
\hline
\end{tabular}

${ }^{\star *}$ Oken et al., (1982) Am J Clin Oncol 5:649-655

\section{VERSION HISTORY}

Preeshila Behary and Agnieska Falinska 11/13. Updated Amir Sam 09/15 


\section{HEPATIC EMBOLISATION OF METASTASES}

\section{DEFINITION}

The liver has a dual blood supply (hepatic artery and portal vein). Hepatic embolization involves the interruption of hepatic arterial supply by its embolisation using foreign substances (e.g. polyvinyl alcohol) in the presence of a patent portal circulation (necessary to sustain liver function). Undertaken under local anaesthetic by Dr James Jackson's radiology team.

\section{INDICATIONS}

Palliation of clinical consequences of hormone production from hepatic secondaries in the carcinoid syndrome and other neuroendocrine tumours.

Diagnosis should be fully established.

More controversially: reduction of tumour load in these patients to improve the well-being of the patient or to reduce local symptoms (e.g. "dragging" abdominal pain from hepatomegaly).

\section{CONTRAINDICATIONS}

Prolonged prothrombin time.

Non-patent portal circulation.

Obvious end-stage illness.

Ischaemic heart disease.

Contrast allergy.

Discuss patients on aspirin/clopidogrel with radiology.

\section{SIDE EFFECTS}

Arterial thrombosis (e.g. femoral artery).

Bleeding from sites of sheath insertion.

Malaise, mild hypotension and fever due to the release of tumour necrosis factor and other vasoactive compounds from necrotic tissue. This can last for weeks after the procedure.

Occasionally life-threatening hypovolaemia with renal failure due to severe vasodilatation. This is now rare when octreotide is used, but patients must be well hydrated pre- and immediately post-

embolisation.

Rarely infarction of other intra-abdominal organs including the gallbladder.

Rarely infection introduced during procedure and rarely abscesses in the liver, which can develop late.

Rarely tumour lysis syndrome, which is why allopurinol has been added to protocol.

\section{PREPARATION}

\section{WEEK BEFORE PROCEDURE:}

- Dual-phase contrast CT abdomen to establish baseline for size and location of metastases.

- Optional Doppler USS liver to establish portal vein patency (this is always established by $\mathrm{Dr}$ Jackson immediately before embolisation).

- Take blood for FBC, U\&Es, clotting, G+S.

- CXR, ECG. 
- Echocardiogram if carcinoid and no previous echo.

\section{DAY BEFORE:}

- May need central venous catheter and urinary catheter (low threshold).

- Insert three large cannulae, if not using central venous catheter.

- Document foot pulses.

- No evidence of infection.

- Informed consent.

- Premed (discuss with radiologist).

- Discuss with anaesthetic registrar on call regarding possible need for ITU bed.

- Start $1 \mathrm{~L} 0.9 \%$ saline with $20 \mathrm{mmol} \mathrm{KCl}$ from midnight before procedure.

\section{WRITE UP PROTOCOL MEDICATION:}

\section{Start on admission:}

Allopurinol $300 \mathrm{mg}$ p.o. od for 10 days.

Cyproheptadine $4 \mathrm{mg}$ p.o. tds (histamine blocker - in carcinoids) for $72 \mathrm{hrs}$ post procedure. (Nicotinamide no longer used as it causes extreme flushing in carcinoids. It can be used in lower doses chronically to avoid Pellagra.)

\section{To start on morning of procedure and continue for $\mathbf{4 8} \mathrm{hrs}$ :}

Octreotide: $1600 \mathrm{mcg}$ in $48 \mathrm{ml} 0.9 \%$ saline, i.v. at $6 \mathrm{ml} / \mathrm{hr}$ (i.e. $8 \mathrm{hrs}$ ). Write up 6 syringes. Trasylol (aprotinin): $50 \mathrm{ml}$ neat $(10,000 \mathrm{U} / \mathrm{ml})$ i.v. at $5 \mathrm{ml} / \mathrm{hr}$ (i.e. $10 \mathrm{hrs}$ ). Write up 5 syringes.

\section{One hour before procedure:}

Methylprednisolone $1 \mathrm{~g}$ i.v.

Premedication (discuss with Dr Jackson).

Antibiotic cover:

Pre-procedure

Amoxicillin $1 \mathrm{~g}$ i.v. (or Teicoplanin $400 \mathrm{mg} 12$ hourly if penicillin allergic).

Metronidazole $500 \mathrm{mg}$ i.v.

Gentamicin 120mg i.v.

\section{Post-procedure}

2 further doses of

Amoxicillin $1 \mathrm{~g}$ i.v. 8 hourly

Metronidazole $500 \mathrm{mg}$ i.v. 8 hourly

\section{Have available:}

Hydralazine i.v. for hypertension (alternatively nitroprusside, labetalol). Colloids for hypotension.

Methylprednisolone. 


\section{POST-EMBOLISATION}

- Usual post angiogram observations (i.e. foot temperature, peripheral pulses, Tㅇ, BP and HR).

- Careful attention to fluid balance is needed.

- Daily biochemistry including GGT, CRP, and haematology for at least 3 days.

- Monitor specific tests, e.g. urinary 5-HIAA in carcinoid syndrome or gut peptides, every other day.

- Expect pyrexia and malaise for up to ten days but perform blood cultures daily until pyrexia subsides.

- If abdominal symptoms persist, arrange appropriate investigations (erect and supine X-rays, $\mathrm{U} / \mathrm{S}$ abdomen) and ask for a surgical opinion.

\section{RESULTS OF TREATMENT}

In approximately $60 \%-80 \%$ of patients who have symptoms from secreting hepatic secondaries there will be an improvement with embolisation.

Revascularisation will occur with a recurrence of symptoms after weeks, months or years.

Embolisation can be successfully repeated.

Hepatic embolisation is not known to prolong life - this is purely a palliative procedure.

\section{REFERENCE}

Allison (1978) Br. J. Hosp. Med. 20:707

Adjani et al. (1988) Ann. Intern. Med. 108:340

\section{VERSION HISTORY}

Stephen Gilbey 11/89; revised Bernard Khoo 7/00 and Sarah Stanley 07/01 


\section{OVARY}

\section{INFERTILITY}

\section{HISTORY}

- Menstrual history

- Weight loss or weight gain

- Hyperandrogenaemia (hirsutism, acne, acanthosis nigricans)

- Use of contraception

- Prescription medication, recreational drugs (esp. cannabis, opioids)

- Stress, weight loss, history of eating disorder, exercise frequency galactorrhoea

- Frequency of sexual intercourse

- Previous pregnancies

- Partner fertility history

\section{INVESTIGATIONS}

Women with irregular menstrual cycles should be offered a test to measure LH, FSH, SHBG, testosterone, 17-OHP, DHEAS, oestrogen, thyroid function, prolactin.

\section{SCREENING FOR OVULATION}

\section{INDICATION}

To confirm ovulation in a woman WITH PERIODS presenting with infertility.

\section{BACKGROUND}

1. LH and FSH rise for approximately 48 hours ("surge") at the onset of the ovulatory phase of the menstrual cycle.

2. Progesterone production rises in the ovulatory phase to a maximum during the luteal phase.

3. Basal body temperature rises by $>0.5^{\circ} \mathrm{C}$ during the ovulatory phase peaking about 8 days after the LH surge.

\section{PREPARATION}

Confirm menstruation. Exclude other causes of infertility including hyperprolactinaemia, chromosomal problems, and thyroid dysfunction. 


\section{METHOD}

1. Arrange for blood for progesterone to be taken in the mid luteal phase. During a 28 day cycle this would be on day 21. During a 35 day cycle this would be on day 28 (i.e. 7 days prior to next predicted menses). In more prolonged cycles, this can be repeated weekly until menses. For women with irregular cycles, one approach could be to request testing on days 18, 21 and 24 for progesterone. This should be undertaken for at least 2 cycles.

2. A more intensive screening regimen is undertaken in the IVF clinic, and referral is an alternative option.

3. Blood for progesterone is taken in red top Vacutainers and may be posted to the lab.

\section{INTERPRETATION}

- Progesterone $>30 \mathrm{nmol} / \mathrm{L}$ indicates an adequate luteal phase (ovulation and production of progesterone by corpus luteum). Levels $>18 \mathrm{nmol} / \mathrm{Lmay}$ correlate with adequate luteal phase but should be repeated.

- Evidence of ovulation and adequate luteal phase should prompt further investigation of causes of infertility unrelated to ovulation or menstrual cycle (husband's sperm count, tube problems etc.). A postcoital test should be considered if there is no evidence for any of these.

- If there is no evidence of ovulation: review screening tests for other systemic causes of infertility or consider clomiphene test.

\section{REFERENCE}

Sverdloff et al., (1988) Endo. Metab. Clin. N. Amer. 17:301

Williams et al., (2003) J Clin Pathol 56:480

\section{PROGESTERONE CHALLENGE}

Medroxyprogesterone $10 \mathrm{mg}$ po OD $\times 5$ days to induce uterine bleeding

If patient has bleeding within one week of stopping progesterone, then she has both a sufficient amount of estrogen to stimulate endometrial growth and a normal outflow tract, but she is lacking in progesterone. Anovulation is the cause. These women are at risk for endometrial hyperplasia from unopposed estrogen. They should be treated with cyclic progesterone to induce withdrawal bleeding periodically ( $\geq 4$ times per year), or alternatively OCPs can be prescribed if no pregnancy is desired. If pregnancy is desired, clomiphene can be used to induce ovulation.

If patient has no bleeding, she either has an outflow-tract defect or is estrogen-deficient from ovarian failure or dysfunction of the hypothalamic-pituitary axis. You can use a combination oral contraceptive pill for 21 days to induce menses; if no bleeding-- the patient likely has outflow tract obstruction-- although this diagnosis is usually easily made by history alone. 


\section{CLOMIPHENE TEST}

\section{INDICATION}

Demonstration of the capacity for ovulation to be induced in a woman with infertility and anovulation, using clomiphene, a selective oestrogen receptor modulator. Clomiphene prevents oestrogen binding at the hypothalamus and pituitary therefore blocking the ususal negative feedback resulting in $\mathrm{LH} / \mathrm{FSH}$ surge.

NB This should be performed by the Fertility Specialists as these patients require follicle tracking

\section{CONTRAINDICATIONS}

Pregnancy

\section{PREPARATION}

Timing of cycle needs to be explained (first day of period $=$ day 0 ).

Women without cycles have to start test at an arbitrary time.

\section{SIDE EFFECTS}

Rarely causes abdominal bloating.

Small risk of multiple pregnancy.

Rarely, ovarian hyperstimulation with cardiovascular collapse, ascites and pleural effusions.

\section{METHOD}

1. Give clomiphene po for 5 days at dose of $50 \mathrm{mg} /$ day starting at day 5 .

2. Blood is taken for baseline measurements on day 6 and at 2 day intervals between days 18 and 24, measuring $\mathrm{LH}, \mathrm{FSH}$, progesterone and oestradiol.

3. Keep a temperature chart.

4. If the test is unsuccessful over 2 cycles, repeat using higher doses of clomiphene (100 and 200 $\mathrm{mg} /$ day), cautiously

\section{INTERPRETATION}

A rise in $\mathrm{LH}$ and $\mathrm{FSH}$ occurs, This in turn leads to follicular maturation, oestrogen production, and ovulation.

Thus a positive result is a:

$$
\begin{aligned}
& \text { rise in } \mathrm{LH} \text { (to }>20 \mathrm{IU} / \mathrm{L} \text { ). rise in } \mathrm{FSH} \text { (to }>10 \mathrm{IU} / \mathrm{L} \text { ). } \\
& \text { rise in progesterone to }>30 \mathrm{nmol} / \mathrm{L} \text {. } \\
& \text { rise in temperature by }>0.5^{\circ} \mathrm{C} \text { to help confirm ovulation. }
\end{aligned}
$$

\section{SENSITIVITY AND SPECIFICITY}

The sensitivity and specificity is poorly defined. The difficulties with this test are:

Variable response to a given dose 
Therefore no clear-cut guidelines for a negative result

The potential value is that a positive result confirms relatively minor hypothalamo-pituitary dysfunction causing anovulation that should resolve spontaneously or be easily treated.

REFERENCE

Sverdloffet al., (1988) Endo. Metab. Clin N. Amer. 17:301

\section{HYPOGONADOTROPHIC HYPOGONADISM}

Fertility possible, but may need subcutaneous gonadotrophins:

Referral to Fertility Services at Queen Charlotte's Hospital (Mr Stuart Lavery) as follicular tracking essential.

\section{POLYCYSTIC OVARIAN SYNDROME}

\section{DIAGNOSTIC CRITERIA}

Exclude hyperprolactinemia, non-classical congenital adrenal hyperplasia, thyroid dysfunction, androgen-secreting tumours (an acute history is suggestive; testosterone usually $>5 \mathrm{nmol} / \mathrm{L}$ ), and Cushing's syndrome first.

Three different sets of diagnostic criteria are currently recognised and used in clinical practice. In the UK, the 2003 Rotterdam criteria trend to be predominant.

\section{Rotterdam criteria}

Two of the following conditions: hyperandrogenism; chronic anovulation; polycystic ovaries

\section{NIH-NICHD criteria}

Both hyperandrogenism and chronic anovulation

\section{Androgen Excess Society criteria}

Hyperandrogenism and ovarian dysfunction (including infrequent or irregular ovulation or anovulation and/or polycystic ovaries).

\section{APPROACH TO PCOS TREATMENT}

Crucially, the approach will depend on what the most pressing symptom is as hirsutism and anovulation/oligomenorrhea are treated differently.

\section{HYPERANDROGENISM}

Clinical: Hirsutism (can be assessed by the modified Ferriman Gallwey score), acne, androgen dependent alopecia.

It can take 6 months for symptoms to improve on therapy, and maximal benefit is usually seen at 18 months. 
Biochemical: Elevated androgens especially testosterone and androstenedione.

In a hirsute woman, an adrenal or ovarian androgen producing tumour must be excluded if testosterone $>5 \mathrm{nmol} / \mathrm{L}$ (unlikely anyway, so some authors ignore this and simply repeat testosterone).

\section{Management}

Weight reduction: This is 2-7\% effective in reducing androgen levels.

Oral contraceptive pill: Oestrogen component increases SHBG,Progestin componentsuppresses LH and thus ovarian androgen production and some progestins can also antagonise androgen receptor and inhibit 5alpha reductase activity. Particularly indicated if patient wishes to have contraception, or wishes to have regular withdrawal bleeds. Contraindicated particularly if $\mathrm{BMI}>35$, past history of DVT/PE, history of breast cancer, uncontrolled hypertension or smoker. Avoid the OCPs with levonorgestrel (e.g. Microgynon, Logynon) as these have androgenic activity. Norgestimate and desogestrel are virtually non-androgenic progestins. Drospirenone is a spironolactone analogue and can be used in combination with ethinyl estradiol.

Antiandrogens (e.g. cyproterone acetate, spironolactone, flutamide, finasteride): Antiandrogens inhibit the binding of testosterone and 5alpha dihydrotestoterone to the androgen receptor. They can be potentially teratogenic, so are usually used in conjunction with reliable contraception. Dianette is a pill-like preparation containing cyproterone acetate and ethinylestradiol, so also provides effective contraception. LFTs need to be monitored, and its use is contraindicated in those with high risk of thromboembolism.

Vaniqa: cream, applied to face (only licensed for facial hirsutism). Can take up to 4 months to show total effects. Often causes skin rash.

Skin laser therapy: best employed if have fair skin/dark hair. There are various types of laser available: needs to be matched to complexion. Not usually available on NHS. Has a suppressive activity on hair growth.

Electrolysis: not usually available on NHS.

Regaine: effective for androgenic alopecia but effects wear off if stopped. Available over the counter ( $2 \%$ solution). Not prescribable on NHS.

Metformin: not effective for hirsutism.

\section{OLIGOMENORRHOEA IN PATIENTS NOT WISHING TO BECOME PREGNANT Management}

Oral contraceptive pill: The Endocrine Society guidelines (2013) advise these as first-line therapy, since this provides regular withdrawal bleeds.

Metformin: only moderately effective at restoring cycles. The 2013 Endocrine Society Guidelines advises metformin is (1) second-line therapy when the pill is not tolerated / contraindicated; (2) firstline in patients with T2DM or IGT failing lifestyle intervention.

Intermittent progestagens: e.g. Duphaston $10 \mathrm{mg}$ OD for 10 days to induce withdrawal bleeds. Usual practice is to prescribe this 3-4 times through the year. This is used if no other therapy is suitable. 


\section{SUBFERTILITY}

\section{Management}

Weight reduction and exercise is recommended by 2013 Endocrine Society Guidelines (for the likely reproductive and metabolic benefits).

Metformin: Clinical ovulation and pregnancy rates may be improved by metformin, but it is unclear whether or not this effect is independent of associated weight loss. Furthermore, metformin monotherapy is inferior to clomiphene citrate at achieving pregnancy or live-birth in obese women (Legro 2007).

Clomiphene citrate: $\mathrm{CC}$ should be administered within a fertility unit with access to ultrasonic follicle tracking. Clomiphene has both oestrogenic and anti-oestrogenic actions. This reduces negative feedback at the level of the hypothalamus and pituitary and increases pulsatile $\mathrm{GnRH}$ secretion.

\section{REFERENCES}

Franks (1995) N. Engl. J. Med. 333:853

Kousta (1997) Human Reproduction Update 3:359

Lord (2003) BMJ 327:951

Ehrmann (2005) N. Engl. J. Med. 352:1223

Dunaif et al., (2008) Nat Clin Pract Endocrinol Metab 4:272

Koulouri et al., (2008) Clin Endocrinol (Oxf) 68:800

Legro et al., (2007) N. Engl. J. Med. 356:551

Legro et al., (2013) Diagnosis and Treatment of PCOS: An Endocrine Society Clinical Practice

Guideline J Clin Endocrinol Metab (2013) 98:4565

\section{VERSION HISTORY}

Updated Sagen Zac-Varghese 11/13, reviewed Alexander Comninos and Channa Jayasena 08/14. 


\section{HORMONE REPLACEMENT THERAPY}

\section{TABLETS}

*The progesterones are arranged according to strength with the strongest at the top and the weakest at the bottom.

ConjEO = Conjugated Equine Oestrogens

\begin{tabular}{|c|c|c|c|c|}
\hline \multicolumn{3}{|c|}{$\begin{array}{l}\text { Sequential Oestrogen \& Progesterone Combinations (induce a period } \\
\text { every } 4 \text { weeks except Tridesta) }\end{array}$} & \multirow[t]{2}{*}{$\begin{array}{l}\text { Continuous } \\
\text { Combined } \\
\text { Equivalent (provide } \\
\text { continuous } \\
\text { progesterone) }\end{array}$} & \multirow[t]{2}{*}{$\begin{array}{l}\text { Unopposed Oestrogens } \\
\text { (only for women without a } \\
\text { uterus or when progesterone } \\
\text { is prescribed seperately) }\end{array}$} \\
\hline & Oestrogen & Progesterone $^{\star}$ & & \\
\hline Climagest & $\begin{array}{l}\text { Oestradiol } \\
(1 \mathrm{mg}, 2 \mathrm{mg})\end{array}$ & Norethisterone $(1 \mathrm{mg})$ & $\begin{array}{l}\text { Climesse } \\
(2 \mathrm{mg} / 0.7 \mathrm{mg})\end{array}$ & Bedol (2 mg) \\
\hline Clinorette & $\begin{array}{l}\text { Oestradiol } \\
(2 \mathrm{mg}, 2 \mathrm{mg})\end{array}$ & Norethisterone $(1 \mathrm{mg})$ & $\begin{array}{l}\text { Elleste Duet Conti } \\
2 \mathrm{mg} / 1 \mathrm{mg})\end{array}$ & Climaval (1mg, 2mg) \\
\hline Elleste Duet & $\begin{array}{l}\text { Oestradiol } \\
(1 \mathrm{mg}, 2 \mathrm{mg})\end{array}$ & Norethisterone $(1 \mathrm{mg})$ & $\begin{array}{l}\text { Kliofem }(2 \mathrm{mg}, 1 \mathrm{mg}) / \\
\text { Kliovance } \\
(1 \mathrm{mg} / 0.5 \mathrm{mg})\end{array}$ & Elleste Solo $(1,2 \mathrm{mg})$ \\
\hline Novofem & $\begin{array}{l}\text { Oestradiol } \\
(1 \mathrm{mg})\end{array}$ & Norethisterone (1mg) & $\begin{array}{l}\text { Nuvelle continuous } \\
(2 \mathrm{mg} / 1 \mathrm{mg})\end{array}$ & $\begin{array}{l}\text { Hormonin (oestriol } \\
\text { 270ug/oestradiol } \\
\text { 600ug/oestrone 1.4mg) }\end{array}$ \\
\hline Trisequens & $\begin{array}{l}\text { Oestradiol } \quad(1- \\
2 \mathrm{mg})\end{array}$ & Norethisterone $(1 \mathrm{mg})$ & & $\begin{array}{l}\text { Premarin }(0.3,0.625,1.25 \mathrm{mg}) \\
\text { (Conjugated } \\
\text { oestrogen) }\end{array}$ \\
\hline & & & & Progynova $(1,2 \mathrm{mg})$ \\
\hline Cyclo-progynova & $\begin{array}{l}\text { Oestradiol } \\
(2 \mathrm{mg})\end{array}$ & Levonorgestrel (250mcg) & & Zumenon $(1,2 \mathrm{mg})$ \\
\hline Nuvelle & $\begin{array}{l}\text { Oestradiol } \\
(2 \mathrm{mg})\end{array}$ & Levonorgestrel $(75 \mathrm{mcg})$ & & \\
\hline Premique Cycle & $\begin{array}{l}\text { ConjEO } \\
(0.625 \mathrm{mg})\end{array}$ & $\begin{array}{l}\text { Medroxyprogesterone } \\
(10 \mathrm{mg})\end{array}$ & $\begin{array}{l}\text { Premique } \\
(0.625 \mathrm{mg} / 5 \mathrm{mg})\end{array}$ & \\
\hline Prempak-C & $\begin{array}{l}\text { ConjEO } \\
(0.625,1.25 \mathrm{mg})\end{array}$ & Norgestrel (150mcg) & $\begin{array}{l}\text { Premique Low Dose } \\
(0.3 \mathrm{mg} / 1.5 \mathrm{mg})\end{array}$ & \\
\hline $\begin{array}{llr}\text { Tridestra } & \text { (induces } & \text { a } \\
\text { period } & \text { every } 13 \\
\text { weeks) } & & \\
\end{array}$ & $\begin{array}{l}\text { Oestradiol } \\
(2 \mathrm{mg})\end{array}$ & $\begin{array}{l}\text { Medroxyprogesterone } \\
(20 \mathrm{mg})\end{array}$ & $\begin{array}{l}\text { Indivina }(1-2 \mathrm{mg} / 2.5- \\
5 \mathrm{mg} M P A)\end{array}$ & \\
\hline Femoston $1 / 10 ; 2 / 10$ & $\begin{array}{l}\text { Oestradiol } \\
(1 \mathrm{mg}, 2 \mathrm{mg})\end{array}$ & Dydrogesterone (10mg) & $\begin{array}{l}\text { Femoston Conti } \\
(1 \mathrm{mg} / 5 \mathrm{mg})\end{array}$ & \\
\hline & & & Femoston Conti Low & \\
\hline
\end{tabular}




\begin{tabular}{|l|l|l|l|l|}
\hline & & & Dose $(0.5 \mathrm{mg} / 2.5 \mathrm{mg})$ & \\
\hline & & Drospirenone & Angeliq $(1 \mathrm{mg} / 2 \mathrm{mg})$ & \\
\hline
\end{tabular}

PATCHES

\begin{tabular}{|c|c|c|c|c|}
\hline \multicolumn{3}{|c|}{ Sequential Oestrogen \& Progesterone Combinations } & \multirow{2}{*}{$\begin{array}{l}\text { Continuous Combined } \\
\text { Equivalent }\end{array}$} & \multirow{2}{*}{$\begin{array}{l}\text { Unopposed Oestrogens } \\
\text { (only for women without a } \\
\text { uterus or when progesterone } \\
\text { is prescribed seperately) }\end{array}$} \\
\hline & Oestrogen & Progesterone & & \\
\hline Evorel-Sequi & $\begin{array}{l}\text { Oestradiol } \\
(50 \mathrm{mcg})\end{array}$ & $\begin{array}{l}\text { Norethisterone } \\
(170 \mathrm{mcg})\end{array}$ & $\begin{array}{l}\text { Evorel Conti } \\
\text { (50ug/170ug NT) }\end{array}$ & Evorel $(25,50,75,100)$ \\
\hline \multirow[t]{5}{*}{ Femseven Sequi } & $\begin{array}{l}\text { Oestradiol } \\
(50 \mathrm{mcg})\end{array}$ & $\begin{array}{l}\text { Levonorgestrel } \\
(10 \mathrm{mcg})\end{array}$ & $\begin{array}{l}\text { FemSeven Conti } \\
(50 \mathrm{mcg} / 7 \mathrm{mcg} \text { LVG) }\end{array}$ & $\begin{array}{lll}\text { Femseven } & (50,75,100) & {[7} \\
\text { days }] & & \end{array}$ \\
\hline & & & & Elleste Solo MX $(40,80)$ \\
\hline & & & & $\begin{array}{lll}\text { Estraderm } & & \text { MX } \\
(25,50,75,100) & \text { or } & \text { TTS } \\
(25,100) & & \end{array}$ \\
\hline & & & & $\begin{array}{l}\text { Estradot }(25,37.5,50,75 \text {, } \\
100)\end{array}$ \\
\hline & & & & $\begin{array}{lll}\text { Progynova } & \text { TS } & (50,100)[7 \\
\text { days }] & & \end{array}$ \\
\hline
\end{tabular}

Patches are changed every 3-4 days apart from those marked 7 days (which are changed every 7 days). Doses are in $\mathrm{mcg} / 24$ hours.

\section{GELS}

Oestrogel - Oestradiol (1.5mg)

Sandrena - Oestradiol $(0.5 \mathrm{mg}, 1 \mathrm{mg})$

\section{VAGINAL OESTROGENS}

\begin{tabular}{|l|l|l|}
\hline Estring & Oestradiol $(7.5 \mathrm{mcg})$ & Vaginal ring \\
\hline
\end{tabular}




\begin{tabular}{|l|l|l|}
\hline Gynest & Oestriol $(0.01 \%)$ & Vaginal cream \\
\hline Ortho-Gynest & Oestriol $(0.5 \mathrm{mg})$ & Pessary \\
\hline Ovestin & Oestriol $(0.1 \%)$ & Vaginal cream \\
\hline Vagifem & Oestradiol $(10 \mathrm{mcg}, 25 \mathrm{mcg})$ & Vaginal tablets \\
\hline
\end{tabular}

SYNTHETIC HRT

Livial - Tibolone $2.5 \mathrm{mg}$ (tablets)

PROGESTERONES

\begin{tabular}{|l|l|l|}
\hline Norethisterone & Norethisterone $5 \mathrm{mg}$ & Tablets \\
\hline Primolut N & Norethisterone $5 \mathrm{mg}$ & Tablets \\
\hline Utovlan & Norethisterone $5 \mathrm{mg}$ & Tablets \\
\hline Climanor & Medroxyprogesterone $(5 \mathrm{mg})$ & Tablets \\
\hline Provera & $\begin{array}{l}\text { Medroxyprogesterone } \\
(5 \mathrm{mg} / 10 \mathrm{mg})\end{array}$ & Tablets \\
\hline Mirena & Levonorgestrel $(20 \mathrm{mcg} / 24 \mathrm{hr})$ & IUS \\
\hline Only combined in Femoston & Dydrogesterone $(10 \mathrm{mg})$ & Tablets \\
\hline Uterogestan & $\begin{array}{l}\text { Micronised progesterone 1- } \\
\text { 200mg Tablets }\end{array}$ & \\
\hline Crinone & Progesterone $(8 \%)$ 90mg & Vaginal Gel \\
\hline Cyclogest & Progesterone $200 \mathrm{mg} / 400 \mathrm{mg}$ & Pessaries \\
\hline Gestone & Progesterone $50 \mathrm{mg} / \mathrm{ml}(5-10 \mathrm{mg}$ & Deep IM injection \\
& daily) & \\
\hline
\end{tabular}

The progesterones are arranged according to strength with the strongest at the top and the weakest at the bottom.

\section{VERSION HISTORY}

Gerry Conway, 11/13 


\section{ANDROLOGY}

\section{MALE HYPOGONADISM}

\section{INVESTIGATION}

1. Measure testosterone, LH, FSH and SHBG. Due to diurnal variation and glucose suppressive effects on $\mathrm{LH}$ and FSH, this should be a morning fasted sample. Stress/ illness and sleep deprivation affect serum $T$ so do not measure during these times.

2. In men with secondary hypogonadism measure prolactin and other pituitary hormones.

3. In men with primary and severe testicular failure of unknown aetiology, obtain a karyotype to exclude Klinefelter's.

4. Request a DXA to assess BMD.

\section{TREATMENT}

Testosterone replacement is advocated in men with symptomatic androgen deficiency to induce and maintain secondary sexual characteristics and muscle and bone mass.

Contraindications (as per Endocrine Society guidelines 2010)

- breast cancer

- prostate cancer

- palpable prostate mass

- do not use without prior urological evaluation if PSA $>4 \mathrm{ng} / \mathrm{ml}$ or PSA $>3 \mathrm{ng} / \mathrm{ml}$ if high risk for prostate cancer (Black ethnicity or first-degree relative with prostate cancer).

- patients at high risk of prostate cancer

- haematocrit $>50 \%$

- untreated obstructive sleep apnoea

- poorly controlled heart failure

\section{Formulations}

- Transdermal gels, 5-10 g of a $1 \%$ gel applied over non genital skin (warn patients to take care to not get gel on their female partners)

- Long acting testosterone undecanoate depot i.m. injections (every 3-5 months)

- Short acting testosterone ester i.m. every 7-21 days, 75-100 mg weekly or 150-200 mg every fortnight.

- Oral testosterone undecanoate (3-4 $\mathrm{x}$ a day with food) 


\section{MONITORING}

- Evaluate 3-6 months following treatment initiation then annually.

- PSA This is controversial. The Endocrine Society recommends regular PSA and DRE for men $>40 \mathrm{y}$ with baseline PSA $>0.6 \mathrm{ng} / \mathrm{ml}$, and recommend referral to urology if PSA increases to greater than $1.4 \mathrm{ng} / \mathrm{ml}$ in any 12 month period. Haematocrit - monitor at 3 and 6 months then annually. If Hct $>54 \%$, withhold until Hct decreases, and evaluate for OSA

- $\quad$ LFTs

- Consider repeat DXA scan .

\section{REFERENCE}

Bhasin et al., (2010) J Clin Endocrinol Metab 95:2536

\section{VERSION HISTORY}

Sagen Zac-Varghese 11/13, reviewed by Alexander Comninos and Channa Jayasena 08/14.

\section{POLICY ON SPERM STORAGE PRIOR TO PITUITARY RADIOTHERAPY}

Men at risk of infertility due to pituitary radiotherapy etc, have two treatment options:

1. If they become infertile, induce spermatogenesis using gonadotrophin injections (see protocol below). This gives the patient the chance to conceive naturally.

2. Refer for sperm freezing, so that the partner can later use frozen sperm during assisted reproductive technology (e.g. IVF).

NHS Funding for sperm freezing is currently supported by The Department of Andrology at Hammersmith Hospital, provided that the patient can be justified as having a form of cancer / tumour. To refer a patient for sperm freezing:

1. Check the following viral blood tests: HIV serology, Hep C serology, Hep B Surface antigen, Hep B Surface antibody, Hep B core antigen, HTLV serology.

2. Write a brief letter-headed referral letter to Dr Channa Jayasena, Consultant, The Department of Andrology, C Block, Hammersmith Hospital (c.jayasena@imperial.ac.uk; Channa.Jayasena@imperial.nhs.uk), which includes the results of the viral serology tests, and includes the diagnosis and treatment (e.g. radiotherapy) which make them high risk for infertility. Please feel free to discuss suitability of any referral to Dr. Jayasena by e-mail or phone. 


\section{FERTILITY INDUCTION IN HYPOGONADOTROPHIC HYPOGONADISM}

Patients who are on regular testosterone replacement should have this discontinued. Where the cause of infertility is hypogonadotrophic hypogonadism, replacement with $\mathrm{LH}+/-\mathrm{FSH}$ is carried out.

Dosing regimen for hypogonadism to induce spermatogenesis in men with testes $>4 \mathrm{ml}$ OR testosterone $>3 \mathrm{nmol} / \mathrm{L}$ (i.e. nearly all patients).

1. HCG (Pregnyl) 1500iu subcutaneously twice per week for 6 months. HCG has the action of pituitary LH.

2. Measure testosterone levels every 8 weeks. HCG stimulates LH receptors onLeydig cells to make testosterone (local concentration is key). If blood levels exceed the upper limit of normal (30nmol/l), the dose of Pregnyl can be halved.

3. Carry out sperm count after 6 months of Pregnyl treatment.

4. If still azoospermic, add to above Menopur 1 vial subcutaneously twice a week. Menopur contains $75 \mathrm{u} \mathrm{LH}$ and $75 \mathrm{u} \mathrm{FSH}$. The aim of this is for the FSH component to hopefully induce spermatogenesis. The dose of Menopur can be titrated aiming for a serum FSH 4-6 IU/L24 hours post-dose. The LH component of Menopur is not an issue in sperm induction and therefore, no adjustment of the Pregnyl dose is necessary.

5. Continue to check testosterone levels every 8 weeks. The dose of both Pregnyl and Menopur can be halved if levels exceed $30 \mathrm{nmol} / \mathrm{L}$. Re-check sperm count after 3 and 6 months of combination treatment. Combination treatment can be continued for 18 months.

6. If successful induction of spermatogenesis occurs but the couple cannot conceive, sperm freezing may be considered while the couple waits for IVF treatment etc. Please contact Dr. Jayasena (c.jayasena@imperial.ac.uk; Channa.Jayasena@imperial.nhs.uk) for advice or to discuss any referral.

7. Preparations of high purity synthetic FSH are available, but these are needed for stimulation of follicles in females, where LH will of course cause problems. These high purity preparations are more expensive, and are not required in males, where LH is given anyway.

FSH should induce an increase in testicular volume to the normal $15 \mathrm{mls}$ bilaterally, which can occur over the course of a year.

In the patients without any pubertal development (i.e. testes $<4 \mathrm{ml}$ and testosterone $<3 \mathrm{nmol} / \mathrm{L}$ ), a recent small study suggested that 4 months pre-treatment with 75-150 IU recombinant FSH (without any LH-like activity) aiming to achieve a serum FSH 7-9 IU/Lmay improve the results of subsequent fertility induction (Dwyer et al. JCEM 2013).

Updated Channa Jayasena 03/15, Alexander Comninos 9/15 


\section{NORMAL SEMEN ANALYSIS RESULTS}

Below are the most important and robust parameters to determine fertility (other tests such as morphology have poor evidence for predicting fertility, and can vary between operators / labs).

$\begin{array}{ll}\text { Parameter } & \text { Reference value } \\ \text { Volume } & \geq 1.5 \mathrm{ml} \\ \text { Spermatozoa conc (million/ml) } & >15 \\ \text { Total sperm number } & >39 \text { million per ejaculate } \\ \text { Total Motility \% } \quad \text { Progressive } & >32 \% \\ \quad \text { Total } & >40 \%\end{array}$

Please contact Dr. Channa Jayasena (c.jayasena@imperial.ac.uk) if you require any further advice.

\section{REFERENCE}

NICE guidelines: Fertility: Assessment and treatment for people with fertility problems February 2013

Updated Sagen Zac-Varghese 11/13 and reviewed by Channa Jayasena 08/14

\section{GYNAECOMASTIA}

Hyperplasia of glandular breast tissue seenin infancy, adolescence and older men, caused by an imbalance between the actions of oestrogen and free androgen in the breast tissue. Nipple bleeding or discharge is seen in $10 \%$ people with breast cancer but is not seen in gynaecomastia. If there is a concern about differentiating gynaecomastia from breast cancer a diagnostic mammogram should be arranged.

\section{CAUSES}

- $\quad$ Drug induced - Methadone, Opiates, PPI, protease inhibitors, phenytoin, spironolactone (these drugs may displace oestrogen more readily that testosterone from SHBG and increase bioavailability of oestrogen).

- Testicular germ cell tumours.

- Extragonadal germ cell tumour or ectopic hCG secreting tumour (large cell lung ca, gastric or renal ca).

- Adrenal neoplasm (produces androgen precursors which are converted to oestrogen in peripheral tissue).

- Secondary hypogonadism.

- Hyperthyroidism (increased SHBG binds testosterone more readily leading to a relative reduction in free testosterone relative to free oestrogen).

- Prolactinaemia. 
- Androgen resistance.

- Increased extraglandular aromatase activity (seen in Klinefelter's, adrenal and testicular tumours).

- Idiopathic.

\section{INVESTIGATIONS}

Measure hCG, LH, testosterone and oestradiol

LH/ FSH

Testosterone

SHBG

Prolactin

Oestradiol

\section{TREATMENT}

- Stop the offending drug.

- Surgery: Idiopathic gynaecomastia is best treated with liposuction by a Plastic surgeon (eg Mr Shehan Hettiaratchyat Charing Cross). There is a worse outcome in older or obese men.

- Two small RCTs suggest that tamoxifen 10-20 mg daily may be effective in treating gynaecomastia induced by bicalutamide (Parker et al. 1986; Perdona et al.) but this application is off-licence.

\section{REFERENCES}

Parker et al., (1986) Metabolism 35:705

Perdonà et al., (2005) Lancet Oncol.6:295

Braunstein, (2007) New Engl J Med 357:1229

\section{VERSION HISTORY}

Updated Sagen Zac-Varghese 11/13 and reviewed by Channa Jayasena 08/14 


\section{OBESITY}

\section{THE IMPERIAL WEIGHT CENTRE TIER 3 WEIGHT MANAGEMENT SERVICE, ST MARY'S HOSPITAL.}

We operate a specialist Tier 3 weight management programme for obese patients who have not responded to a previous Tier 2, community-based, obesity management service. Our tier 3 service is comprised of a multi-disciplinary team that offers a non-surgical, holistic approach to the long term management of obesity. The team consists of an endocrinologist with a specialist interest in bariatric medicine, a specialist weight management dietician and a clinical psychologist.

We assess patients for obesity related comorbidities including type 2 diabetes, hypertension, obstructive sleep apnoea, ischaemic heart disease, hypercholesterolaemia, and polycystic ovarian syndrome. Our aim is to empower, educate and encourage patients with managing their weight through better eating habits, increasing physical activity and managing their feelings around food with a view to improving health and quality of life.

\section{CRITERIA FOR REFERRAL TO THE TIER 3 WEIGHT MANAGEMENT SERVICE}

- $\quad B M I \geq 40 \mathrm{~kg} / \mathrm{m}^{2}$ or

- BMI between $35 \mathrm{~kg} / \mathrm{m}^{2}$ and $40 \mathrm{~kg} / \mathrm{m}^{2}$ with a significant obesity related comorbidity, such as type 2 diabetes, hypertension, obstructive sleep apnoea, ischaemic heart disease, hypercholesterolaemia, and polycystic ovarian syndrome.

- Consider a referral to our tier 3 weight management service in patients being considered for bariatric surgery with a BMI of $30-34.9 \mathrm{~kg} / \mathrm{m}^{2}$, who have a recent onset of type 2 diabetes $\quad<$ 10 years from the time of diagnosis).

\section{BARIATRIC SURGERY AT THE IMPERIAL WEIGHT CENTRE, ST MARY'S HOSPITAL}

Information regarding bariatric surgery at The Imperial Weight Centre, St Mary's Hospital, ICHNT, including the types of weight loss surgery performed can be found at http://www.imperial.nhs.uk/services/weightloss/

It is important to be aware of the post-bariatric surgery metabolic complications that can occur in some patients. These include:

Post-bypass hypoglycemia (see Post Bypass Hypoglycaemia Protocol)

Nutritional deficiencies (see Post-surgery diet) 
We also use post-operative protocols relevant to the management of certain patient groups:

Type 1 diabetes

Type 2 diabetes

Pregnancy in women who have undergone bariatric surgery

These protocols are available at http://www.imperial.nhs.uk/services/patientinformation/index.htm

Click on the bariatric tab

\section{CRITERIA FOR REFERRAL FOR BARIATRIC SURGERY AT ST MARY'S HOSPITAL}

- $\mathrm{BMI} \geq 40 \mathrm{~kg} / \mathrm{m}^{2}$ or

- BMI between $35 \mathrm{~kg} / \mathrm{m}^{2}$ and $40 \mathrm{~kg} / \mathrm{m}^{2}$ and a significant obesity related comorbidity, such obstructive sleep apnoea, ischaemic heart disease, hypercholesterolaemia, polycystic ovarian syndrome and depression.

- All appropriate non-surgical measures have been tried but the person has not achieved or maintained adequate, clinically beneficial weight loss.

\section{CRITERIA FOR REFERRAL FOR BARIATRIC SURGERY AT ST MARY'S HOSPITAL FOR PATIENTS WITH RECENT ONSET TYPE 2 DIABETES}

The NICE Guidance (2014) defines recent onset of type 2 diabetes as diagnosis within the last 10 years

Consider an assessment for bariatric surgery for people with

- BMI of $\geq 30 \mathrm{~kg} / \mathrm{m}^{2}$ who have recent-onset type 2 diabetes.

- In particular, in patients from an Asian family background, who have recent-onset type 2 diabetes, consider an assessment for bariatric surgery at a lower BMI than other populations

Roux-en-Y gastric bypass is the surgical option most likely to result in diabetes remission. Improvement in glycaemic control is often evident within days to weeks, an effect that is independent of weight loss.

The longer the duration of diabetes, the less likely it is that patients receiving insulin therapy will come off it all together post-bariatric surgery. A pre-operative duration of type 2 diabetes greater than 10 years significantly reduces the chance of diabetes remission. 


\section{DEFINITION OF THE REMISSION OF TYPE 2 DIABETES}

- Partial remission: HBA1C $<6.5 \%$ and FG 5.6-6.9 mmol/L(off diabetes medications for $1 \mathrm{yr})$

- Complete remission: $\mathrm{HBA} 1 \mathrm{C}<6 \%$ and $\mathrm{FG}<5.6 \mathrm{mmol} / \mathrm{L}$ (off diabetes medications for 1yr)

- Prolonged remission: At least 5 years of complete remission

\section{PRE-OPERATIVE ASSESSMENT}

Pre-operatively, patients are assessed by the following members of the ICHNT Bariatric Team:

Bariatric Physician; Bariatric Surgeon; Psychologist/Psychiatrist; Bariatric Dietician; Specialist Anesthetist. Patients might also be referred for a specialist opinion regarding an associated comorbidity e.g. cardiology, respiratory, gastroenterology.

Once the pre-operative assessment is complete the case is discussed at the ICHNT Bariatric MDT and a decision made regarding the patient's suitability for surgery. For further information see http://www.imperial.nhs.uk/services/weightloss/

\section{REFERRALS}

Referrals for assessment at the Imperial Weight Centre should be sent to:

Dr Harvinder Chahal, Consultant Endocrinologist and Lead Bariatric Physician, Imperial College Healthcare NHS Trust, 3rd Floor, Salton House, St. Mary's Hospital Praed Street, London W2 1NY

\section{REFERENCES}

Pories et al., (1995) Who would have thought it? An operation proves to be the most effective therapy for adult-onset diabetes mellitus. Ann Surg 222:339

Buchwald et al., (2004) Bariatric surgery: a systematic review and meta-analysis. JAMA 292:1724

Sjöström et al., (2004) Lifestyle, diabetes, and cardiovascular risk factors 10 years after bariatric surgery. N Engl J Med. 351:2683

Longitudinal Assessment of Bariatric Surgery (LABS) Consortium (2009) N Engl J Med. 361:445

Buse, et al., (2009) Diabetes Care 32:2133

Hall et al., (2010) Preoperative factors predicting remission of type 2 diabetes mellitus after Roux-enY gastric bypass surgery for obesity. Obes Surg 20:1245

Obesity: identification, assessment and management of overweight and obesity in children, young people and adults NICE guidelines [CG189]. November 2014 https://www.nice.org.uk/guidance/cg189 
Dixon et al (2008) Adjustable gastric banding and conventional therapy for type 2 diabetes: a randomized controlled trial. JAMA 299316-323

Mingrone et al (2012) et al. Bariatric Surgery versus Conventional Medical Therapy for Type 2 Diabetes. N Engl J Med. 2366:1577-1585

Ikramuddin et al (2013) Roux-en-Y Gastric Bypass vs Intensive Medical Management for the Control of Type 2 Diabetes, Hypertension, and Hyperlipidemia The Diabetes Surgery Study Randomized Clinical Trial. JAMA 309:2240-2249.

International Diabetes Federation Taskforce on Epidemiology and Prevention (2011). Bariatric surgery: an IDF statement for obese Type 2 diabetes. Diabetic Medicine 28:628-642.

Mingrone et al (2012) Bariatric surgery versus conventional medical therapy for type 2 diabetes. N Engl J Med. 366:1577-1585.

Schauer et al (2012) Bariatric surgery versus intensive medical therapy in obese patients with diabetes. N Engl J Med.;366:1567-1576.

Schauer et al (2014) the STAMPEDE Investigators. Bariatric Surgery versus Intensive Medical Therapy for Diabetes - 3-Year Outcomes. N Engl J Med. 370:2002-13.

Mingrone et al (2015) Bariatric-metabolic surgery versus conventional medical treatment in obese patients with type 2 diabetes: 5 year follow-up of an open-label, single-centre, randomised controlled trial. Lancet. 386:964-73

\section{VERSION HISTORY}

Saira Hameed and Harvinder Chahal 03/15 


\section{OTHER MISCELLANEOUS CONDITIONS}

\section{SYSTEMIC MASTOCYTOSIS}

\section{METHOD}

1. Collect a sample of urine shortly after an attack for urinary methyl histamine, which will be excreted in the following hour. A spot urine is adequate.

2. Also collect a clotted sample of blood for serum tryptase.

3. Collect a further sample of urine and blood $24 \mathrm{~h}$ later to serve as a baseline for comparison.

- Thus two samples of serum and two samples of urine should be sent together for assay of urinary methyl histamine and serum tryptase to Chemical Pathology on a white miscellaneous form.

- Assays for urinary methyl histamine and serum tryptase are carried out by Dr John Watkins, Department of Immunology, NorthernGeneralHospital, P.O. Box 894, SheffieldS5 7YT. Tel: 01742 434343 ext 5728 Fax: 01742619893

\section{INTERPRETATION}

Normal methyl histamine:

$5-20 \mathrm{ng} / \mathrm{ml}$.

Typical patient with systemic mastocytosis: $>100 \mathrm{ng} / \mathrm{ml}$

Typical patient following beesting: $>2000 \mathrm{ng} / \mathrm{ml}$

Normal plasma tryptase $<1$

\section{VERSION HISTORY}

Karim Meeran 7/94

\section{ISCHAEMIC LACTATE TEST}

\section{INDICATIONS}

Suspected metabolic muscle disease.

This protocol is from Professor Land at Queen's Square.

Contact numbers: 02078373611 / 02078339391.

\section{CONTRAINDICATIONS}

None. 


\section{PREPARATION}

- Warn biochemistry $24 \mathrm{hrs}$ prior to test that assays for pyruvate, ammonia and lactate will be required.

- Tubes for pyruvate: Tubes prepared in the lab by the addition of $2 \mathrm{mls}$ perhexilene and refrigerated overnight. Add $1 \mathrm{ml}$ of blood to each tube accurately. Specimens for pyruvate must be handled carefully and placed on ice and taken to the lab immediately.

- Tubes for lactate: Grey top fluoride oxalate bottles (samples stored on ice).

- Tubes for ammonia: 9 paediatric lithium-heparin tubes (samples stored on ice). The 9th tube is a control, to measure the background ammonia levels in the samples.

\section{METHODS}

1. Fast from midnight.

2. The patient must spend the day relaxing, not doing any exercise.

3. 2 people needed to assist with sampling.

4. Insert i.v. cannula into large forearm vein with a three-way tap.

5. All specimens should be free flowing blood.

6. Take baseline bloods (-2 $\mathrm{min}$ ) for lactate, pyruvate, ammonia, CK, phosphate and uric acid.

- At each time point discard $3 \mathrm{mls}$ of blood from the cannula, take $1 \mathrm{ml}$ for pyruvate in a $2 \mathrm{ml}$ syringe so that the volume is accurate, and $6 \mathrm{~m} / \mathrm{s}$ in a $10 \mathrm{~m} /$ syringe for the rest. Flush the cannula with normal saline and put the bottles on ice immediately.

7. Place sphygmomanometer on the cannulated arm and inflate the cuff above systolic pressure. The patient exercises the arm rhythmically by squeezing some rolled up paper towels or a ball. The hand must be fully extended between squeezes. Exercise the hand for 2 minutes.

8. Release the cuff, this is time $=0$.

9. At time $0,1,2,4,6,8$ and 10 min take blood for lactate, pyruvate and ammonia as above.

\section{INTERPRETATION}

- Normally the lactate rises by $3-5 \times$ baseline.

- The ammonia rises from $40 \mu \mathrm{mol} / \mathrm{Lto}$ about $100 \mu \mathrm{mol} / \mathrm{L}$.

- The normal lactate:pyruvate ratio is $10-20$ which rises to $30-40$ on exercise.

The lactate test is positive when the patient exercises and they can't open their hand fully. The lactate level remains unchanged, as glycogenolysis is defective. The ammonia level rises dramatically to $300-400 \mu \mathrm{mol} / \mathrm{L}$. The lactate to pyruvate ratio is $10-30$ and does not change on exercise.

\section{VERSION HISTORY}

Arshia Panahloo and Leighton Seal 01/98 


\section{REFERENCE RANGES}

These are correct at time of publishing.

Note that these ranges only apply to assays performed at ICHNT.

\begin{tabular}{|c|c|c|c|}
\hline Compound [MW] & Conditions & Reference range & Sample \\
\hline \multicolumn{4}{|c|}{ STEROIDS \& RELATED } \\
\hline Oestradiol [272] & $\begin{array}{l}\text { Early follicular } \\
\text { Luteal } \\
\text { Pre-ovulatory } \\
\text { Post-menopausal } \\
\text { Male }\end{array}$ & $\begin{array}{l}200-500 \mathrm{pmol} / \mathrm{L} \\
250-1000 \mathrm{pmol} / \mathrm{L} \\
500-1500 \mathrm{pmol} / \mathrm{L} \\
<100 \mathrm{pmol} / \mathrm{L} \\
<190 \mathrm{pmol} / \mathrm{L}\end{array}$ & $P$ \\
\hline Oestrone & Post menopausal & $<260 \mathrm{pmol} / \mathrm{L}$ & $P$ \\
\hline Testosterone [288] & $\begin{array}{l}\text { Female } \\
\text { Male }\end{array}$ & $\begin{array}{l}<2.7 \mathrm{nmol} / \mathrm{L} \\
10-30 \mathrm{nmol} / \mathrm{L}\end{array}$ & $\mathrm{P} / \mathrm{S}$ \\
\hline Dihydrotestosterone & $\begin{array}{l}\text { Female } \\
\text { Male }\end{array}$ & $\begin{array}{l}<1.0 \mathrm{nmol} / \mathrm{L} \\
1.0-3.0 \mathrm{nmol} / \mathrm{L}\end{array}$ & $P$ \\
\hline Androstenedione & & $<9 \mathrm{nmol} / \mathrm{L}$ & $P$ \\
\hline DHEAS & $\begin{array}{l}\text { Female } 20-40 y \\
\text { Female } 40-60 y \\
\text { Female }>60 y\end{array}$ & $\begin{array}{l}0.7-11.5 \mu \mathrm{mol} / \mathrm{L} \\
0.8-6.9 \mu \mathrm{mol} / \mathrm{L} \\
0.4-4.7 \mu \mathrm{mol} / \mathrm{L}\end{array}$ & $P$ \\
\hline$S H B G$ & $\begin{array}{l}\text { Male } \\
\text { Female }\end{array}$ & $\begin{array}{l}15-55 \mathrm{nmol} / \mathrm{L} \\
30-100 \mathrm{nmol} / \mathrm{L}\end{array}$ & S \\
\hline Progesterone & $\begin{array}{l}\text { Follicular } \\
\text { Luteal }\end{array}$ & $\begin{array}{l}<5 \mathrm{nmol} / \mathrm{L} \\
>20 \mathrm{nmol} / \mathrm{L}\end{array}$ & $P$ \\
\hline 17-OH progesterone & Adult & $<9.6 \mathrm{nmol} / \mathrm{L}$ & $P$ \\
\hline
\end{tabular}




\begin{tabular}{|c|c|c|c|}
\hline Cortisol [362] & $\begin{array}{l}0900 \mathrm{~h} \\
2400 \mathrm{~h} \\
\text { We don't have a } \\
\text { midnight reference } \\
\text { range at the moment. } \\
\text { Current assay reads } \\
\sim 20 \% \text { lower than } \\
\text { previous assay so } \\
\text { ?amend accordingly }\end{array}$ & $\begin{array}{l}160-550 \mathrm{nmol} / \mathrm{L} \\
\text { (old }=50-260)\end{array}$ & $\mathrm{P} / \mathrm{S}$ \\
\hline $24 \mathrm{hr}$ urine free cortisol & $\begin{array}{l}\text { Plain bottle unless cats } \\
\text { also required }\end{array}$ & $50-270 \mathrm{nmol} / 24 \mathrm{hr}$ & U1 \\
\hline \multicolumn{4}{|c|}{ ANTERIOR PITUITARY } \\
\hline$A C T H[4500]$ & $\begin{array}{l}0900 h \\
2400 h\end{array}$ & $\begin{array}{l}<30 \mathrm{ng} / \mathrm{L} \\
<10 \mathrm{ng} / \mathrm{L}\end{array}$ & $E^{*}$ \\
\hline$\beta-h C G$ & non-pregnant & $0-<5 \mathrm{iU} / \mathrm{l}$ & $P$ \\
\hline$L H[28000]$ & $\begin{array}{l}\text { Follicular } \\
\text { Luteal } \\
\text { Mid-cycle } \\
\text { Postmenopausal } \\
\text { Male }\end{array}$ & $\begin{array}{l}2-10 \mathrm{U} / \mathrm{L} \\
4-14 \mathrm{U} / \mathrm{L} \\
20-60 \mathrm{U} / \mathrm{L} \\
>20 \mathrm{U} / \mathrm{L} \\
2-12 \mathrm{U} / \mathrm{L}\end{array}$ & $\mathrm{P} / \mathrm{S}$ \\
\hline$F S H[28-41,000]$ & $\begin{array}{l}\text { Follicular } \\
\text { Luteal } \\
\text { Mid-cycle } \\
\text { Postmenopausal } \\
\text { Male }\end{array}$ & $\begin{array}{l}1.5-10 \mathrm{U} / \mathrm{L} \\
1.5-8 \mathrm{U} / \mathrm{L} \\
10-507-20 \mathrm{U} / \mathrm{L} \\
>20 \mathrm{U} / \mathrm{L} \\
1.7-8 \mathrm{U} / \mathrm{L}\end{array}$ & $\mathrm{P} / \mathrm{S}$ \\
\hline Prolactin [21000] & $\begin{array}{l}\text { Female } \\
\text { Male }\end{array}$ & $\begin{array}{l}100-500 \mathrm{mlU} / \mathrm{L} \\
60-300 \mathrm{mIU} / \mathrm{L}\end{array}$ & $\mathrm{P} / \mathrm{S}$ \\
\hline$G H[21500]$ & $\begin{array}{l}\text { During ITT } \\
\text { During GTT }\end{array}$ & $\begin{array}{l}>6 \mu \mathrm{g} / \mathrm{L} \\
<0.6 \mu \mathrm{g} / \mathrm{L}\end{array}$ & $S$ \\
\hline
\end{tabular}




\begin{tabular}{|c|c|c|c|}
\hline \multicolumn{4}{|c|}{ THYROID } \\
\hline$T S H[27000]$ & & $0.3-4.2 \mathrm{mU} / \mathrm{L}$ & S \\
\hline Free T4 [711] & & $9.0-23.0 \mathrm{pmol} / \mathrm{L}$ & $S$ \\
\hline Free T3 & & $2.5-5.7 \mathrm{pmol} / \mathrm{L}$ & S \\
\hline Thyroglobulin & & $\begin{array}{l}\text { Not provided } \\
<1.0 \mathrm{mg} / \mathrm{Lin} \\
\text { throidectomised patients }\end{array}$ & B \\
\hline \multicolumn{4}{|c|}{ CALCIUM METABOLISM } \\
\hline Calcitonin & & $\begin{array}{l}0-4.8 \mathrm{ng} / \mathrm{L} \text { (female) } \\
0-11.8 \mathrm{ng} / \mathrm{L} \text { (male) }\end{array}$ & $\mathrm{P} / \mathrm{S}^{*}$ \\
\hline PTH & & $1.1-6.8 \mathrm{pmol} / \mathrm{L}$ & $E^{*}$ \\
\hline $25-\mathrm{OH}$ vitamin $\mathrm{D}$ & $\begin{array}{l}\text { Sufficient } \\
\text { Insufficient } \\
\text { Deficient }\end{array}$ & $\begin{array}{l}70-150 \mathrm{pmol} / \mathrm{Lnmol} / \mathrm{L} \\
40-70 \mathrm{pmol} / \mathrm{Lnmol} / \mathrm{L} \\
<40 \mathrm{pmol} / \mathrm{Lnmol} / \mathrm{L}\end{array}$ & S \\
\hline \multicolumn{4}{|c|}{ PEPTIDE HORMONES } \\
\hline Insulin [5807] & Fasting & $3-15 \mathrm{mU} / \mathrm{L}$ & $\mathrm{P} / \mathrm{S}^{*}$ \\
\hline C-peptide & Fasting & $\sim 30-70 x$ insulin & $\mathrm{P} / \mathrm{S}^{*}$ \\
\hline$I G F-1$ & $\begin{array}{l}<6 y \\
6-8 y \\
9-11 y \\
12-15 y \\
16-20 y \\
21-40 y \\
41-60 y \\
>61 y\end{array}$ & $\begin{array}{l}3.5-22 \mathrm{nmol} / \mathrm{L} \\
7-32 \mathrm{nmol} / \mathrm{L} \\
11-52 \mathrm{nmol} / \mathrm{L} \\
14-66 \mathrm{nmol} / \mathrm{L} \\
35-62 \mathrm{nmol} / \mathrm{L} \\
13-50 \mathrm{nmol} / \mathrm{L} \\
9-40 \mathrm{nmol} / \mathrm{L} \\
6-36 \mathrm{nmol} / \mathrm{L}\end{array}$ & $S$ \\
\hline Somatostatin & Fasting & $<150 \mathrm{pmol} / \mathrm{L}$ & $E^{*}$ \\
\hline $\begin{array}{l}\text { Chromogranin } A \\
\text { Chromogranin } B\end{array}$ & Fasting & $\begin{array}{l}<60 \mathrm{pmol} / \mathrm{L} \\
<150 \mathrm{pmol} / \mathrm{L}\end{array}$ & $E^{*}$ \\
\hline
\end{tabular}




\begin{tabular}{|c|c|c|c|}
\hline Glucagon & Fasting & $<50 \mathrm{pmol} / \mathrm{L}$ & $E^{*}$ \\
\hline Gastrin & Fasting & $<40 \mathrm{pmol} / \mathrm{L}$ & $E^{*}$ \\
\hline VIP & Fasting & $<30 \mathrm{pmol} / \mathrm{L}$ & $E^{*}$ \\
\hline Pancreatic polypeptide & Fasting & $<300 \mathrm{pmol} / \mathrm{L}$ & $E^{*}$ \\
\hline \multicolumn{4}{|c|}{ OTHER ADRENAL HORMONES } \\
\hline Renin & $\begin{array}{l}\text { Supine } \\
\text { (NOT on ice) }\end{array}$ & $0.5-3.1 \mathrm{pmol} / \mathrm{ml} / \mathrm{h}$ & $\mathrm{H}^{\star *}$ \\
\hline Aldosterone & Supine & $100-800 \mathrm{pmol} / \mathrm{L}$ & $\mathrm{H}(\text { or } \mathrm{P} / \mathrm{S})^{* *}$ \\
\hline \multicolumn{4}{|c|}{ CARCINOID SYNDROME } \\
\hline 24 hr urine $5-H I A A$ & & $<40 \mu \mathrm{mol} / 24 \mathrm{hrs}$ & U2 \\
\hline
\end{tabular}

Updated by Ben Jones 11/13, Jaimini Cegla 04/15.

\section{BLOOD}

$\mathrm{P}$ - plain tube (red top Vacutainer) delivered to the lab the same day

$S$-SST tube (yellow top Vacutainer) delivered to the lab the same day

E - EDTA tube (purple top Vacutainer)

$\mathrm{H}$ - lithium heparin tube (green top Vacutainer)

*deliver to lab on ice within 30 mins

** deliver to lab within 30 mins, NOT ON ICE

Note that in many cases $\mathrm{P}$ (red) and $\mathrm{S}$ (yellow) tubes are interchangeable. However this is not always the case - in particular, most sex steroids require a red tube as there is a risk they would be adsorbed onto the gel in a yellow tube.

\section{URINE (U)}

Two main types of bottles are available for 24 hour urine collections.

1. No Preservative: ELUC $\left(\mathrm{Na}^{+}, \mathrm{K}^{+}\right.$, urea, creatinine), creatinine clearance, total protein, uric acid, amylase, cortisol, urinary steroid profile.

2. $10 \% \mathrm{HCl}$ : (hydrochloric acid): ELUC $\left(\mathrm{Na}^{+}, \mathrm{K}^{+}\right.$, Urea, Creatinine), creatinine clearance, calcium, phosphate, magnesium, oxalate, catecholamines, VMA, 5HIAA, cortisol 
Since an acid bottle can be used for most tests, provided you are not measuring total protein, uric acid or amylase, an acid bottle should be requested.

\section{URGENT SAMPLES AND LOCALISATION STUDIES}

- Please discuss urgent samples with the duty biochemist on 30348.

- For localisation studies it is better to warn the lab in advance and on the day:

Give at least $1-2$ days notice

Provide lab with patients name and type of study and starting time.

Keep lab informed if samples likely to arrive after $5 \mathrm{pm}$, or if procedure cancelled.

If the samples are to be delivered within an hour of collection, it is not necessary to collect samples for PTH and insulin on ice.

ACTH and gut peptides must be collected on ice.

\section{REFERENCE RANGES FOR THYROID FUNCTION IN PREGNANCY (ICHNT)}

\section{Up to 12 weeks gestation}

fT4 9.9-15.2 pmol/L TSH 0.2-3.6 mU/L

\section{2-24 weeks gestation}

fT4 9-14.3 pmol/L TSH 0.6-2.8 mU/L

\section{4-36 weeks gestation}

fT4 8.1-13.4 pmol/L TSH 0.4-3.9 mU/L

\section{VERSION HISTORY}

Courtesy of Queen Charlotte's Hospital, Niamh Martin 11/08 


\section{SURGICAL CONTACTS}

\section{Mr Nigel Mendoza}

Consultant Neurosurgeon for all pituitary surgery.

For referrals: secretary tel no. 02088681790 and fax no. 020884067487

\section{Mr Fausto Palazzo}

Consultant Endocrine Surgeon. Patients for parathyroidectomy, adrenalectomy or resection of neuroendocrine tumours should be referred to Mr Fausto Palazzo, endocrine surgeon at Hammersmith Hospital. Patients with thyroid masses needing FNA can be referred to him via his clinic at Hammersmith.

For referrals: secretary tel no. 02083838542 and fax no. 020838332037

\section{Miss Veronica Ferguson and Miss Jane Olver}

Consultant Opthalmologists to see patients with thyroid eye disease needing review at Charing Cross Hospital.

For referrals:

Miss Ferguson's secretary: 02088461499

Eye clinic: tel no. 02088461955 and fax no. 02088461959

\section{Professsor Alun Davies}

Consultant Vascular Surgeon at Charing Cross hospital for sympathectomies in patients with sweating in whom an endocrine cause eg carcinoid, phaeochromocytoma, has been excluded.

For referrals: secretary tel no. 02088467320 and fax no. 02088467362

\section{Mr Shehan Hettiaratchy}

Consultant Plastic Surgeon at Charing Cross Hospital for surgical treatment of gynaecomastia. For referrals: secretary tel no. 02033111790 and fax no. 02033111719

\section{Mr Stuart Lavery}

Consultant Gynaecologist and Director IVF Hammersmith (Queen Charlotte's Hospital) for infertility For referrals: Tel: 02083834152 Fax: 02087496973 


\section{USEFUL NAMES AND ADDRESSES}

CAH Support Group

CLIMB (Children Living with Inherited Metabolic Diseases)

Diabetes UK

MedicAlert Foundation

National Osteoporosis Society
2 Windrush Close

Flitwick, Bedfordshire

MK45 1PX

Tel: 08006523181

www.livingwithcah.com

Climb Building

176 Nantwich Road

Crewe

CW2 6BG

Tel: 08006523181

www.climb.org.uk

Macleod House

10 Parkway

London

NW1 7AA

Tel: 02074241000

www.diabetes.org.uk

MedicAlert House

327-329 Witan Court

Upper Fourth Street

Milton Keynes

MK9 1EH

Tel: 0800581420

www.medicalert.org.uk

Camerton

Bath

BA2 0PJ

Tel: 01761471771

www.nos.org.uk 
National Society for the

Relief of Paget's Disease

Society for Endocrinology

The British Thyroid Foundation

The Child Growth Foundation

The Pituitary Foundation
1 Church Road

Eccles

Manchester

M30 ODL

Tel: 01617079225

www.paget.org.uk

22 Apex Court

Woodlands

Bradley Stoke

Bristol

BS32 4JT

Tel: 01454642200

www.endocrinology.org

2nd floor

3 Devonshire Place

Harrogate

HG1 4AA

Tel: 01423709707

www.btf-thyroid.org

21 Malvern Drive

Sutton Coldfield

B76 1PZ

Tel: 02089950257

www.childgrowthfoundation.org

86 Colston Street

Bristol

BS1 5BB

Tel: 08454500376

www.pituitary.org.uk 